\title{
MODEL OF TRANSPORT AND CHEMICAL KINETICS IN A SOLAR THERMOCHEMICAL REACTOR TO SPLIT CARBON DIOXIDE
}

\author{
(REVISED)
}

\author{
Rohini Bala Chandran ${ }^{\mathrm{a}}$ and Jane H. Davidson ${ }^{\mathrm{a}^{*}}$ \\ ${ }^{a}$ University of Minnesota, Minneapolis, MN 55455, USA \\ *Corresponding author. Address: Department of Mechanical Engineering, University of \\ Minnesota, Minneapolis, MN. Phone: 612-626-9850. \\ Email address: jhd@me.umn.edu
}




\section{ABSTRACT}

Solar thermochemical reactors to carry out the nonstoichiometric reduction and oxidation of cerium dioxide (ceria) to split water and carbon dioxide provide a pathway to store sunlight in a chemical fuel. One of the challenges in the design of these reactors is understanding the complex coupling of heat and mass transfer and redox chemistry. To elucidate this coupling, we present a three-dimensional, transient model of a recently developed prototype solar reactor that implements an isothermal, pressure-swing ceria redox cycle. Radiative transport is modeled by a hybrid Monte Carlo/finite volume approach and paired with the transport and chemical processes within a fixed bed of porous ceria particles. Morphology specific reaction rate coefficients for the gas-solid reactions in ceria are extracted for the first time from global rate measurements in a bench-top reactor at $1773 \mathrm{~K}$. Results demonstrate the interdependent spatial and temporal variations in temperature, species concentration and reaction rates, and provide insight on the effects of optical properties on reactor performance. For a solar input of $4.2 \mathrm{~kW}$, the reactor achieves nearly isothermal cycling at $1791 \mathrm{~K}$ with carbon monoxide produced continuously at $3.6 \times 10^{-4} \mathrm{~mol} \mathrm{~s}^{-1}$. At this temperature, global reaction rates are driven by advective mass transport rates and the intrinsic material thermodynamics. Predicted surface temperatures and fuel production rates compare favorably to measured data.

Keywords: ceria, kinetics, solar reactor, heat exchanger, radiation, packed bed 


\section{NOMENCLATURE}

Symbols

\begin{tabular}{|c|c|}
\hline$A$ & pre-exponential factor, $\mathrm{s}^{-1}$ \\
\hline C & Concentration ratio \\
\hline$C_{E}$ & Ergun coefficient, $\mathrm{m}^{-1}$ \\
\hline$d$ & diameter, $\mathrm{m}$ \\
\hline$D$ & mass diffusivity, $\mathrm{m}^{2} \mathrm{~s}^{-1}$ \\
\hline$E$ & activation energy, $\mathrm{kJ} \mathrm{mol}^{-1} \mathrm{~K}^{-1}$ \\
\hline $\bar{h}$ & molar enthalpy, $\mathrm{J} \mathrm{mol}^{-1}$ \\
\hline$h$ & enthalpy, $\mathrm{J} \mathrm{kg}^{-1}$ \\
\hline $\mathrm{HHV}$ & higher heating value of $\mathrm{CO}=\mathrm{J} \mathrm{mol}^{-1}$ \\
\hline$I$ & radiation intensity, $\mathrm{W} \mathrm{m}^{-2} \mathrm{sr}^{-1}$ \\
\hline$I_{b}$ & black body radiation, $\mathrm{W} \mathrm{m}^{-2}$ \\
\hline$k$ & thermal conductivity, $\mathrm{W} \mathrm{m}^{-1} \mathrm{~K}^{-1}$ or reaction rate coefficient, $\mathrm{s}^{-1}$ \\
\hline$k_{o x}$ & oxidation rate constant, mol $_{\mathrm{O}} \mathrm{mol}_{\text {ceria }}^{-1} \mathrm{~s}^{-1}$ \\
\hline$k_{\mathrm{d}, \mathrm{CO}_{2}}$ & dissociation rate constant, $\mathrm{mol}_{\mathrm{CO}} \mathrm{mol}_{\text {ceria }}{ }^{-1} \mathrm{~s}^{-1}$ \\
\hline$K$ & permeability, $\mathrm{m}^{2}$ or equilibrium constant \\
\hline$L$ & length, $\mathrm{m}$ \\
\hline$\dot{m}$ & mass flow rate, $\mathrm{kg} \mathrm{s}^{-1}$ \\
\hline M & molecular mass, $\mathrm{kg} \mathrm{mol}^{-1}$ \\
\hline$n$ & reaction order \\
\hline$\dot{n}$ & molar flow rate, $\mathrm{mol} \mathrm{s}^{-1}$ \\
\hline$\hat{n}$ & unit normal vector \\
\hline$N$ & number \\
\hline $\mathrm{Pe}$ & Peclet Number, $\frac{U_{a v g} L}{D_{i, \mathrm{eff}}}$ \\
\hline$p$ & pressure, $\mathrm{Pa}$ \\
\hline $\boldsymbol{q}_{\mathrm{rad}}$ & heat flux vector, $\mathrm{W} \mathrm{m}^{-2}$ \\
\hline$\dot{Q}$ & power, W \\
\hline $\operatorname{Re}$ & Reynolds number \\
\hline$R_{u}$ & universal rate constant, $\mathrm{J} \mathrm{mol}^{-1} \mathrm{~K}^{-1}$ \\
\hline$r$ & radial position, $\mathrm{m}$ or $\mathrm{mm}$ \\
\hline$\dot{r}$ & volumetric mass source/sink, $\mathrm{kg} \mathrm{m}^{-3} \mathrm{~s}^{-1}$ \\
\hline$\hat{s}$ & direction vector \\
\hline$\dot{S}$ & energy source, $\mathrm{W} \mathrm{m}^{-3}$ \\
\hline$T$ & temperature, $\mathrm{K}$ \\
\hline$t$ & time, $\mathrm{s}$ \\
\hline $\boldsymbol{u}$ & velocity vector, $\mathrm{m} \mathrm{s}^{-1}$, Darcy velocity in porous media \\
\hline$U$ & overall heat loss coefficient, $\mathrm{W} \mathrm{m} \mathrm{m}^{-2} \mathrm{~K}^{-1}$ \\
\hline$V$ & volume, $\mathrm{m}^{3}$ \\
\hline$X$ & species mole fraction \\
\hline$Y$ & species mass fraction \\
\hline $\mathrm{z}$ & axial coordinate, $\mathrm{m}$ \\
\hline
\end{tabular}




\section{Greek}

\begin{tabular}{|c|c|}
\hline$\beta$ & extinction coefficient $\left[\mathrm{m}^{-1}\right]$ \\
\hline$\delta$ & ceria nonstoichiometery \\
\hline$\varepsilon$ & heat exchanger effectiveness \\
\hline$\eta$ & efficiency \\
\hline$\kappa$ & absorption coefficient, $\mathrm{m}^{-1}$ \\
\hline$\omega$ & scattering albedo \\
\hline$\phi$ & porosity \\
\hline$\Phi$ & scattering phase function \\
\hline$\mu$ & viscosity, $\mathrm{kg} \mathrm{m}^{-1} \mathrm{~s}^{-1}$ \\
\hline$\rho$ & density, $\mathrm{kg} \mathrm{m}^{-3}$ \\
\hline$\sigma$ & scattering coefficient, $\mathrm{m}^{-1}, \sigma=\beta \omega$ \\
\hline$\Omega$ & solid angle, sr \\
\hline$\Gamma$ & surface of a volume, $\mathrm{m}^{2}$ \\
\hline \multicolumn{2}{|l|}{ Subscripts } \\
\hline amb & ambient conditions \\
\hline ap & reactor aperture \\
\hline bed & ceria bed \\
\hline $\mathrm{c}$ & cold side of the heat exchanger \\
\hline ceria & ceria material \\
\hline chem & heat transfer due to chemical reactions of oxidation or reduction \\
\hline $\mathrm{d}$ & pertaining to dissociation \\
\hline diss & dissociation reaction of $\mathrm{CO}_{2}$ \\
\hline eff & effective value of transport properties \\
\hline eq & equilibrium \\
\hline $\mathrm{f}$ & fluid region \\
\hline $\mathrm{h}$ & hot side of the heat exchanger \\
\hline $\mathrm{i}$ & general index \\
\hline in & inlet \\
\hline ins & insulation \\
\hline loss & heat losses due to convection and conduction \\
\hline $\mathrm{p}$ & particle \\
\hline out & outlet \\
\hline ox & oxidation half-cycle or oxidizer flow \\
\hline particle & single ceria particle \\
\hline pump & pumping power \\
\hline ref & reference pressure of $1 \mathrm{~atm} / 101.325 \mathrm{kPa}$ \\
\hline $\mathrm{rad}$ & radiative heat transfer \\
\hline rd & reduction half-cycle \\
\hline ref & reference conditions \\
\hline rerad & heat losses due to thermal emission from a hot surface \\
\hline $\mathrm{s}$ & solid region \\
\hline $\mathrm{t}$ & pertinent to time \\
\hline
\end{tabular}




$\begin{array}{cl}\mathrm{s} \rightarrow \mathrm{E} & \text { solar to electric conversion efficiency } \\ \text { sep } & \text { energetic cost of gas separation } \\ \mathrm{sg} & \text { pertaining to sweep gas flow } \\ \text { solar } & \text { incident solar power } \\ \mathrm{w} & \text { value at the wall of the reactive element }\end{array}$

Other

$\begin{array}{cl}\langle\rangle & \text { volume-averaged or spatially averaged quantities } \\ \text { ppm } & \text { parts per million } \\ \text { PPI } & \text { pores per inch } \\ \text { HX } & \text { heat exchanger } \\ \text { RE } & \text { reactive element } \\ \text { RMSE } & \text { root mean square error } \\ \text { RPC } & \text { reticulate porous ceramic }\end{array}$




\section{INTRODUCTION}

A sustainable approach to produce synthetic fuels and to store solar energy in chemical form is to use concentrated sunlight to split water and carbon dioxide via thermochemical metaloxide redox cycles. Excellent reviews of solar redox cycles are available in recent publications (Agrafiotis et al., 2015; Muhich et al., 2015a; Smestad and Steinfeld, 2012). The products, hydrogen and carbon monoxide, can be combusted directly, used in a fuel cell, or further processed to liquid fuels, hence providing a pathway to convert the abundant yet intermittently available energy from the sun into a storable and transportable fuel.

In the present study we consider conversion of sunlight to fuel via the cerium dioxide (ceria) redox cycle (Abanades and Flamant, 2006; Chueh and Haile, 2010). Ceria undergoes partial reduction in an endothermic reaction at temperatures above $1600 \mathrm{~K}$ in a low oxygen partial pressure environment (eq. 1). Hydrogen and carbon monoxide are produced via the exothermic reactions $(2 \mathrm{a}, \mathrm{b})$ when the reduced ceria is reoxidized with $\mathrm{H}_{2} \mathrm{O}$ and $\mathrm{CO}_{2}$.

$$
\begin{gathered}
\mathrm{CeO}_{2-\delta_{\text {ox }}}=\mathrm{CeO}_{2-\delta_{\text {rd }}}+\frac{\delta_{\text {rd }}-\delta_{\text {ox }}}{2} \mathrm{O}_{2} \\
\mathrm{CeO}_{2-\delta_{\text {rd }}}+\left(\delta_{\text {rd }}-\delta_{\text {ox }}\right) \mathrm{H}_{2} \mathrm{O}=\mathrm{CeO}_{2-\delta_{\text {ox }}}+\left(\delta_{\text {rd }}-\delta_{\text {ox }}\right) \mathrm{H}_{2} \\
\mathrm{CeO}_{2-\delta_{\text {rd }}}+\left(\delta_{\text {rd }}-\delta_{\text {ox }}\right) \mathrm{CO}_{2}=\mathrm{CeO}_{2-\delta_{\text {ox }}}+\left(\delta_{\text {rd }}-\delta_{\text {ox }}\right) \mathrm{CO}
\end{gathered}
$$

Fuel is produced in proportion to the change in the non-stoichiometry between reduction and oxidation, $\delta_{\mathrm{rd}}-\delta_{\mathrm{ox}}$. In the present study, we investigate a "nearly isothermal", pressure swing redox cycle (Bader et al., 2013; Hao et al., 2013; Krenzke and Davidson, 2015; Roeb and Sattler, 2013; Venstrom et al., 2014). The driving potential to produce fuel is generated at approximately $1773 \mathrm{~K}$ by maintaining low $\mathrm{O}_{2}$ partial pressures during reduction $(\sim 10 \mathrm{~Pa})$ via an inert sweep gas. The isothermal redox cycle is an alternative to the "temperature swing" cycle in which reaction (2) is carried out after cooling the ceria by hundreds of degrees to produce a larger 
difference in nonstoichiometry (Chueh et al., 2010; Furler et al., 2012a, 2012b; Krenzke and Davidson, 2015; Lapp et al., 2012). Although the temperature swing cycle is favored by the material thermodynamics (Panlener et al., 1975), it requires recovery of the sensible heat of the ceria to avoid irreversible heat losses during cycling (Ermanoski et al., 2013; Krenzke and Davidson, 2015; Lapp et al., 2012). However, solid phase heat recovery has proven difficult to implement in solar thermochemical reactors. Proposed reactor concepts for solid phase heat recovery require moving components that are subjected to large thermal gradients (Diver et al., 2010; James et al., 2006; Lapp and Lipinski, 2014; Lapp et al., 2013). The isothermal cycle eliminates the need for solid phase heat recovery between the reaction steps, reduces thermal stresses in the reactor components and simplifies the overall reactor design. The efficiency of both isothermal and temperature swing cycles will gain from gas phase heat recovery.

At the University of Minnesota, we have developed a $4 \mathrm{~kW}_{\text {th }}$ solar reactor prototype with integrated gas phase heat recovery to implement the isothermal ceria redox cycle and have demonstrated continuous, production of $\mathrm{CO}$ from $\mathrm{CO}_{2}$ (Hathaway et al., 2015). Prior publications present the supporting analyses for design and operation of the reactor (Bader et al., 2015; Hathaway et al., 2015; Venstrom et al., 2014) and the gas heat recovery system (Bala Chandran et al., 2015b; Banerjee et al., 2015). In the present study, we present a transient, threedimensional (3-D) numerical model of the reactor that couples heat and mass transport processes with the chemical reactions for splitting $\mathrm{CO}_{2}$. Surface reaction rate coefficients are extracted from experimental data for an isothermal bench top reactor (Venstrom et al., 2014). Prior numerical transport models for isothermal and temperature swing ceria-based reactors are limited in scope to heat transfer analyses (Furler and Steinfeld, 2015; Lapp and Lipinski, 2014; Lapp et 
al., 2013) or only consider kinetics for the reduction step (Bala Chandran et al., 2015a; Keene et al., 2014, 2013).

\section{REACTOR}

The reactor (Figure 1) has a cylindrical receiver cavity lined with six tubular reactive elements each integrated with a ceramic heat exchanger. Concentrated sunlight enters the $347 \mathrm{~mm}$ long, $305 \mathrm{~mm}$ diameter cavity through an open $42 \mathrm{~mm}$ diameter aperture. Each reactive element is a concentric assembly of two alumina tubes. Within the solar cavity, the annulus is filled with $590 \mathrm{~g}$ of $5 \mathrm{~mm}$ cylindrical, ceria particles. The particles are $75 \%$ porous and the void fraction in the packed bed is $45 \%$. The tubular assemblies extend beyond the solar cavity to integrate with a tubular heat exchanger. The heat exchanger tubes are filled with alumina reticulate porous ceramic (RPC) to enhance heat transfer (Bala Chandran et al., 2015b). The alumina RPC has a fluid accessible porosity of $85-90 \%$ and pore densities of 10 and 5 PPI (pores per inch) in the annulus and centre channel of the heat exchanger, respectively. During reduction, an inert $\mathrm{N}_{2}$ sweep gas is passed through the heat exchanger and then through the ceria bed. The inlet gas is preheated by the hot gases leaving the reactive element. During oxidation, the gas flow is switched to pure $\mathrm{CO}_{2}$. Fuel is produced continuously by alternating the gas flows between reactive elements. The design gas flow rates and cycling period are set to maximize reactor thermal efficiency and fuel productivity (Hathaway et al., 2015; Venstrom et al., 2014). The design flow rates are $0.67 \times 10^{-4} \mathrm{~mol} \mathrm{~s}^{-1} \mathrm{~g}_{\text {ceria }}{ }^{-1}$ of $\mathrm{N}_{2}$ and $\mathrm{CO}_{2}$ for a $200 \mathrm{~s}$ cycle equally split between reduction and oxidation. The reactor is well insulated to reduce thermal losses to the ambient. Based on operation of the reactor, thermal losses are anticipated to equal $35 \%$ of the absorbed solar energy (Hathaway et al., 2015). 


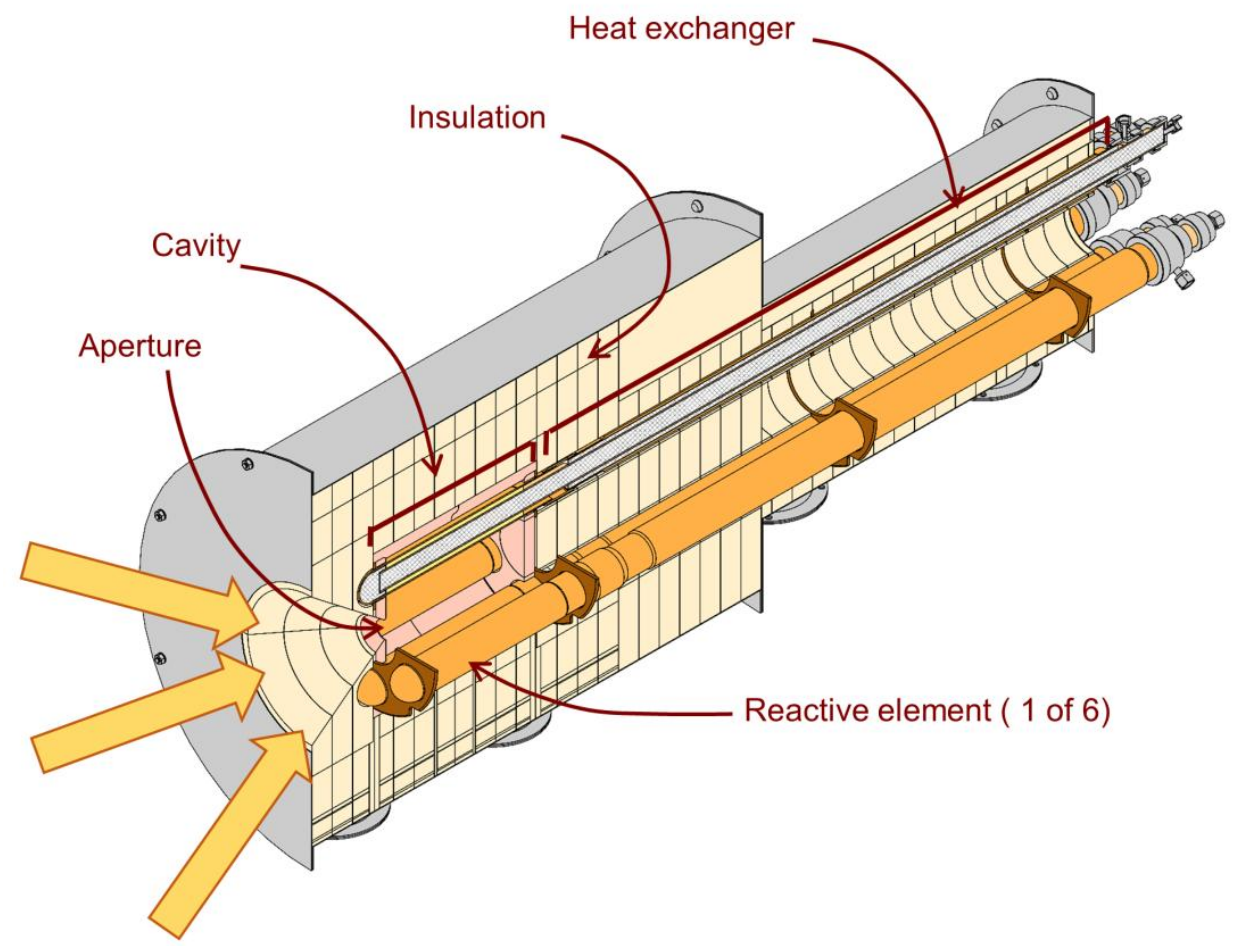

(a)

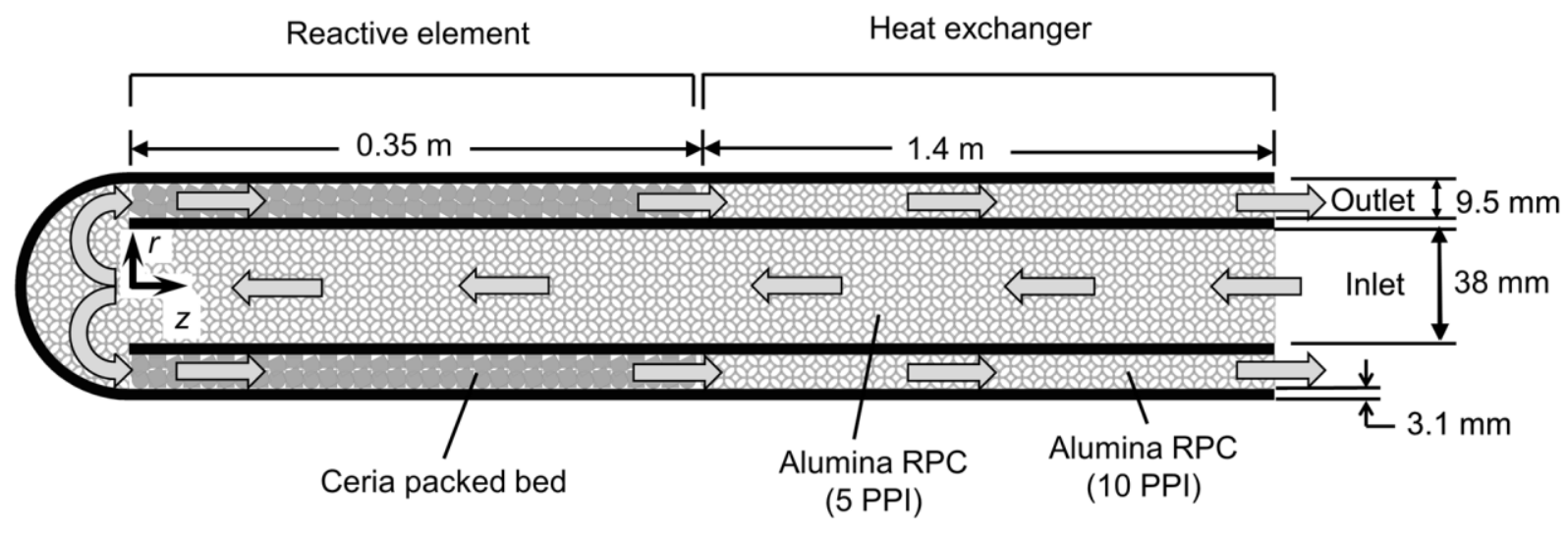

(b)

Figure 1 Cross section of the solar reactor: (a) overview showing the cavity and integrated heat exchanger and (b) details of the reactive element and heat exchanger assembly. Arrows indicate gas flow direction. (The aspect ratio is distorted to better visualize the reactive element.) 


\section{APPROACH}

\subsection{Reactor Model}

The transient, 3-D model is developed in ANSYS Fluent 15.0 (ANSYS® Academic Research, 2014a). To make the problem more tractable, the computational domain is a $60^{\circ}$ angular sector of the reactor cavity with two adjacent reactive elements in opposing states of reduction and oxidation (Figure 2). Table 1 presents the operating and boundary conditions for the baseline case of the reactor model. Symmetry conditions are applied on the planes AB and AC supported by two assumptions. Incident radiation is distributed uniformly at the aperture. Thermal losses are modeled by a uniformly distributed overall loss coefficient as shown in Figure 2. The modeled length of the reactive element (Figure. 1(b)) extends to $\mathrm{z}=0.38 \mathrm{~m}$. Inclusion of the entire length of the heat exchanger would greatly increase the computing time. To address this issue, the reactor model is used in conjunction with a separate CFD model of the heat exchanger (Bala Chandran et al., 2015b). Iterations are performed between the two models until the changes in the inlet and outlet temperatures of the 3-D model are less than $2 \%$.

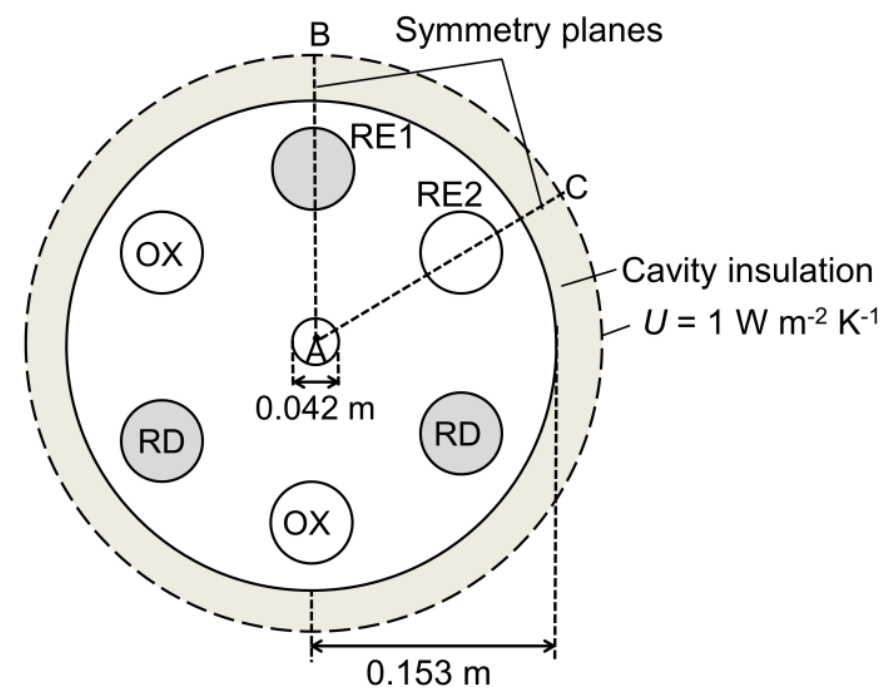

Figure 2 Computational domain viewed from the aperture showing the symmetry planes. The reducing $(\mathrm{RD})$ and oxidizing $(\mathrm{OX})$ elements RE1 and RE2 are simulated. Figure is not to scale. 
Table 1 List of operating conditions and boundary conditions at the specified surfaces of the model domain for the baseline case

\section{Operating Conditions}

\begin{tabular}{ll}
\hline Parameters & Value \\
\hline Input power $(\mathrm{kW})$ & 4.2 \\
Concentration ratio (suns/ $\left.\mathrm{kW} \mathrm{m}^{-2}\right)$ & 3000 \\
& \\
Sweep gas/oxidizer flow rate $\left(\mathrm{g} \mathrm{s}^{-1}\right)$ & $0.11 / 0.17$ \\
Reduction/oxidation half-cycle time (s) & $100 / 100$ \\
$\begin{array}{l}\text { Sweep gas/oxidizer composition } \\
\text { Sweep gas and oxidizer inlet temperature } \\
\text { to the integrated reactive element/heat } \\
\text { exchanger }(\mathrm{K})\end{array}$ & 300
\end{tabular}

\section{Boundary Conditions ( $n$ is the unit normal area vector for the respective surface)}

\begin{tabular}{ll}
\hline Surface & Conditions \\
\hline Aperture & $\varepsilon_{\mathrm{ap}}=1 ; \frac{\partial T}{\partial n}=0$ \\
Cavity insulation & $\varepsilon_{\mathrm{ins}}=1 ; k \frac{\partial T}{\partial n}=U\left(T-T_{\mathrm{amb}}\right)$ \\
Symmetry planes & $\frac{\partial T}{\partial n}=0$ \\
Gas inlet & $\varepsilon_{\mathrm{RPC}}=1 ;$ Refer to equations $(14)$ and $(15) ; T=$ \\
& $T_{\mathrm{c}, \mathrm{out}}(\mathrm{obtained}$ by iterating with the heat exchanger \\
& model $)$ \\
Gas outlet & $\varepsilon_{\mathrm{RPC}}=1 ; p=p_{\mathrm{atm}}$ \\
RE/HX tube walls & $\varepsilon_{\mathrm{RE} / \mathrm{HX}}=0.7 ; \boldsymbol{u}=0$ \\
\hline
\end{tabular}

Radiative heat transfer is incorporated via a combination of Monte Carlo ray tracing for the incident solar radiation and a discrete ordinates model (Chui and Raithby, 1993; Raithby and Chui, 1990) to simulate emitted radiation. As a base reference case, the porous cavity surface is 
assumed to be black, and the alumina tube surfaces are treated as opaque, grey-diffuse with an assumed emissivity of 0.7 based on available data for alumina at temperatures up to $2200 \mathrm{~K}$ (Markham et al., 1990). As discussed briefly in the results, a second case is considered for more reflective materials. The incident solar power is $4.2 \mathrm{~kW}$ with a concentration of 3000 suns $\left(1 \mathrm{sun}=1 \mathrm{~kW} \mathrm{~m}^{-2}\right)$ and a half cone angle of $37.7^{\circ}$ at the aperture to match the test conditions in the University of Minnesota high flux simulator (Krueger et al., 2013). The input power is selected based on an overall energy balance on the reactor (Bala Chandran et al., 2015b; Venstrom et al., 2014).

The collision based Monte Carlo simulation launches at least $10^{7}$ rays from the reactor aperture and tracks the absorbed component of the incident solar radiation at the surface of the cavity and reactive elements. Because the optical properties are assumed to be temperature independent, the solar ray-tracing step can be decoupled from the fluid flow, heat and mass transfer in the reactive elements. The absorbed solar energy is incorporated as volumetric heat sources across thin slices of the reactor surfaces. The aperture is assumed to be cold and black for the emitted radiation from the solar cavity. The finite volume method for radiation computes the emitted radiation from the heated reactor surfaces and yields computational advantages by using the same spatial mesh as the CFD model (Martinek and Weimer, 2013). In addition to the spatial domain, the angular domain of $4 \pi$ steradians is divided into discrete, non-overlapping solid angles $\left(\Omega_{\mathrm{i}}\right)$ and the radiative transport equation is integrated over the volume element, $V$, and solid angle $\Omega_{\mathrm{i}}$ as,

$$
\int_{\Omega_{i}} \int_{\Gamma} I \hat{s} \cdot \hat{n} d \Gamma d \Omega_{i}=\int_{\Omega_{i}} \int_{V}\left(\kappa I_{b}-\beta I\right) d V d \Omega_{i}+\int_{\Omega_{i}} \int_{V} \frac{\sigma}{4 \pi} \int_{4 \pi} \Phi\left(\widehat{s^{\prime}}, \hat{s}\right) I\left(\widehat{s^{\prime}}\right) d \Omega^{\prime} d V d \Omega_{i} .
$$


Pixelization is included on the control angles that do not align with the control volume faces (ANSYS® Academic Research, 2014a; Murthy and Mathur, 1998) to divide the intensities into outgoing and incoming components. The air in the cavity is treated as non-participating.

The ceria particles and the alumina RPC are assumed homogenous and isotropic. The gases are ideal and incompressible. Using the superficial or the Darcy velocity, the Reynolds number based on the centre channel hydraulic diameter is less than 700 and the pore-scale Reynolds number in the packed bed of ceria and RPC alumina is less than 60. Transient, continuum transport equations are solved with effective transport properties determined from published correlations for packed beds (M Kaviany, 1995) and RPCs (Bhattacharya et al., 2002; Lu et al., 2006; Schuetz and Glicksman, 1984) (Table 2). The permeability for flow of gases through the particle is much lower than that for flow around the mm-sized ceria particles, $10^{-13}$ vs. $10^{-8} \mathrm{~m}^{2}$. Therefore, the model simulates gas flow around the particles yielding the volumeaveraged mass and momentum conservation equation as,

$$
\begin{gathered}
\frac{\partial \rho_{f}}{\partial t}+\nabla \cdot\left(\rho_{f} \boldsymbol{u}\right)=\sum_{i} \dot{r}_{i} \\
\frac{1}{\phi} \frac{\partial}{\partial t}\left(\rho_{f} \boldsymbol{u}\right)+\frac{1}{\phi^{2}} \nabla \cdot\left(\rho_{f} \boldsymbol{u} \boldsymbol{u}\right)=-\nabla p+\frac{1}{\phi} \nabla \cdot(\mu \nabla \boldsymbol{u})-\frac{\mu}{K} \boldsymbol{u}-\rho_{f} C_{E}|\boldsymbol{u}| \boldsymbol{u}
\end{gathered}
$$

The pressure drop due to the presence of walls and interfaces confining the porous medium, shear stresses from the pore walls and the inertial drag forces are included in eq. (5) (M Kaviany, 1995). The porosity in eq. (5) equals $\phi_{\text {bed }}$ in the packed bed of ceria and $\phi_{\mathrm{RPC}}$ for the alumina RPC.

Table 2 Effective transport properties for the packed bed of ceria and RPC

\section{Effective}

Equation
Value 


\begin{tabular}{|c|c|c|}
\hline $\begin{array}{l}\text { Transport } \\
\text { Property }\end{array}$ & & \\
\hline & $\begin{array}{c}\text { Packed bed } \\
\phi_{\text {bed }}=0.45 ; \phi_{\text {particle }}=0.75 ; d_{\text {ceria }}=5 \times 10^{-3} \mathrm{~m}\end{array}$ & \\
\hline$K\left(\mathrm{~m}^{2}\right)$ & $\frac{\phi_{\text {bed }}^{3} d_{\text {ceria }}^{2}}{180\left(1-\phi_{\text {bed }}\right)^{2}}($ M Kaviany, 1995$)$ & $4.2 \times 10^{-8}$ \\
\hline$C_{E}\left(\mathrm{~m}^{-1}\right)$ & $\frac{1.8\left(1-\phi_{\text {bed }}\right)}{\phi_{\text {bed }}^{3} d_{\text {ceria }}}($ M Kaviany, 1995) & 2112.5 \\
\hline $\begin{array}{l}k_{\mathrm{s}, \mathrm{eff}} \text { at } 1773 \mathrm{~K} \\
\left(\mathrm{~W} \mathrm{~m}^{-1} \mathrm{~K}^{-1}\right)\end{array}$ & $k_{s}\left(1-\phi_{\text {bed }}\right)\left(1-\phi_{\text {particle }}\right)($ M Kaviany, 1995$)$ & 0.12 \\
\hline$\beta\left(\mathrm{m}^{-1}\right)$ & $\begin{array}{c}\frac{3\left(1-\phi_{\text {bed }}\right)}{d_{\text {ceria }}}(\text { Hulst and Christoffel, 2012; Singh and } \\
\text { Kaviany, 1992) }\end{array}$ & 330 \\
\hline$\omega(-)$ & 1 & 1 \\
\hline
\end{tabular}

\begin{tabular}{|c|c|c|}
\hline \multicolumn{3}{|c|}{$\begin{array}{c}\text { Alumina RPC } \\
\phi_{\mathrm{RPC}}=0.85 ; 10 / 5 \text { PPI RPCs }\end{array}$} \\
\hline$K\left(\mathrm{~m}^{2}\right)$ & $\begin{array}{c}0.0073\left(1-\phi_{\mathrm{RPC}}\right)^{-0.224}\left(\frac{d_{f}}{d_{p}}\right)^{-1.11} d_{p}^{2} \\
d_{p}=\frac{0.0254}{\mathrm{PPI}} ; d_{f}=1.18 \sqrt{\frac{1-\phi_{\mathrm{RPC}}}{3 \pi}} \frac{d_{p}}{1-e^{-\frac{1-\phi_{\mathrm{RPC}}}{0.04}}} \\
\text { (Bhattacharya et al., 2002; Calmidi, 1998) }\end{array}$ & $5.8 \times 10^{-8} / 2.3 \times 10^{-7}$ \\
\hline$C_{E}\left(\mathrm{~m}^{-1}\right)$ & $\frac{0.3 a_{s f}}{\phi_{\mathrm{RPC}}^{2}} ; a_{s f}=\frac{3 \pi d_{f}\left(1-e^{-\frac{1-\phi_{\mathrm{RPC}}}{0.04}}\right)}{0.59 d_{p}^{2}}($ Bhattacharya et al., & $775 / 387$ \\
\hline $\begin{array}{l}k_{\mathrm{s}, \mathrm{eff}} \text { at } 1773 \mathrm{~K} \\
\left(\mathrm{~W} \mathrm{~m} \mathrm{~m}^{-1} \mathrm{~K}^{-1}\right)\end{array}$ & $\frac{0.8 k_{s}}{3}\left(1-\phi_{\mathrm{RPC}}\right)($ Schuetz and Glicksman, 1984) & 0.25 \\
\hline$\beta\left(\mathrm{m}^{-1}\right)$ & $\frac{4.4\left(1-\phi_{\mathrm{RPC}}\right)}{d_{\mathrm{p}}}($ Hendricks and Howell, 1996) & $260 / 520$ \\
\hline$\omega(-)$ & 0.81 (Hale and Bohn, 1992) & 0.81 \\
\hline
\end{tabular}

The species conservation equation is

$$
\frac{\partial\left(\phi_{\mathrm{eff}} \rho_{f} Y_{i}\right)}{\partial t}+\nabla \cdot\left(\rho_{f} \boldsymbol{u} Y_{i}\right)=\nabla \cdot\left(\rho_{f} D_{i, \mathrm{eff}} \nabla Y_{i}\right)+\dot{r}_{i}
$$

where, $\dot{r}_{i}$ is the rate of production/consumption of species $i=\mathrm{O}_{2}, \mathrm{CO}$ and $\mathrm{CO}_{2}$. The binary mass diffusivities, $D_{i j}$, of the gases are obtained by applying the Chapman-Enskog theory (Cussler, 1997) and the diffusion coefficient for species $i$ in the multicomponent mixture is, 


$$
D_{i}=\frac{1-X_{i}}{\sum_{j \neq i} \frac{X_{i}}{D_{i j}}}
$$

Effective diffusivity is $\phi D_{i}$ and the inter-particle void fraction is considered in the particle bed.

Heat transfer through the packed bed and the RPC alumina is modeled by assuming local thermal equilibrium:

$$
\begin{array}{r}
\frac{\partial}{\partial t}\left(\phi_{\mathrm{eff}} \rho_{f} \sum_{i} Y_{i} h_{i f}+\left(1-\phi_{\mathrm{eff}}\right) \rho_{s} h_{s}\right)+\nabla \cdot\left(\rho_{f} \boldsymbol{u} \sum_{i} Y_{i} h_{i f}\right) \\
=\nabla \cdot\left(\left(k_{\mathrm{s}, \mathrm{eff}}+k_{\mathrm{f}, \mathrm{eff}}\right) \nabla T\right)-\nabla \cdot \boldsymbol{q}_{\mathrm{rad}}+\dot{S}_{\mathrm{rxn},\{\mathrm{rd} / \mathrm{ox}\}}
\end{array}
$$

For the packed bed and the alumina RPC, the differences in the gas/solid temperatures between the thermal equilibrium and non-equilibrium formulations are expected to be less than $10 \%$ and $3 \%$ respectively, based on the dimensionless numbers that compare the thermal resistances for solid phase conduction, interfacial heat transfer and fluid phase conduction (Lee and Vafai, 1999). Moreover, the temperature variation over the system dimension, i.e. the thickness of the annulus and the radius of the centre channel, is expected to be larger than the pore level difference in the solid and fluid phase temperatures (M. Kaviany, 1995). The transient energy storage terms for the fluid and solid phases are determined using the effective volume fraction,

$$
\phi_{\text {eff }}=1-\left(1-\phi_{\text {particle }}\right)\left(1-\phi_{\text {bed }}\right),
$$

in the packed bed and $\phi_{\text {eff }}=\phi_{R P C}$ in the alumina RPC. The energy sink/sources due to chemical reactions in the packed bed of ceria are given by

$$
\begin{gathered}
\dot{S}_{\text {rxn,rd }}=-\frac{\dot{r}_{\mathrm{O}_{2, \text { ceria }}}}{M_{\mathrm{O}_{2}}} \bar{h}_{O_{2, \text { ceria }}}(\delta), \\
\dot{S}_{\text {rxn,ox }}=\frac{\dot{r}_{\mathrm{O}_{2}, \text { ceria }}}{M_{\mathrm{O}_{2}}} \bar{h}_{O_{2}, \text { ceria }}(\delta)-\frac{\dot{r}_{\mathrm{CO}, \text { diss }}}{M_{\mathrm{CO}}} \bar{h}_{\mathrm{diss}}(T),
\end{gathered}
$$


with the absolute values of the reaction enthalpies. For the expected range of ceria nonstoichiometry $(0.02-0.04$ at $1773 \mathrm{~K})$, the enthalpy for the reduction of ceria, $\bar{h}_{\mathrm{O}_{2, \text { ceria }}}$, is 910-860 kJ mol ceria $^{-1}$ (Panlener et al., 1975) and the enthalpy for dissociation of $\mathrm{CO}_{2}, \bar{h}_{\text {diss }}$, is $279 \mathrm{~kJ} \mathrm{~mol}_{\mathrm{CO}_{2}}^{-1}$ (Binnewies and Milke, 2002) The packed bed and the RPC are treated as participating media with isotropic, gray and diffuse radiative properties. The radiative source term $\nabla \cdot \boldsymbol{q}_{\text {rad }}$ is computed using the finite volume method for unstructured meshes (Chui and Raithby, 1993; Raithby and Chui, 1990) and the radiative flux vector in a control volume, $p$, is evaluated as a discrete sum over $i$ angular directions,

$$
\begin{gathered}
\boldsymbol{q}_{p, \mathrm{rad}}=\sum_{i} I_{p i} \boldsymbol{s}_{i}, \\
\boldsymbol{s}_{i}=\int_{\Omega_{i}} \hat{\boldsymbol{s}} d \Omega .
\end{gathered}
$$

The packed bed extinction coefficient is determined by applying geometric optics $\left(\frac{\pi d}{\lambda} \gg 1\right)$ for large, opaque, spherical particles with independent scattering (Hulst and Christoffel, 2012; Singh and Kaviany, 1992) (see Table 1). Though this value, $330 \mathrm{~m}^{-1}$, is an order of magnitude smaller than the mean extinction coefficient measured for fibrous alumina with fiber diameters of 1-9 $\mu \mathrm{m}$ (Zhang et al., 2008) (similar to the length scale of the fibers in the ceria particles), it is reasonable to anticipate the extinction coefficient of a packed bed of ceria fibers to be much lower than that of the individual particles. The scattering albedo for the baseline case is 1 , which is in agreement with room temperature radiative property measurements on porous ceria structures (Ganesan and Lipiński, 2011; Ganesan et al., 2013). For this case, thermal radiation is attenuated only by scattering. We also modeled a scattering albedo of 0.8 and found that the volume-averaged temperatures and the fuel production rates changed by less than $3 \%$. 
The mass flow rate and the composition of the gases are specified as step inputs to simulate the reduction and oxidation half-cycles for the two reactive elements (equations (14) and (15)).

$$
\begin{gathered}
\dot{m}_{\mathrm{in}}(t)=\left\{\begin{array}{cc}
\dot{m}_{\mathrm{sg}}=0.11 \mathrm{~g} \mathrm{~s}^{-1} & t \in\left(0, t_{\mathrm{rd}}\right] \\
\dot{m}_{\mathrm{ox}}=0.17 \mathrm{~g} \mathrm{~s}^{-1} & t \in\left(t_{\mathrm{rd},} t_{\mathrm{ox}}\right]
\end{array}\right. \\
X_{\mathrm{O}_{2}, \mathrm{in}}(t), X_{\mathrm{CO}, \mathrm{in}}(t), X_{\mathrm{CO}_{2}, \mathrm{in}}(t)=\left\{\begin{array}{cc}
10^{-5}, 0,0 & t \in\left(0, t_{\mathrm{rd}}\right] \\
X_{\mathrm{O}_{2}, \mathrm{eq}}, X_{\mathrm{CO}, \mathrm{eq}}, X_{\mathrm{CO}_{2}, \mathrm{eq}} & t \in\left(t_{\mathrm{rd},} t_{o x}\right.
\end{array}\right]
\end{gathered}
$$

During oxidation, the inlet gas composition is the equilibrium composition due to thermal dissociation of $\mathrm{CO}_{2}$ at the oxidizer inlet temperature. The inlet gas temperatures are established by iterating the gas temperatures at the outlet of the 3-D model domain with the heat exchanger model at time intervals of $10 \mathrm{~s}$. The gases are stipulated to leave the reactive elements at atmospheric pressure and all other field variables at the outflow boundaries are extrapolated from the interior solution domain by applying zero normal derivatives at the boundary. The insulating material surrounding the cavity is not modeled explicitly but rather treated as a $3.5 \mathrm{~cm}$ thick layer of alumina with temperature dependent thermal conductivity (ZIRCAR Ceramics Inc, 2006) with an overall heat loss coefficient, $U=1 \mathrm{~W} \mathrm{~m}^{-2} \mathrm{~K}^{-1}$, applied to the external surface (see Figure 2). This value is determined by trial and error to match the total thermal loss to the measured values, i.e., about $35 \%$ of the absorbed power. To reduce the computational time to reach steady-periodic cycling, the initial flow field, temperature and species concentration distribution are determined from solutions of the steady transport equations for $\mathrm{CO}_{2}$ and $\mathrm{N}_{2}$ flowing through the reactive elements. The initial non-stoichiometry of ceria is established by the equilibrium oxidation state $(0.0214)$ due to thermal dissociation of $\mathrm{CO}_{2}$ at $1773 \mathrm{~K}$. 


\subsection{Reaction Kinetics}

To our knowledge, kinetic expressions for $\mathrm{CO}_{2}$ splitting by ceria at $1773 \mathrm{~K}$ are not available in the literature. In the present study we use a modified form of the kinetic expression developed by Bulfin et al. (Bulfin et al., 2013) for oxidation of ceria in an oxygen atmosphere at 773-1273 K. To reduce the number of the morphology dependent reaction rate parameters (preexponential factors), the prior model is rearranged to express the rate of generation of oxygen vacancies as a function of the oxidation rate constant, $k_{\mathrm{ox}}$,

$$
\frac{d \delta}{d t}=k_{\mathrm{ox}} \delta\left(\left(\frac{p_{\mathrm{O}_{2}, \mathrm{eq}}}{p_{\mathrm{ref}}}\right)^{n}-\left(\frac{p_{\mathrm{O}_{2}}}{p_{\mathrm{ref}}}\right)^{n}\right),
$$

where,

$$
k_{\mathrm{ox}}=A_{\mathrm{ox}} \exp \left(-\frac{E_{\mathrm{ox}}}{R_{u} T}\right),
$$

and $p_{\mathrm{O}_{2} \text {,eq }}$ is evaluated from the thermodynamic data (Panlener et al., 1975) as a function of ceria nonstoichiometry and temperature. Equation (16) can be deduced from the reaction rate equation provided by Bulfin et al. (eq. (20) in (Bulfin et al., 2013)) by applying the thermodynamic equilibrium constraint, which relates the reduction and oxidation reaction rate constants to the equilibrium oxygen partial pressure,

$$
k_{\mathrm{rd}}=k_{o x}\left(\frac{p_{\mathrm{O}_{2}, \mathrm{eq}}}{p_{\mathrm{ref}}}\right)^{n} .
$$

The values of the reaction order, $n$ and the activation energy, $E_{o x}$, are fixed at 0.22 . and $38 \mathrm{~kJ} \mathrm{~mol}^{-1} \mathrm{~K}^{-1}$ respectively based on the estimates provided by Bulfin et al. (Bulfin et al., 2013) and the temperature, $T$, is fixed at $1773 \mathrm{~K}$. At thermodynamic equilibrium, rate expression in equation (16) yields oxygen vacancy concentrations that are within $0.05 \%$ of the equilibrium 
values reported by (Panlener et al., 1975); Bulfin et al. (Bulfin et al., 2013) report a similar match to the thermodynamic data. The volumetric, mass source/sink term for $\mathrm{O}_{2}$ release/uptake from the ceria particles is

$$
\dot{r}_{\mathrm{O}_{2}, \text { ceria }}=\frac{M_{\mathrm{O}_{2}}}{2 M_{\mathrm{CeO}_{2}}}\left(1-\phi_{\text {eff }}\right) \rho_{\mathrm{CeO}_{2}} k_{\mathrm{ox}} \delta\left(\left(\frac{p_{\mathrm{O}_{2}, \mathrm{eq}}}{p_{\text {ref }}}\right)^{n}-\left(\frac{p_{\mathrm{O}_{2}}}{p_{\mathrm{ref}}}\right)^{n}\right) .
$$

Prior work indicates direct thermal dissociation of $\mathrm{CO}_{2}$ is significant at elevated temperatures (Muhich et al., 2015b; Venstrom et al., 2014). The reversible rate of the direct thermolysis of $\mathrm{CO}_{2}$ is modeled with a rate coefficient, $k_{\mathrm{d}, \mathrm{CO}_{2}}$, maintaining the reaction order of $n$ with respect to $\mathrm{O}_{2}$ resulting in the following reaction rates for the $i^{\text {th }}$ species:

$$
\begin{aligned}
\dot{r}_{\mathrm{i}, \mathrm{diss}} & =\frac{v_{i} M_{\mathrm{i}}}{M_{\mathrm{CeO}_{2}}}\left(1-\phi_{\mathrm{eff}}\right) \rho_{\mathrm{CeO}_{2}} k_{{\mathrm{d}, \mathrm{CO}_{2}}}\left(\left(K_{\mathrm{eq}, \mathrm{CO}_{2}}(T) \frac{p_{\mathrm{CO}_{2}}}{p_{\mathrm{ref}}}\right)^{2 n}\right. \\
& \left.-\left(\frac{p_{\mathrm{CO}}}{p_{\text {ref }}}\right)^{2 n}\left(\frac{p_{\mathrm{O}_{2}}}{p_{\text {ref }}}\right)^{n}\right),
\end{aligned}
$$

where $v_{i}$ is $1 / 2,1$ and -1 for $\mathrm{O}_{2}, \mathrm{CO}$ and $\mathrm{CO}_{2}$ respectively. The net rate of oxygen release due to the dissociation reaction and the reoxidiation of ceria is,

$$
\dot{r}_{\mathrm{O}_{2}, \text { net }}=\dot{r}_{\mathrm{O}_{2} \text {,diss }}+\dot{r}_{\mathrm{O}_{2}, \text { ceria }}
$$

Because the thermolysis products are anticipated to recombine without a rapid quench, we assume complete recombination. In this case, the resulting molar flow rate of $\mathrm{CO}$ at the packed bed outlet is expressed as,

$$
\dot{n}_{\mathrm{CO}, \text { out }}=\dot{n}_{\mathrm{CO}, \mathrm{diss}}-\dot{2} \dot{n}_{\mathrm{O}_{2}, \text { net }}
$$

The morphology dependent rate coefficients, $A_{o x}$ and $k_{\mathrm{d}_{1} \mathrm{CO}_{2}}$ are determined by modeling the experimental bench top reactor used by Venstrom et al. (Venstrom et al., 2014) to obtain global reaction rates of reduction and oxidation of a packed bed of ceria particles at $1773 \mathrm{~K}$. The 
reaction rate coefficients that yield the best fit of the model predictions with the experimentally measured rates of $\mathrm{O}_{2}$ and $\mathrm{CO}$ production are determined via optimization. Step response analyses on the gas analyzer system used for the experimental measurements indicate a 90\% rise time of less than $4 \mathrm{~s}$ and hence dispersion effects are assumed to be negligible (Venstrom et al., 2015). The minimization function to determine $k_{\mathrm{ox}}$ and $k_{\mathrm{d}, \mathrm{CO}_{2}}$ is a vector sum (over all gas flow rates) of the root mean square error values normalized by the inlet flow rate,

$$
R M S E_{\mathrm{f},\{\mathrm{sg} / \mathrm{ox}\}}=\frac{\sqrt{\frac{\sum_{i=1}^{i=N_{t}}\left(\dot{n}_{\left\{\mathrm{O}_{2} / \mathrm{CO}\right\}, i}^{\bmod }-\dot{n}_{\left\{\mathrm{O}_{2} / \mathrm{CO}\right\}, i}^{\exp }\right)^{2}}{N_{t}-1}}}{\dot{n}_{i n}} .
$$

The range considered for parameter estimation of $A_{o x}$ is $0.01-100$ and $0.01-10$ for $k_{\mathrm{d}_{1} \mathrm{CO}_{2}}$ with a resolution/accuracy of 0.5 and 0.1 respectively. The selected upper bounds results in species mole fraction and ceria nonstoichiometry within $1 \%$ of the thermodynamic equilibrium values at all the gas flow rates considered.

The bench top reactor is a $9.5 \mathrm{~mm}$ diameter alumina tube containing $\sim 1 \mathrm{~g}$ of $3-5 \mathrm{~mm}$ sized, $\sim 65 \%$ porous ceria particles heated in a tubular IR imaging furnace (Venstrom et al., 2014). The governing transport equations described in section 3.1 (eqs. (4)-(6)) for the solar reactor are applied to the isothermal bench top reactor. The model simulates $1000 \mathrm{~s}$ of reduction and about $300 \mathrm{~s}$ of oxidation for sweep gas and oxidizer molar flow rates of $0.67 \times 10^{-4}$ to $4 \times 10^{-4} \mathrm{~mol} \mathrm{~s}^{-1} \mathrm{~g}_{\text {ceria }}{ }^{-1}$. Prior to reduction, the non-stoichiometry for the ceria bed is initialized to the equilibrium value of 0.0214 due to the dissociation of $100 \% \mathrm{CO}_{2}$ at $1773 \mathrm{~K}$. For the oxidation step ceria nonstoichiometry is initialized based on the measured CO production.

The values for the reaction rate coefficients determined from the model of the bench-top reactor are used in the 3-D reactor model to determine the volumetric mass sinks/sources 
(eqs. (19)-(21)) and applied in the transport equations (4) and (6). The rate constants evaluated at $1773 \mathrm{~K}$ are deemed acceptable because $k_{\mathrm{ox}}$ changes by less than $15 \%$ over the largest range of temperatures predicted in the reactor.

\subsection{Solution Procedure}

The transport equations are solved using the finite volume method on an unstructured, hexagonal dominant mesh with approximately 600,000 cells for the 3-D reactor model. Mapped or structured cells are used wherever possible and a higher density of cells is present within the reactive elements than in the reactor cavity. Every octant space is discretized into $5 \times 5$ control or solid angles and the angles that are not aligned with the mesh boundaries are further pixelated into $3 \times 3$ solid angles. Doubling the resolution of the angular discretization on the same spatial mesh results in increased ray effects (or oscillations in heat flux solutions) despite lower errors due to false scattering or smearing of the intensity field, as observed by Martinek et al. (Martinek and Weimer, 2013), and resulted in less than 3\% change to the spatially averaged temperature and ceria non-stoichiometry. Increasing the spatial refinement of the mesh to 900,000 cells altered the volume averaged temperature and non-stoichiometry by less than $1 \%$. A first-order Euler implicit scheme is used for time integration with a time step of $1 \mathrm{~s}$. The SIMPLE algorithm is used to couple the pressure and the velocity fields, with second order upwinding for the advection terms in the momentum, energy transport and the radiative transfer equations. The rate of change of ceria nonstoichiometry is implemented as a user-defined scalar transport equation (ANSYS® Academic Research, 2014b) without the advection and diffusion terms. The source terms for mass, momentum, and energy have been linearized appropriately to enforce the positivity criterion (Patankar, 1980). The governing equations are solved with the globally scaled residual values for convergence set as $10^{-8}$ for continuity, momentum, and species transport 
equations and $10^{-10}$ for the energy, intensity and the scalar transport equation. Solution monitors are placed for the volumetric average temperature and $\delta$ to ensure changes less than $0.1 \mathrm{~K}$ and $10^{-5}$ over 10 inner iterations at every time step. To enable high performance computing, the 3-D reactor mesh is partitioned over eight nodes. The transient three-dimensional simulations are performed on 32 Intel Xeon X5690 (4.1 GHz, 12 GB) cores.

\section{RESULTS}

\subsection{Reaction Kinetics}

Figures 3 and 4 compare the measured rates of $\mathrm{O}_{2}$ and $\mathrm{CO}$ production at $1773 \mathrm{~K}$ to those predicted by the model. The best fit kinetics parameters are $A_{\mathrm{ox}}=1.5 \mathrm{molo}_{\mathrm{O}} \mathrm{mol}_{\text {ceria }}{ }^{-1} \mathrm{~s}^{-1}$, which yields $k_{\mathrm{OX}}=0.11 \mathrm{~mol}_{\mathrm{O}}$ mol $_{\text {ceria }^{-1}} \mathrm{~s}^{-1}$, and $k_{\mathrm{d}, \mathrm{CO}_{2}}=0.3 \mathrm{~mol}_{\mathrm{CO}}$ mol $_{\text {ceria }}{ }^{-1} \mathrm{~s}^{-1}$. The vector sum of the normalized root mean square error for the gas flow rates simulated is less than $1.5 \times 10^{-3}$ for the identified rate coefficients. The predicted $\mathrm{O}_{2}$ production is insensitive to an increase in $A_{\mathrm{ox}}$ except for the highest $\mathrm{N}_{2}$ flow rate considered. This result implies that gas phase mass transport limits reduction rates for slower sweep gas flow rates. The rate of oxidation is impacted by both mass transport and surface kinetics. Both these results are concurrent with the findings in a recent publication by Venstrom et al. (Venstrom et al., 2015). 


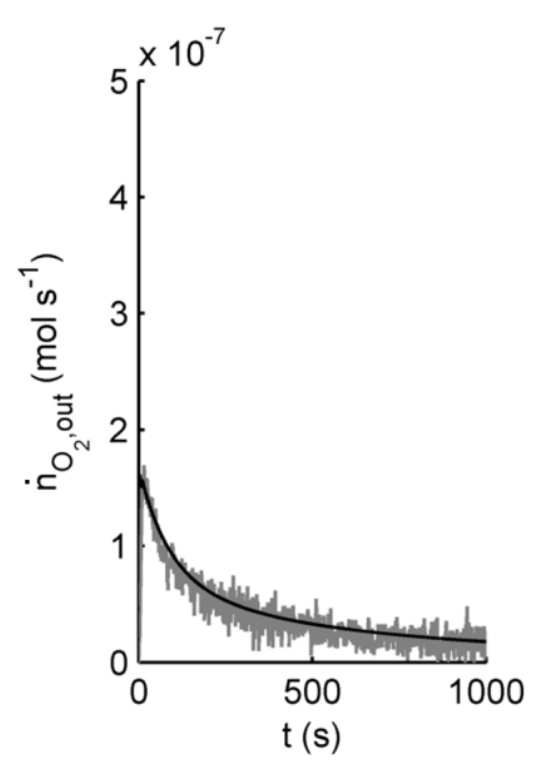

(a)

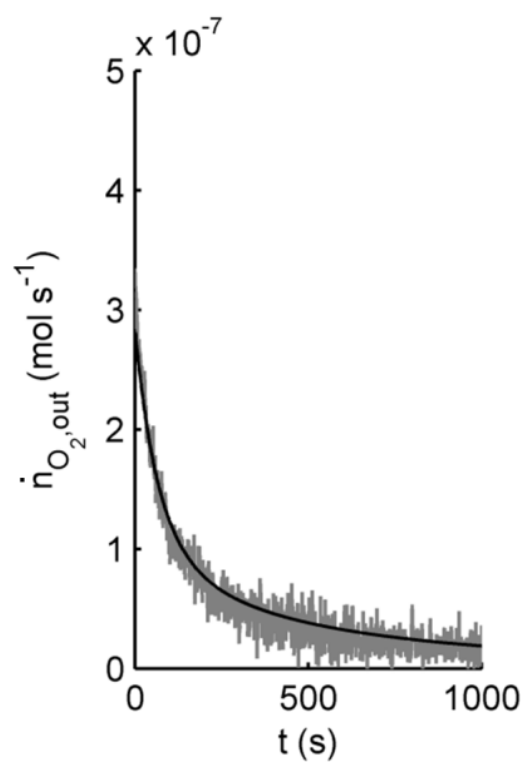

(b)

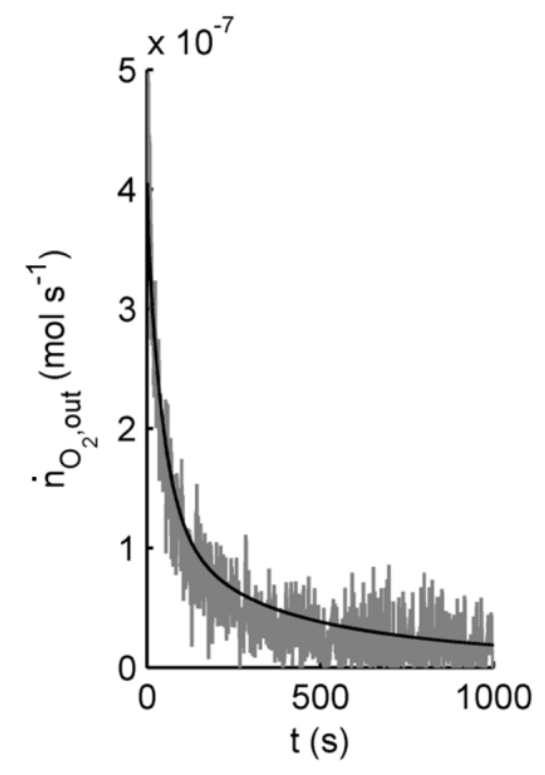

(c)

Figure 3 Comparison of measured (grey line) and predicted (black line) rates of $\mathrm{O}_{2}$ release at $1773 \mathrm{~K}$ for $\mathrm{N}_{2}$ sweep gas $\left(10 \mathrm{ppm} \mathrm{O}_{2}\right.$ ) flow rates of (a) $1 \times 10^{-4}$, (b) $2 \times 10^{-4}$ and (c) $4 \times 10^{-4} \mathrm{~mol} \mathrm{~s}^{-1} \mathrm{~g}_{\text {ceria }}{ }^{-1}$.

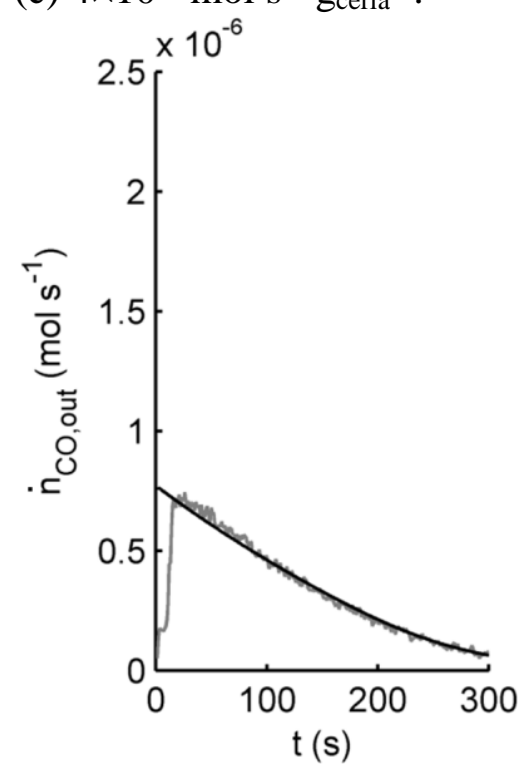

(a)

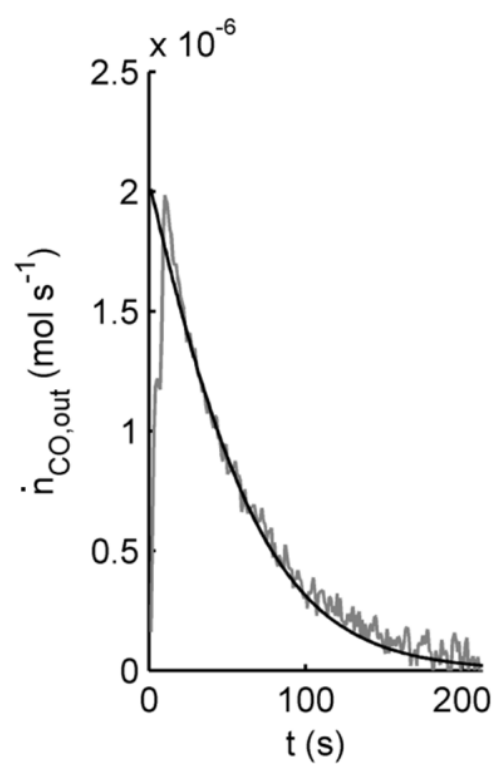

(b)

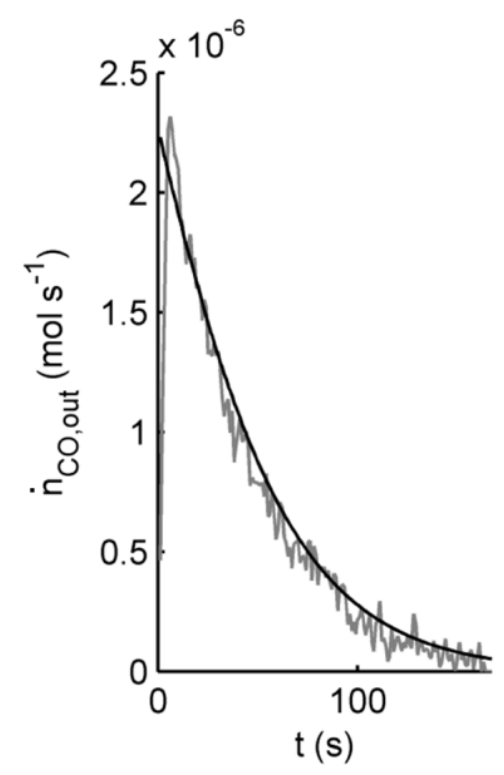

(c)

Figure 4 Comparison of measured (grey line) and predicted (black line) rates of $\mathrm{CO}$ release at $1773 \mathrm{~K}$ with $100 \% \mathrm{CO}_{2}$ flow rates of (a) $0.67 \times 10^{-4}$, (b) $3 \times 10^{-4}$ and (c) $4 \times 10^{-4} \mathrm{~mol} \mathrm{~s}^{-1} \mathrm{~g}_{\text {ceria }}{ }^{-1}$ 


\subsection{Reactor Performance}

The transient behavior during steady periodic cycling is presented with an emphasis on transport and chemical processes within the reactive elements. Figure 5 shows the distribution of absorbed solar flux on the surfaces of the cavity and six reactive elements based on application of rotational symmetry on the $60^{\circ}$ angular sector depicted in Figure 2. The overall absorption efficiency, defined as

$$
\eta_{\text {abs }}=\frac{\dot{Q}_{\text {solar,abs }}}{Q_{\text {solar }}}
$$

is $99.8 \%$. The reactive elements effectively intercept the incident light and obstruct the direct view of the cylindrical cavity walls by the aperture resulting in 51\% absorption of the incident power on the reactive elements and $47 \%$ absorption on the cavity surfaces, equally split along the circumference and the back plane. The average flux on a reactive element is $4700 \mathrm{~W} \mathrm{~m}^{-2}$. The regions of higher flux, $1300-5 \times 10^{4} \mathrm{~W} \mathrm{~m}^{-2}$, are where the tubes are directly illuminated. On the cavity surface, the fluxes vary from 325 to $7880 \mathrm{~W} \mathrm{~m}^{-2}$. On the back plane of the cavity, the flux distribution is $2 \times 10^{4} \pm 1 \times 10^{4} \mathrm{~W} \mathrm{~m}^{-2}$. The localized regions of high flux are consistent with the conical spread of the incident light and the geometric intersection of light with the cavity and reactor tube surfaces. 


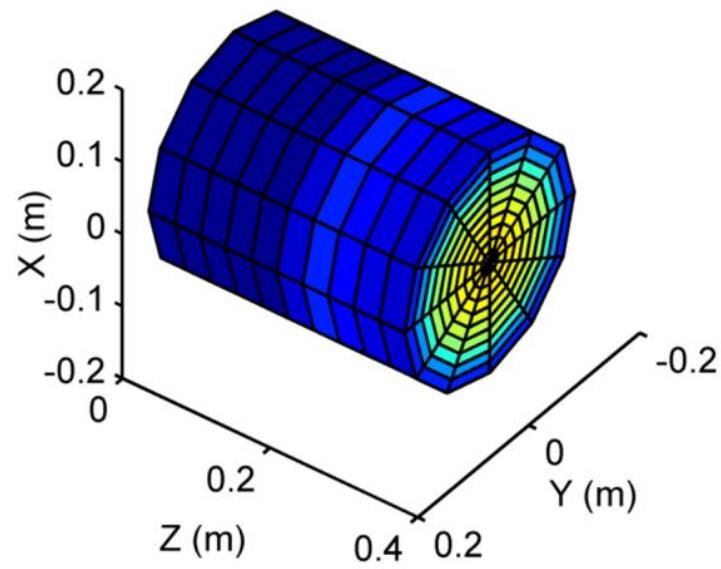

(a)

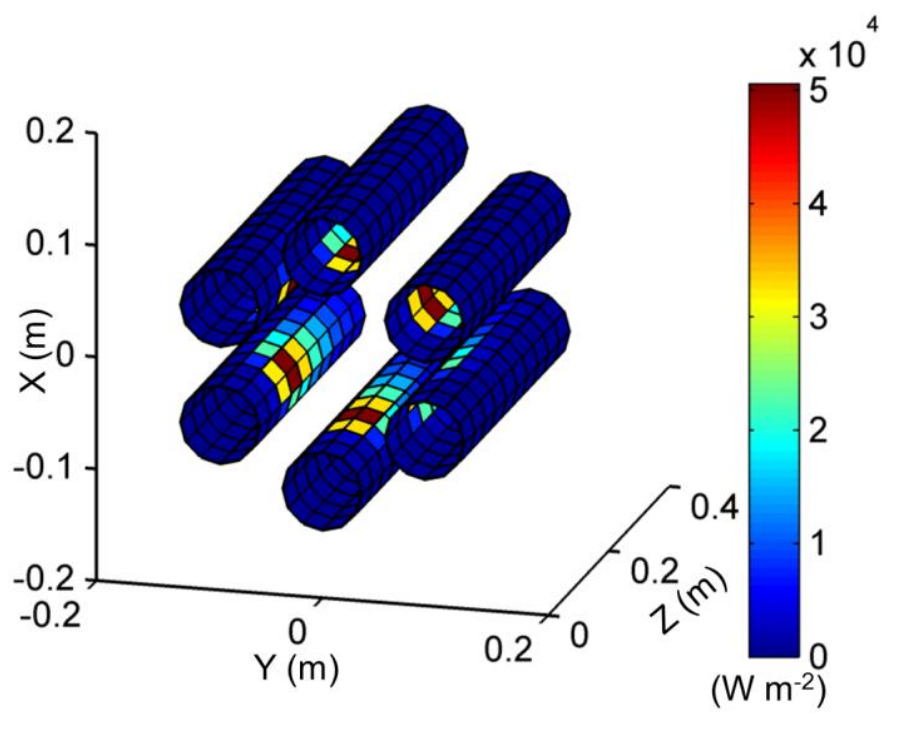

(b)

Figure 5 Spatial contours of the absorbed incident solar fluxes for a diffusely incident input solar power of $4.2 \mathrm{~kW}$ with a half-cone angle of $37.7^{\circ}$ on the surfaces of the (a) cavity and (b) reactive elements.

\section{Spatial Temperature Profiles}

Temperature distributions in the cavity and the integrated reactive element/heat exchanger are provided at one instant (Figure 6); spatial trends are similar throughout the cycle. The area-averaged temperature of the cylindrical surface of the cavity is $1786 \mathrm{~K}$. The back plane of the cavity where the absorption of the incident flux is higher (see Figure 5(a)) is $1800 \mathrm{~K}$. About half of the input solar power is transferred to the reactive elements by surface-to-surface radiative exchange resulting in average temperatures of 1797 and $1795 \mathrm{~K}$ for RE1 at the end of reduction and RE2 at the end of oxidation. 


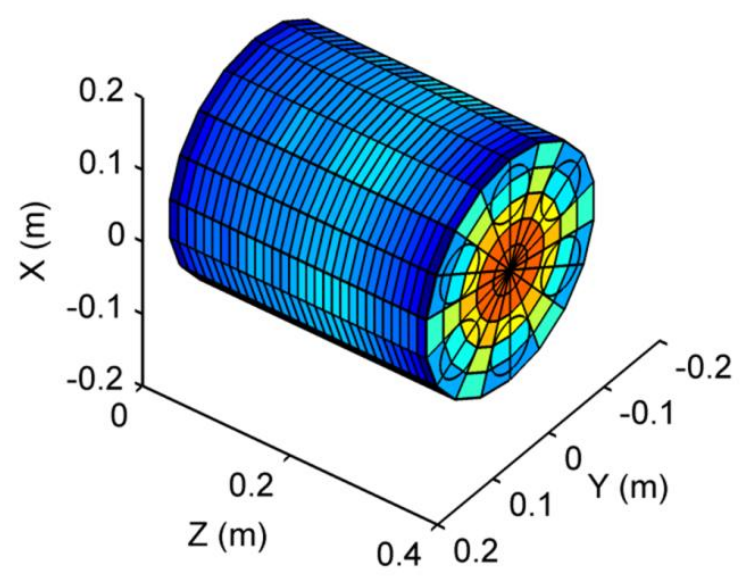

(a)

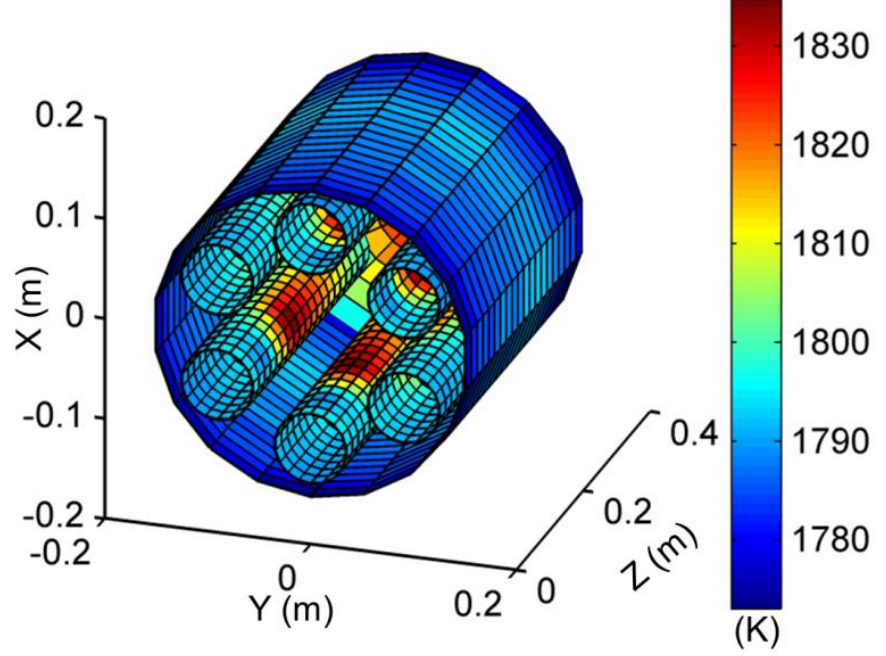

(b)

Figure 6 Spatial contours of the surface temperatures for an input solar power of $4.2 \mathrm{~kW}$ with a half-cone angle of $37.7^{\circ}$ for (a) the cavity and (b) the reactive elements.

Figure 7 illustrates the axial temperature profile in the integrated reactive element/heat exchanger at the end of reduction in RE1 (7a), and the 3-D temperature distributions in the annulus (7b) and the center channel (7c) at the end of reduction and oxidation in RE1 and RE2 respectively. Figure 7(a) also compares predicted and measured axial temperatures along the outer surface of the integrated reactive element/heat exchanger. There is excellent agreement along the heat exchanger. Measured data within the cavity are within 10 to $30 \mathrm{~K}$ of the predicted temperature. This difference is relatively small compared to the absolute temperature in the cavity. Potential causes for the difference include nonuniform flux at the aperture in the solar simulator, uncertainty in the assumed value for surface optical properties, and measurement uncertainty $( \pm 9 \mathrm{~K})$. As shown in the plot, the $\mathrm{N}_{2}$ sweep gas entering the reactor is preheated 


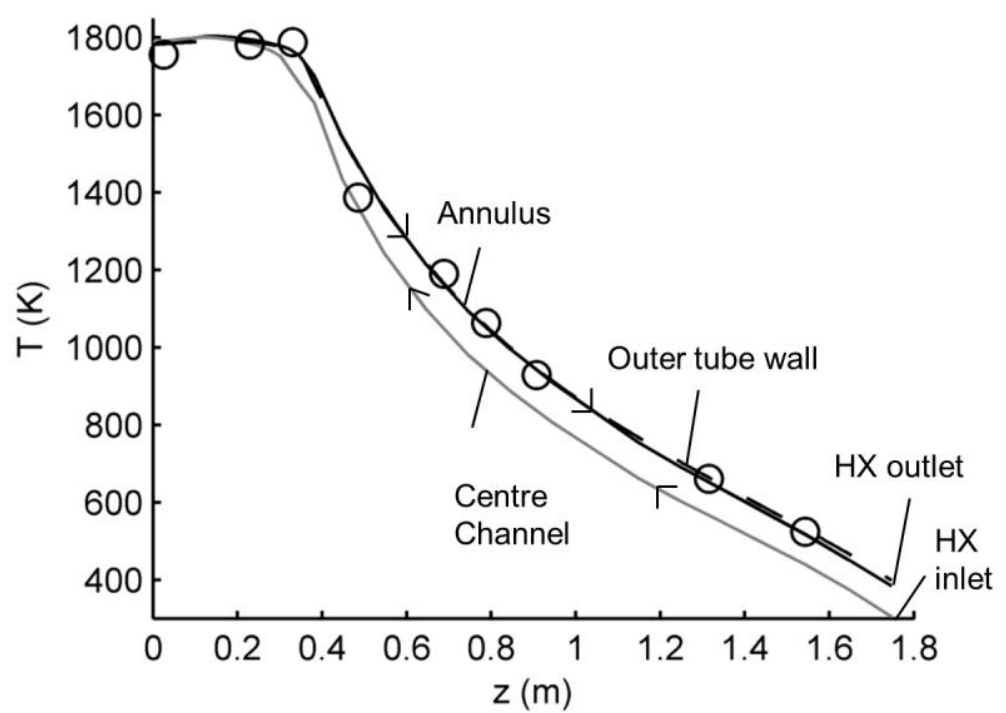

(a)

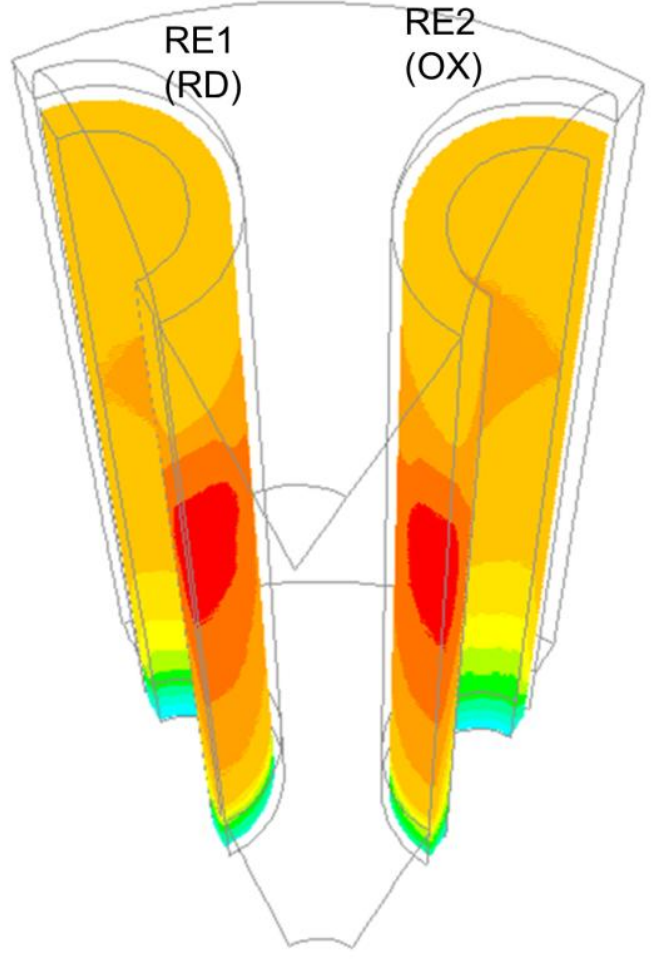

(b)

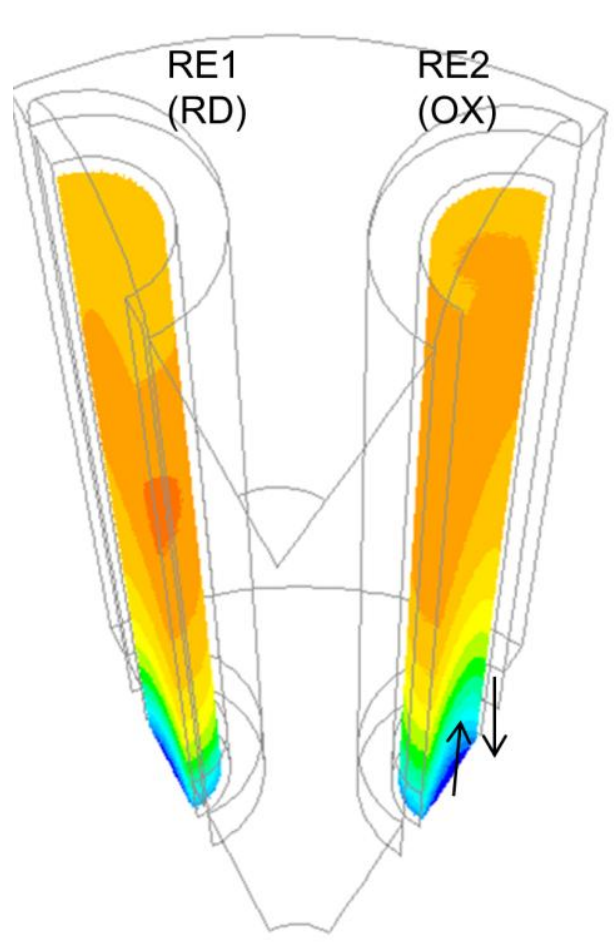

(c)

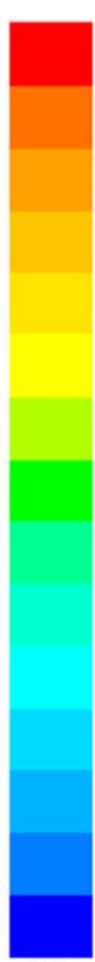

1835

1821

1808

1794

1780

1767

1753

1739

1726

1712

1698

1685

1671

1657

1644

(K)

1630

Figure 7 Axial distribution of the (a) bulk mean gas temperature (solid lines) and comparison of predicted (dashed line) and measured (open circles) temperatures along the outer surface of the integrated reactive element (RE1)/heat exchanger; 3-D contours of predicted temperatures in RE1 and RE2 in the (b) annulus and (c) centre channel. Mass specific sweep gas and oxidizer flow rates are $0.67 \mathrm{~mol} \mathrm{~s}^{-1} \mathrm{~g}_{\text {ceria }}{ }^{-1}$. Arrows indicate flow direction. 
from ambient to $1787 \mathrm{~K}$ at the inlet of the particle bed $(\mathrm{z}=0 \mathrm{~m})$. The product gas leaves the ceria bed at $1760 \mathrm{~K}$, and exits the heat exchanger at $400 \mathrm{~K}$. The average difference in the bulk gas temperature in the annulus and the centre channel is less than $100 \mathrm{~K}$ due to enhanced flow mixing in the porous media and effective radiative transport. Based on the axial temperature distribution, the steady periodic heat recovery effectiveness,

$$
\varepsilon_{\{\mathrm{sg}, \mathrm{ox}\}}=\frac{\bar{h}_{\{\mathrm{sg}, \mathrm{ox}\}}\left(T_{\mathrm{c}, \mathrm{out}}\right)-\bar{h}_{\{\mathrm{sg}, \mathrm{ox}\}}\left(T_{\mathrm{amb}}\right)}{\bar{h}_{\{\mathrm{sg}, \mathrm{ox}\}}\left(T_{\mathrm{h}, \mathrm{in}}\right)-\bar{h}_{\{\mathrm{sg}, \mathrm{ox}\}}\left(T_{\mathrm{amb}}\right)},
$$

is 91 to $93 \%$ in a cycle. The predicted pressure drop across the integrated reactive element/heat exchanger is $10 \mathrm{kPa}$ during reduction and $15 \mathrm{kPa}$ during oxidation. The pressure drop across the ceria bed results in less than a 5\% drop in fuel production rate at 1 atm for reduction and oxidation. The benefit of heat recovery outweighs this slight decrease in fuel production.

The temperature contours in Figure $7(b, c)$ reveal that the largest temperature variations are in the streamwise direction, as expected for large axial Peclet numbers $\left(\mathrm{Pe}_{\mathrm{ax}}>4000\right)$. Highly effective radiation from the tube surfaces and within the ceria bed maintains greater spatial uniformity radially and circumferentially. The predicted temperatures and intensity distributions (not shown in the figure) are analyzed to compare the relative contributions of the heat transfer modes in the ceria packed bed. Radiative heat flux vectors are evaluated as in eq. (12) and the convective heat flux vector in the $k^{\text {th }}$ direction is obtained by integrating $\nabla_{k} \cdot\left(\rho_{f} \boldsymbol{u}_{\boldsymbol{k}} \sum_{i} Y_{i} h_{i f}\right)$. Heat transfer in the radial direction is dominated by radiation $(\sim 95 \%)$, whereas heat transfer in the axial direction is dominated by convection (85\%). Solid phase conduction contributes negligibly $(<1 \%)$ to heat transfer due to the low bulk thermal conductivity of ceria $\left(\bar{k}_{\mathrm{s}, \mathrm{eff}}=0.12 \mathrm{~W} \mathrm{~m}^{-1} \mathrm{~K}^{-1}\right.$ at $\left.1773 \mathrm{~K}\right)$. 


\section{Transient Phenomena}

The volume-averaged temperatures and fuel production are shown for two redox cycles (Figure 8). The reactive elements behave identically except they are out of phase by the halfcycle time of $100 \mathrm{~s}$. The peak CO production, $2 \times 10^{-4} \mathrm{~mol} \mathrm{~s}^{-1}$, is at the onset of oxidation (Figure $8(\mathrm{a}))$ when the ceria is the most reduced and decays to $0.6 \times 10^{-4} \mathrm{~mol} \mathrm{~s}^{-1}$ after $100 \mathrm{~s}$. In the first $25 \mathrm{~s}$ of oxidation, the average bed temperature increases from $1791 \mathrm{~K}$ by approximately $1 \mathrm{~K}$ due to the exothermic reoxidation of ceria and decreases thereafter as the rate of $\mathrm{CO}$ production decreases (Figure $8(\mathrm{~b})$ ). Oxygen is released at $0.7 \times 10^{-4} \mathrm{~mol} \mathrm{~s}^{-1}$ at the start of reduction and the rate decays as the nonstoichiometry (volume-averaged) of the ceria increases from 0.026 to 0.030. During reduction, the ceria temperature decreases initially, from 1791 to $1790 \mathrm{~K}$, due to the endothermic reduction of ceria. Overall, during steady cycling nearly isothermal conditions are maintained at $\sim 1791 \mathrm{~K}$ with time-averaged temperature variations less than $1 \mathrm{~K}$ between reduction and oxidation. The cycle-averaged CO production is $3.6 \times 10^{-4} \mathrm{~mol} \mathrm{~s}^{-1}$. The mass specific, cycle-averaged CO production is $0.1 \mu \mathrm{mol} \mathrm{s}^{-1} \mathrm{~g}_{\text {ceria }}{ }^{-1}$. For comparison, during testing the prototype reactor produced $0.09 \mu$ mol $_{\mathrm{CO}} \mathrm{s}^{-1} \mathrm{~g}_{\text {ceria }}{ }^{-1}$ with slightly lower sweep gas and oxidizer flow rates. 


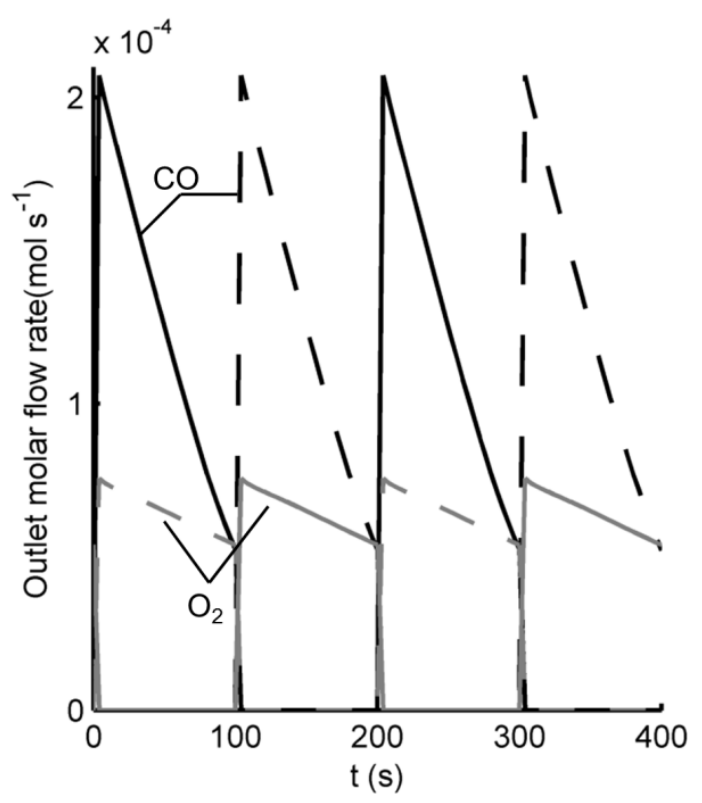

(a)

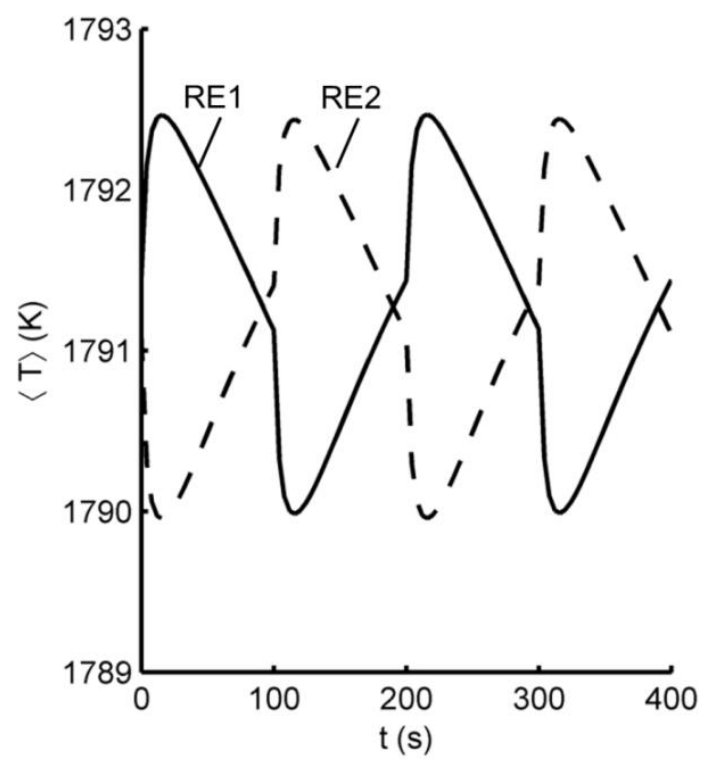

(b)

Figure 8 Transient (a) outlet molar production of $\mathrm{CO}$ and $\mathrm{O}_{2}$ with sweep gas and oxidizer flow rates of $0.67 \times 10^{-4} \mathrm{~mol} \mathrm{~s}^{-1} \mathrm{~g}_{\text {ceria }}{ }^{-1}$ and (b) volume-averaged ceria temperatures in RE1 (solid lines) and RE2 (dashed lines). Oxidation occurs from 1-100 s and 101-200 s, and reduction occurs from 101-200 s and 1-100 s in RE1 and RE2 respectively.

Simulations were also performed assuming more reflective surfaces in the cavity. In modeling the incident radiation, emissivities of the alumina insulation and alumina tubes were set to 0.3 and 0.4 , consistent with data for total normal emittance at $700-1500 \mathrm{~K}$ for the porous alumina insulation and spectral emittance at $0.64 \mu \mathrm{m}$ for the dense alumina tubes (Toulukian and Dewitt, 1972). Absorption increases from $350 \mathrm{~W}$ to $460 \mathrm{~W}$ on the tube surfaces. As a result, the volume averaged temperature of ceria increases from 1791 to $1798 \mathrm{~K}$ during reduction and from 1792 to $1799 \mathrm{~K}$ during oxidation. The $\mathrm{CO}$ production rate increases by $12 \%$ to $4 \times 10^{-4} \mathrm{~mol} \mathrm{~s}^{-1}$. The higher temperature during isothermal operation improves chemical performance by increasing the extent of reduction.

Figure 9 depicts the time evolution of the area-averaged rates, partial pressure of $\mathrm{O}_{2}$ and $\mathrm{CO}$, temperature and the oxidation state of ceria in the streamwise direction for RE1 over one 


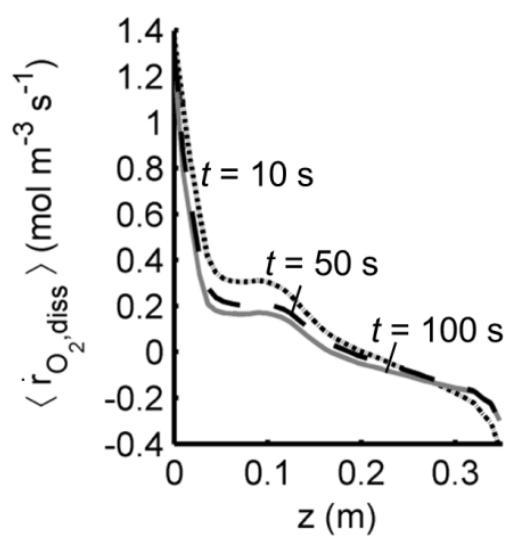

(a)

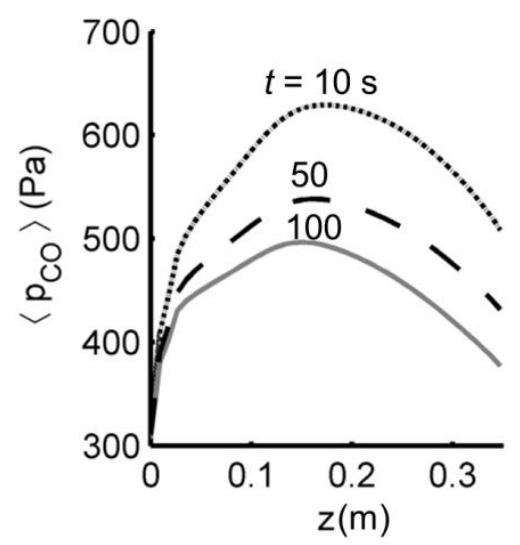

(c)

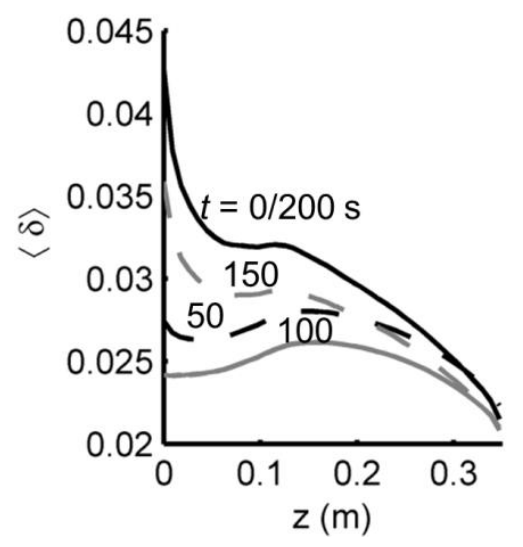

(e)

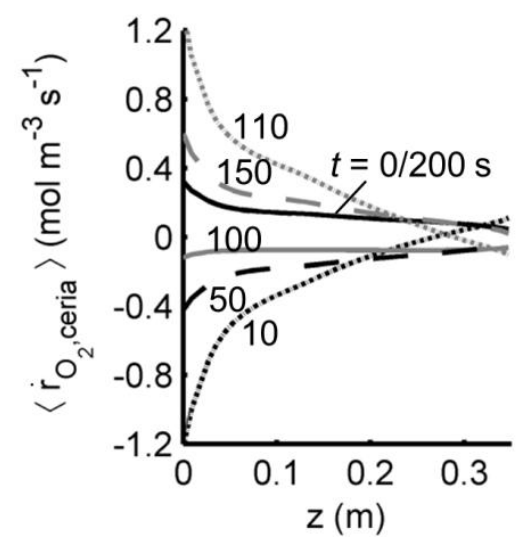

(b)

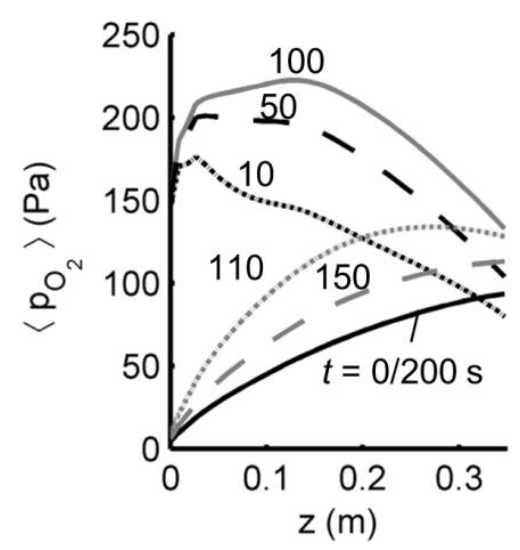

(d)

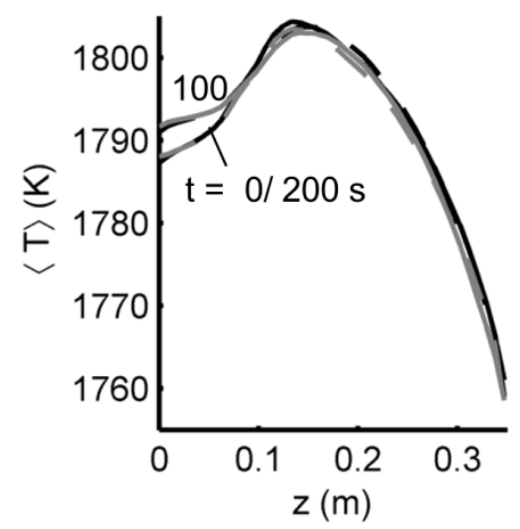

(f)

Figure 9 Axial and transient variations in the area-averaged (a) rate of oxygen produced due to $\mathrm{CO}_{2}$ dissociation (b) rate of oxygen produced by ceria (c) $\mathrm{CO}$ partial pressure (d) oxygen partial pressure, (e) nonstoichiometry and (f) temperature with $0.67 \mathrm{~mol} \mathrm{~s}^{-1} \mathrm{~g}_{\text {ceria }}{ }^{-1}$ of $\mathrm{N}_{2}$ and $\mathrm{CO}_{2}$. 
cycle. The data for RE2 follow the same trends. These data illustrate the interrelated transport processes and their effects on reaction rates. At $t=1 \mathrm{~s}$, the flow of $\mathrm{CO}_{2}$ is initiated. The gas flow is switched to $\mathrm{N}_{2}$ at $t=101 \mathrm{~s}$. First consider oxidation. Figure 9(a) shows the highest rate of dissociation of $\mathrm{CO}_{2}$ is at the inlet of the bed; the peak dissociation rate is $1.4 \mathrm{~mol} \mathrm{~m}^{-3} \mathrm{~s}^{-1}$ at $t=10 \mathrm{~s}$. Dissociation slows in the streamwise direction due to the accumulation of thermolysis products. Likewise, the ceria uptake of $\mathrm{O}_{2}$ decreases along the flow direction (Figure 9 (b)). This decrease in the oxidation state of ceria combined with the decrease in the bed temperature (Figure 9(f)) leads to the recombination of dissociation products (indicated by negative values of $\dot{r}_{\mathrm{O}_{2}, \mathrm{diss}}$ ) and a decrease in the CO partial pressure (Figure 9(c)). For $t<30 \mathrm{~s}$, ceria uptakes oxygen (Figure 9(b)), nearly as fast as $\mathrm{CO}_{2}$ dissociates. For $t>30 \mathrm{~s}$, the rate of oxygen uptake is slower than dissociation. At the inlet, the rate of oxygen uptake drops from $1.2 \mathrm{~mol} \mathrm{~m}^{-3} \mathrm{~s}^{-1}$ at $t=10 \mathrm{~s}$ to $0.43 \mathrm{~mol} \mathrm{~m}^{-3} \mathrm{~s}^{-1}$ at $t=50 \mathrm{~s}$, whereas the dissociation rate decreases by only $10 \%$ to $1.3 \mathrm{~mol} \mathrm{~m}^{-3} \mathrm{~s}^{-1}$ over the same duration. Corresponding to the decrease in the rate of uptake of $\mathrm{O}_{2}$, the nonstoichiometry decreases from 0.028 to 0.025 . The transient profiles during reduction are tied closely to the state of the bed at the end of oxidation. As the ceria is reduced, the $\mathrm{O}_{2}$ partial pressure increases in the axial direction (Figure 9(d)). This increase reduces the driving force for the chemical reaction and $\mathrm{O}_{2}$ production slows (Figure 9(b)). At $t=110 \mathrm{~s}$, a small region near the exit of the bed $(z>0.25 \mathrm{~m})$ is reoxidized due to the higher oxygen partial pressure and lower bed temperature. The $\mathrm{O}_{2}$ release slows over the course of the half cycle with the fastest decrease at $z=0 \mathrm{~m}$ (see Figure 9(e)) where ceria is most reduced. The largest swings in ceria nonstoichiometry are at the inlet (Figure 9(e)), where the fastest reaction rates are observed (Figure 9(a,b)). 
Temperature variations during cycling are influenced primarily by the differences in convective heat transfer rates. The only location where the energy release/consumption by the chemical reactions accounts for the difference in temperature between oxidation and reduction is within $80 \mathrm{~mm}$ of the inlet. Here the temperature during oxidation is as much as $5 \mathrm{~K}$ higher than during reduction. The rest of the bed experiences a $1-2 \mathrm{~K}$ thermodynamically favorable temperature swing due to the higher thermal capacitance of the flow of $\mathrm{CO}_{2}$ compared to $\mathrm{N}_{2}$.

The results of the model and interpretation of the bench top data lead us to the conclusion that fuel production is limited by the thermodynamic capacity of the flowing gas to change the oxidation state of the ceria. To support this conclusion, we show the model predictions for ceria nonstoichiometry approaches the thermodynamic equilibrium state of ceria corresponding to the local oxygen partial pressure and temperature (Figure 10). The maximum deviation in nonstoichiometry is $15 \%$ during reduction and $6 \%$ during oxidation. The implications of this result are surface kinetics is rapid relative to gas phase mass transport and the fixed bed flow configuration provides highly effective utilization of the sweep gas and the oxidizer for the chosen material morphology, gas flow rates and the cycle times (Venstrom et al., 2015). 


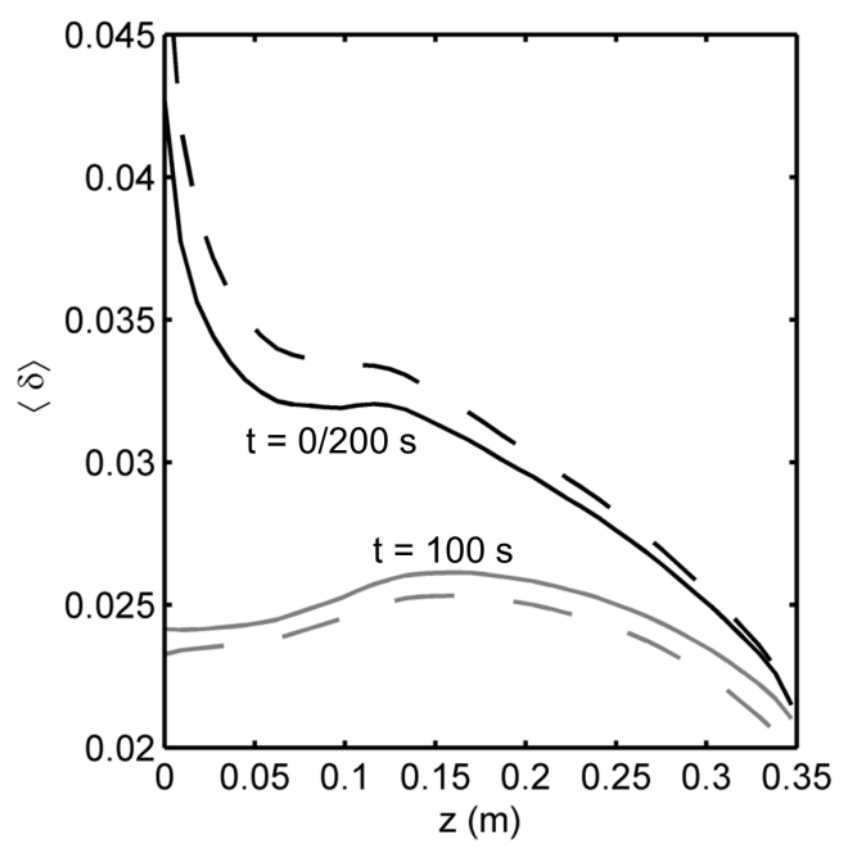

Figure 10 Comparison of model predictions (solid lines) of area-averaged ceria bed nonstoichiometry and the equilibrium values (dashed lines) at the end of oxidation and reduction with $0.67 \mathrm{~mol} \mathrm{~s}^{-1} \mathrm{~g}_{\text {ceria }}{ }^{-1}$ of sweep gas and $\mathrm{CO}_{2}$.

\subsection{Reactor Efficiency}

To discuss the energetic impacts of the selected operating conditions, the energy balance of the reactor prototype is considered during steady periodic operation:

$$
\begin{aligned}
\dot{Q}_{\text {solar }}=\underbrace{\sum_{i, \text { out }} I_{\text {ap }, i}\left|s_{i} \cdot \hat{k}\right|}_{\dot{Q}_{\text {rerad }}}-\underbrace{\iint\left(k_{\text {ins }} \nabla_{r} T\right) \cdot d A_{\text {ins }}}_{\dot{Q}_{\text {loss }}} \\
+ \\
+\underbrace{\left(\frac{1}{2}\right) \dot{n}_{\mathrm{sg}}\left[\bar{h}_{\mathrm{sg}}\left(T_{\mathrm{RE}, \mathrm{out}}\right)-\bar{h}_{\mathrm{sg}}\left(T_{\mathrm{RE}, \mathrm{in}}\right)\right]}_{\dot{Q}_{\mathrm{sg}}}+\underbrace{\left(\frac{1}{2}\right) \dot{n}_{\mathrm{ox}}\left[\bar{h}_{\mathrm{ox}}\left(T_{\mathrm{RE}, \mathrm{out}}\right)-\bar{h}_{\mathrm{ox}}\left(T_{\mathrm{RE}, \mathrm{in}}\right)\right]}_{\dot{Q}_{\mathrm{ox}}} \\
+\iiint \underbrace{\frac{\int_{t}\left(\dot{S}_{\mathrm{rxn}, \mathrm{rd}}+\dot{S}_{\mathrm{rxn}, \mathrm{ox}}\right) d t}{t_{\mathrm{cycle}}} d V}_{\dot{Q}_{\mathrm{chem}}}
\end{aligned}
$$


At steady state, the input solar power $\dot{Q}_{\text {solar }}$ is equal to the sum of the heat loss due to reflection and thermal emission, $\dot{Q}_{\text {rerad }}$, the thermal loss to the ambient via natural convection from the aperture and conduction through the insulation, $\dot{Q}_{\text {loss }}$, the sensible energy required for the sweep gas and oxidizer gas, $\dot{Q}_{\text {sg }}$ and $\dot{Q}_{\text {ox }}$, and the energy requirements of the net reaction, $\dot{Q}_{\text {chem. }}$. The reradiation loss, $\dot{Q}_{\text {rerad }}$, is calculated from the angular profiles of the outgoing intensity $\left(I_{\mathrm{ap}}\right)$ distributions at the aperture and equals $880 \mathrm{~W}$. The conduction loss is obtained from a surface integral of the heat fluxes on the outer surface of the insulation and equals $1210 \mathrm{~W}$. The gas phase sensible heating load is $2 \mathrm{~kW}, 660 \mathrm{~W}$ for reduction $\left(\dot{Q}_{\mathrm{sg}}\right)$ and $1.34 \mathrm{~kW}$ for oxidation $\left(\dot{Q}_{\mathrm{ox}}\right)$. Despite remarkably high heat recovery effectiveness, the sensible heating load approaches 50\% of the input power. The chemical energy requirement is computed by time averaging the volume integrals of the energy sources/sinks (eq. (8)) over a cycle and equals $108 \mathrm{~W}$. The magnitude of $\dot{Q}_{\text {chem }}$ is much smaller than the other energy terms due to the small swings in ceria nonstoichiometry $(\sim 0.004)$ during isothermal cycling.

We define the overall solar-to-fuel efficiency of the reactor as,

$$
\eta=\frac{\overline{\dot{n}}_{\mathrm{f}} \cdot \mathrm{HHV}_{\mathrm{f}}}{\dot{Q}_{\text {solar }}+\frac{\dot{W}_{\text {sg,sep }}+\dot{W}_{\text {ox,sep }}+\dot{W}_{\text {ox,pump }}}{\eta_{\mathrm{s} \rightarrow \mathrm{E}}}}
$$

where the numerator is the rate at which chemical energy is stored in the fuel. The denominator includes the concentrated solar power plus the solar thermal equivalents of the parasitic work requirements for separation of the sweep gas $\mathrm{N}_{2}$ from air, separation of the oxidation products, and pumping. The work terms are assumed to be provided by solar energy with a solar to electric energy conversion efficiency $\left(\eta_{\mathrm{s} \rightarrow \mathrm{E}}\right)$ of $25 \%$. The energy required for $\mathrm{N}_{2}$ production in the desired purity (1-10 ppm $\left.\mathrm{O}_{2}\right), \dot{W}_{\mathrm{sg}, \mathrm{sep}}$, is $12.1 \mathrm{~kJ}$ mol- $\mathrm{N}_{2}{ }^{-1}$ for a cryogenic air separation plant, 
which delivers the gas at an elevated pressure of 8 bars (Häring, 2008). The theoretical minimum work with an efficiency factor of $10 \%$ is used to calculate the energy costs to separate pure CO from the product stream, $\dot{W}_{\text {ox,sep }}$. The power required to pump the oxidizer, $W_{\text {ox,pump }}$, through the integrated reactive element/heat exchanger is evaluated assuming an $80 \%$ efficient compressor. At mass specific flow rates of $0.67 \times 10^{-4} \mathrm{~mol} \mathrm{~s}^{-1} \mathrm{~g}_{\text {ceria }}{ }^{-1}, 5.7 \mathrm{~kW}$ is needed to produce pure $\mathrm{N}_{2}$. The energetic cost to produce $\mathrm{N}_{2}$ is comparable to the input solar power and is the largest of the parasitic energy terms. Smaller contributions to the parasitic energy are pumping the oxidizer $(210 \mathrm{~W})$ across a pressure drop of $15 \mathrm{kPa}$ and $\mathrm{CO}$ separation $(240 \mathrm{~W})$ in the product stream.

The predicted solar-to-fuel conversion efficiency is $0.9 \%$ according to the definition of efficiency in eq. (27). As a comparison, state-of-the art ceria-based solar reactor prototypes that implement the two-temperature ceria cycle and produce fuel in a batch process have reported solar-to-fuel efficiencies of $0.4-1.6 \%$ (Chueh et al., 2010; Furler et al., 2014, 2012a). Though the efficiency for the isothermal ceria redox cycle is inherently limited by the chemical thermodynamics, modest improvements in efficiency may be possible by alternating the flow direction as each reactive element is switched between reduction and oxidation, or introduction of a mild vacuum during reduction. The only method proposed to substantially improve performance is the partial oxidation of methane/ceria cycle proposed by Krenzke and Davidson (Krenzke and Davidson, 2014).

\section{CONCLUSION}

Results of a transient three-dimensional model of a $4 \mathrm{~kW}_{\mathrm{th}}$ solar thermochemical reactor for splitting carbon dioxide via the isothermal ceria redox cycle at $1773 \mathrm{~K}$ provide insight to the interactions between transport processes and chemical kinetics and how these interactions impact 
temperature, pressure, species concentrations, and fuel production. The modeled reactor has two major benefits compared to the prior art. First, it produces fuel continuously on-sun by alternating the reduction and oxidation reactions between six independent reactive elements in $100 \mathrm{~s}$ half-cycles. Redox cycling is accomplished by switching the inlet gas between a nitrogen sweep gas for reduction and carbon dioxide for oxidation. As a consequence, the reactor has no high temperature moving parts. Second, heat recovery of the sensible heat of the gases is integral to the reactor. Each reactive element is a concentric assembly of two alumina tubes. Gases flow into the reactive element through the inner channel and out of the reactor through the annulus. Within the solar cavity, the annulus is filled with porous ceria particles that provide rapid diffusion of oxygen, low pressure drop, and effective heat transport. Outside the solar cavity the tubes are filled with alumina reticulated porous ceramic (RPC) to provide highly effective heat recuperation.

Two challenges in modeling the reactor were the limitation of the available kinetic models for the redox chemistry, particularly for oxidation, and the lack of data for optical surface properties in the solar spectrum at the temperatures of interest. To address the first challenge, we applied reversible reaction rate expressions for the dissociation of $\mathrm{CO}_{2}$ in addition to the reduction/oxidation reactions in ceria. The rate expression provided by Buffin et al. (Bulfin et al., 2013) for oxidation of ceria in an oxygen atmosphere at $773-1273 \mathrm{~K}$ was rearranged for simplicity. The necessary reaction rate coefficients were extracted from published global rates obtained in a bench top isothermal reactor at $1773 \mathrm{~K}$ (Venstrom et al., 2014). With reference to equations (16) and (20), the kinetic parameters are $A_{\mathrm{ox}}=1.5$ molo $_{\mathrm{O} o l}{ }_{\text {ceria }}{ }^{-1} \mathrm{~s}^{-1}$ and $k_{\mathrm{d}, \mathrm{CO}_{2}}=0.3$ mol $_{\mathrm{CO}} \mathrm{mol}_{\text {ceria }}{ }^{-1} \mathrm{~s}^{-1}$. To address the second challenge, we explored the relative differences in the reactor performance for reflective versus absorptive cavity surfaces. Higher absorption on the 
reactor tube surfaces for a reflective cavity increased the volume-averaged ceria temperature, from 1791 to $1799 \mathrm{~K}$ yielding a $12 \%$ boost in fuel production rate.

The results illustrate the effectiveness of the reactor to carry out the isothermal redox cycle and at the same time expose the thermodynamic limitations of the isothermal approach. Radiative transport is highly effective at achieving high absorption efficiency and isothermal conditions at the nominal operating temperature of $1773 \mathrm{~K}$. More than half of the incident solar power is absorbed by the surfaces of the reactive elements in which the redox chemistry takes place. The spatially averaged surface temperatures of the reactive elements are closely coupled - $1795 \mathrm{~K}$ during reduction and $1797 \mathrm{~K}$ during oxidation. The volume and time averaged temperature of the indirectly irradiated ceria particles is $1791 \mathrm{~K}$ during reduction and $1792 \mathrm{~K}$ during oxidation; except for a small region of the ceria bed close to the inlet, a slightly favorable thermodynamically favorable temperature swing is achieved due to the relative differences in the convective cooling capacity of the gases. Even with demonstrated heat recovery effectiveness greater than $90 \%$, increasing the flow rate of the oxidizer further to improve the fuel production rate and the temperature swing is not beneficial due to the additional power required to heat the unreacted $\mathrm{CO}_{2}$. Moreover, reducing the flow rate of sweep gas, to promote a favorable temperature swing and reduce the energy penalty for $\mathrm{N}_{2}$ production, will adversely impact the rate of oxygen release from the ceria.

For the design operating conditions, fuel is produced continuously at $3.6 \times 10^{-4} \mathrm{~mol} \mathrm{~s}^{-1}$ with an energetic power of $100 \mathrm{~W}$ based on the higher heating value of CO. Spatial and temporal reaction rates and species concentration profiles reveal that the oxygen release/uptake by ceria is strongly influenced by the streamwise rate of advection of the reactants and products. The reaction rates are limited by the thermodynamic capacity of the gas to carry away/deliver 
products/reactants. Efficient gas utilization and exemplary (91-93\% during cycling) gas phase heat recovery effectiveness are noteworthy milestones, especially due to their dramatic impacts on the overall process efficiencies for isothermal ceria cycles.

\section{ACKNOWLEDGEMENTS}

The authors wish to acknowledge the contributions of Prof. Thomas R. Chase, and Stephen Sedler for their contributions to the final design of the reactor and preparation of Figure 1. Dr. Luke J. Venstrom and Robert M. De Smith conducted the bench top experiments with ceria (Venstrom et al., 2014) and provided the data for our use in the development of reaction rate models. Dr. Brandon J. Hathaway led the experimental work from which the comparative data in Figure 7 was obtained. As a former member of the reactor design team, Dr. Roman Bader developed a Monte Carlo ray tracing model for the incident radiation in the cavity (Bader et al., 2015). This model has been modified in the present work and integrated with a finite volume scheme to compute the emitted radiation. We also acknowledge the many helpful discussions for interpretation of the modeling work provided by the collaborators at the University of Minnesota, as well as Peter T. Krenzke and Dr. Adam C. Gladen.

The financial support by the U.S. Department of Energy's Advanced Research Projects Agency-Energy (DOE ARPA-E, award no. DE-AR0000182) to the University of Minnesota, the University of Minnesota Initiative for Renewable Energy and the Environment (IREE, grant no. RM-0001-12) and the Doctoral Dissertation Fellowship from the University of Minnesota is gratefully acknowledged. The information, data, or work presented herein was funded in part by an agency of the United States Government. Neither the United States Government nor any agency thereof, nor any of their employees, makes any warranty, express or implied, or assumes any legal liability or responsibility for the accuracy, completeness, or usefulness of any 
information, apparatus, product, or process disclosed, or represents that its use would not infringe privately owned rights. Reference herein to any specific commercial product, process, or service by trade name, trademark, manufacturer, or otherwise does not necessarily constitute or imply its endorsement, recommendation, or favoring by the United States Government or any agency thereof. The views and opinions of authors expressed herein do not necessarily state or reflect those of the United States Government or any agency thereof. 


\section{REFERENCES}

Abanades, S., Flamant, G., 2006. Thermochemical hydrogen production from a two-step solardriven water-splitting cycle based on cerium oxides. Sol. Energy 80, 1611-1623.

doi:10.1016/j.solener.2005.12.005

Agrafiotis, C., Roeb, M., Sattler, C., 2015. A review on solar thermal syngas production via redox pair-based water/carbon dioxide splitting thermochemical cycles. Renew. Sustain. Energy Rev. 42, 254-285. doi:10.1016/j.rser.2014.09.039

ANSYS ${ }^{\circ}$ Academic Research, 2014a. Ansys Fluent Theory Guide, Release 15.0. ANSYS ${ }^{\circledR}$ Academic Research, 2014b. Ansys Fluent User Defined Functions Guide, Release 15.0.

Bader, R., Bala Chandran, R., Venstrom, L.J., Sedler, S.J., Krenzke, P.T., De Smith, R.M., Banerjee, A., Chase, T.R., Davidson, J.H., Lipinski, W., 2015. Design of a Solar Reactor to Split $\mathrm{CO}_{2}$ Via Isothermal Redox Cycling of Ceria. J. Sol. Energy Eng. 137, 031007. doi: $10.1115 / 1.4028917$

Bader, R., Venstrom, L.J., Davidson, J.H., Lipiński, W., 2013. Thermodynamic Analysis of Isothermal Redox Cycling of Ceria for Solar Fuel Production. Energy \& Fuels 27, 5533-5544. doi:10.1021/ef400132d

Bala Chandran, R., Bader, R., Lipiński, W., 2015a. Transient heat and mass transfer analysis in a porous ceria structure of a novel solar redox reactor. Int. J. Therm. Sci. 92, 138-149. doi:10.1016/j.ijthermalsci.2015.01.016

Bala Chandran, R., De Smith, R.M., Davidson, J.H., 2015b. Model of an integrated solar thermochemical reactor/reticulated ceramic foam heat exchanger for gas-phase heat recovery. Int. J. Heat Mass Transf. 81, 404-414. doi:10.1016/j.ijheatmasstransfer.2014.10.053

Banerjee, A., Bala Chandran, R., Davidson, J.H., 2015. Experimental investigation of a reticulated porous alumina heat exchanger for high temperature gas heat recovery. Appl. Therm. Eng. 75, 889-895. doi:10.1016/j.applthermaleng.2014.10.033

Bhattacharya, A., Calmidi, V., Mahajan, R., 2002. Thermophysical properties of high porosity metal foams. Int. J. Heat Mass Transf. 45, 1017-1031. doi:10.1016/S0017-9310(01)00220-4 
Binnewies, M., Milke, E., 2002. Thermochemical Data of Elements and Compounds. WileyVCH Verlag GmbH \& Co. KGaA.

Bulfin, B., Lowe, A.J., Keogh, K.A., Murphy, B.E., Lübben, O., Krasnikov, S.A., Shvets, I. V., 2013. Analytical Model of $\mathrm{CeO}_{2}$ Oxidation and Reduction. J. Phys. Chem. C 117, 24129-24137. doi:10.1021/jp406578z

Calmidi, V. V, 1998. Transport phenomena in high porosity fibrous metal foams. University of Colorado Boulder.

Chueh, W.C., Falter, C., Abbott, M., Scipio, D., Furler, P., Haile, S.M., Steinfeld, A., 2010.

High-flux Solar-driven Thermochemical Dissociation of $\mathrm{CO}_{2}$ and $\mathrm{H}_{2} \mathrm{O}$ Using Nonstoichiometric Ceria. Science 330, 1797-801. doi:10.1126/science.1197834

Chueh, W.C., Haile, S.M., 2010. A Thermochemical Study of Ceria: Exploiting an Old Material for New Modes of Energy Conversion and $\mathrm{CO}_{2}$ Mitigation. Philos. Trans. A. Math. Phys. Eng. Sci. 368, 3269-94. doi:10.1098/rsta.2010.0114

Chui, E.H., Raithby, G.D., 1993. Computation of radiant heat transfer on a nonorthogonal mesh using the finite-volume method. Numer. Heat Transf. Part B Fundam. 23, 269-288. doi:10.1080/10407799308914901

Cussler, E.L., 1997. Diffusion Mass Transfer in Fluid Systems, Second. ed. Cambridge University Press.

Diver, R.B., Miller, J.E., Siegel, N.P., Moss, T.A., 2010. Testing of a CR5 Solar Thermochemical Heat Engine Prototype, in: ASME 2010 4th International Conference on Energy Sustainability. ASME, pp. 97-104. doi:10.1115/ES2010-90093

Ermanoski, I., Siegel, N.P., Stechel, E.B., 2013. A New Reactor Concept for Efficient SolarThermochemical Fuel Production. J. Sol. Energy Eng. 135, 031002. doi:10.1115/1.4023356

Furler, P., Scheffe, J., Gorbar, M., Moes, L., Vogt, U., Steinfeld, A., 2012a. Solar Thermochemical $\mathrm{CO}_{2}$ Splitting Utilizing a Reticulated Porous Ceria Redox System. Energy \& Fuels 26, 7051-7059. doi:10.1021/ef3013757

Furler, P., Scheffe, J., Marxer, D., Gorbar, M., Bonk, A., Vogt, U., Steinfeld, A., 2014.

Thermochemical CO2 splitting via redox cycling of ceria reticulated foam structures with dual- 
scale porosities. Phys. Chem. Chem. Phys. 16, 10503. doi:10.1039/c4cp01172d

Furler, P., Scheffe, J.R., Steinfeld, A., 2012b. Syngas Production by Simultaneous Splitting of $\mathrm{H}_{2} \mathrm{O}$ and $\mathrm{CO}_{2}$ via Ceria Redox Reactions in a High-temperature Solar Reactor. Energy Environ. Sci. 5, 6098-6103. doi:10.1039/c1ee02620h

Furler, P., Steinfeld, A., 2015. Heat transfer and fluid flow analysis of a 4kW solar thermochemical reactor for ceria redox cycling. Chem. Eng. Sci. doi:10.1016/j.ces.2015.05.056

Ganesan, K., Dombrovsky, L.A., Lipiński, W., 2013. Visible and near-infrared optical properties of ceria ceramics. Infrared Phys. Technol. 57, 101-109.

Ganesan, K., Lipiński, W., 2011. Experimental Determination of Spectral Transmittance of Porous Cerium Dioxide in the Range 900-1700 nm. J. Heat Transfer 133, 104501. doi:10.1115/1.4003970

Hale, M.J., Bohn, M.S., 1992. Measurement of the radiative transport properties of reticulated alumina foams, in: Conference: SOLAR `93: American Society of Mechanical Engineers (ASME)/American Solar Energy Society (ASES) Joint Solar Energy Conference. Washington, DC.

Hao, Y., Yang, C.-K., Haile, S.M., 2013. High-temperature isothermal chemical cycling for solar-driven fuel production. Phys. Chem. Chem. Phys. 15, 17084-92. doi:10.1039/c3cp53270d Häring, H.W., 2008. The Air Gases Nitrogen, Oxygen and Argon, in: Häring, H.-W. (Ed.), Industrial Gases Processing. Wiley-VCH Verlag GmbH \& Co. KGaA, Germany, pp. 9-109. Hathaway, B.J., Bala Chandran, R., Sedler, S.J., Thomas, D., Gladen, A., Chase, T.R., Davidson, J.H., 2015. Effect of Flow Rates on Operation of a Solar Thermochemical Reactor for Splitting $\mathrm{CO}_{2}$ via the Isothermal Ceria Redox Cycle. J. Sol. Energy Eng. Submitted.

Hendricks, T.J., Howell, J.R., 1996. Absorption/Scattering Coefficients and Scattering Phase Functions in Reticulated Porous Ceramics. J. Heat Transfer 118, 79-87. doi:10.1115/1.2824071 Hulst, van de, Christoffel, H., 2012. Light scattering by small particles. Courier Dover Publications.

James, D.L., Siegel, N.P., Diver, R.B., Boughton, B.D., Hogan, R.E., 2006. Numerical Modeling of Solar Thermo-Chemical Water-Splitting Reactor, in: Solar Energy. ASME, pp. 221-227. 
doi:10.1115/ISEC2006-99141

Kaviany, M., 1995. Fluid Mechanics, in: Principles of Heat Transfer in Porous Media. SpringerVerlag, New York, pp. 13-109.

Kaviany, M., 1995. Conduction Heat Transfer, in: Principles of Heat Transfer in Porous Media. Springer-Verlag, New York, pp. 120-122.

Keene, D.J., Davidson, J.H., Lipiński, W., 2013. A Model of Transient Heat and Mass Transfer in a Heterogeneous Medium of Ceria Undergoing Nonstoichiometric Reduction. J. Heat Transfer 135, 052701. doi:10.1115/1.4023494

Keene, D.J., Lipiński, W., Davidson, J.H., 2014. The effects of morphology on the thermal reduction of nonstoichiometric ceria. Chem. Eng. Sci. 111, 231-143.

doi:10.1016/j.ces.2014.01.010

Krenzke, P.T., Davidson, J.H., 2015. On the Efficiency of Solar $\mathrm{H}_{2}$ and CO Production via the Thermochemical Cerium Oxide Redox Cycle: The Option of Inert-Swept Reduction. Energy \& Fuels 1045-1054. doi:10.1021/ef502601f

Krenzke, P.T., Davidson, J.H., 2014. Thermodynamic Analysis of Syngas Production via the Solar Thermochemical Cerium Oxide Redox Cycle with Methane-Driven Reduction. Energy \& Fuels 28, 4088-4095. doi:10.1021/ef500610n

Krueger, K.R., Lipiński, W., Davidson, J.H., 2013. Operational Performance of the University of Minnesota 45 kW e High-Flux Solar Simulator. J. Sol. Energy Eng. 135, 044501. doi:10.1115/1.4023595

Lapp, J., Davidson, J.H., Lipiński, W., 2013. Heat Transfer Analysis of a Solid-Solid Heat Recuperation System for Solar-Driven Nonstoichiometric Redox Cycles. J. Sol. Energy Eng. 135, 031004. doi:10.1115/1.4023357

Lapp, J., Davidson, J.H., Lipiński, W., 2012. Efficiency of two-step solar thermochemical nonstoichiometric redox cycles with heat recovery. Energy 37, 591-600. doi:10.1016/j.energy.2011.10.045

Lapp, J., Lipinski, W., 2014. Transient Three-Dimensional Heat Transfer Model of a Solar Thermochemical Reactor for $\mathrm{H}_{2} \mathrm{O}$ and $\mathrm{CO}_{2}$ Splitting Via Nonstoichiometric Ceria Redox 
Cycling. J. Sol. Energy Eng. 136, 031006. doi:10.1115/1.4026465

Lee, D.-Y., Vafai, K., 1999. Analytical characterization and conceptual assessment of solid and fluid temperature differentials in porous media. Int. J. Heat Mass Transf. 42, 423-435. doi:10.1016/S0017-9310(98)00185-9

Lu, W., Zhao, C.Y., Tassou, S.A., 2006. Thermal analysis on metal-foam filled heat exchangers. Part I: Metal-foam filled pipes. Int. J. Heat Mass Transf. 49, 2751-2761. doi:10.1016/j.ijheatmasstransfer.2005.12.012

Markham, J.R., Solomon, P.R., Best, P.E., 1990. An FT-IR based instrument for measuring spectral emittance of material at high temperature. Rev. Sci. Instrum. 61, 3700. doi: $10.1063 / 1.1141538$

Martinek, J., Weimer, A.W., 2013. Evaluation of finite volume solutions for radiative heat transfer in a closed cavity solar receiver for high temperature solar thermal processes. Int. J. Heat Mass Transf. 58, 585-596. doi:10.1016/j.ijheatmasstransfer.2012.11.065

Muhich, C.L., Ehrhart, B.D., Al-Shankiti, I., Ward, B.J., Musgrave, C.B., Weimer, A.W., 2015a. A review and perspective of efficient hydrogen generation via solar thermal water splitting. Wiley Interdiscip. Rev. Energy Environ. doi:10.1002/wene.174

Muhich, C.L., Weston, K.C., Arifin, D., McDaniel, A.H., Musgrave, C.B., Weimer, A.W., 2015b. Extracting Kinetic Information from Complex Gas-Solid Reaction Data. Ind. Eng. Chem. Res. 54, 4113-4122. doi:10.1021/ie503894f

Murthy, J.Y., Mathur, S.R., 1998. Finite Volume Method for Radiative Heat Transfer Using Unstructured Meshes. J. Thermophys. Heat Transf. 12, 313-321. doi:10.2514/2.6363

Panlener, R.J., Blumenthal, R.N., Garnier, J.E., 1975. A thermodynamic study of nonstoichiometric cerium dioxide. J. Phys. Chem. Solids 36, 1213-1222. doi:10.1016/00223697(75)90192-4

Patankar, S., 1980. Source-Term Linearization, in: Phillips, M.A., Millman, E.M. (Eds.), Numerical Heat Transfer and Fluid Flow. Hemisphere Publishing Corporation, pp. 143-145. Raithby, G.D., Chui, E.H., 1990. A Finite-Volume Method for Predicting a Radiant Heat Transfer in Enclosures With Participating Media. J. Heat Transfer 112, 415. 
doi:10.1115/1.2910394

Roeb, M., Sattler, C., 2013. Isothermal Water Splitting. Science (80-. ). 341, 470-471. doi:10.1126/science.1241311

Schuetz, M.A., Glicksman, L.R., 1984. A Basic Study of Heat Transfer Through Foam Insulation. J. Cell. Plast. 20, 114-121. doi:10.1177/0021955X8402000203

Singh, B.P., Kaviany, M., 1992. Modelling radiative heat transfer in packed beds. Int. J. Heat Mass Transf. 35, 1397-1405. doi:10.1016/0017-9310(92)90031-M

Smestad, G.P., Steinfeld, A., 2012. Review: Photochemical and Thermochemical Production of Solar Fuels from $\mathrm{H}_{2} \mathrm{O}$ and $\mathrm{CO}_{2}$ Using Metal Oxide Catalysts. Ind. Eng. Chem. Res. 51, 1182811840. doi:10.1021/ie3007962

Toulukian, Y., Dewitt, D., 1972. Thermal Radiative Properties Nonmetallic Solids. New York, pp. 141-176.

Venstrom, L.J., De Smith, R.M., Bala Chandran, R., Boman, D.B., Krenzke, P.T., Davidson, J.H.D., 2015. Applicability of an equilibrium model to predict rates of reduction and oxidation in a fixed bed of cerium oxide. Energy \& Fuels Submitted.

Venstrom, L.J., De Smith, R.M., Hao, Y., Haile, S.M., Davidson, J.H., 2014. Efficient Splitting of $\mathrm{CO}_{2}$ in an Isothermal Redox Cycle Based on Ceria. Energy \& Fuels 28, 2732-2742. doi:10.1021/ef402492e

Zhang, B.-M., Zhao, S.-Y., He, X.-D., 2008. Experimental and theoretical studies on hightemperature thermal properties of fibrous insulation. J. Quant. Spectrosc. Radiat. Transf. 109, 1309-1324. doi:10.1016/j.jqsrt.2007.10.008

ZIRCAR Ceramics Inc, 2006. Alumina Insulation Type SALI-2 [WWW Document]. URL http://www.zircarceramics.com/pages/rigidmaterials/specs/sali2.htm (accessed 1.5.15). 

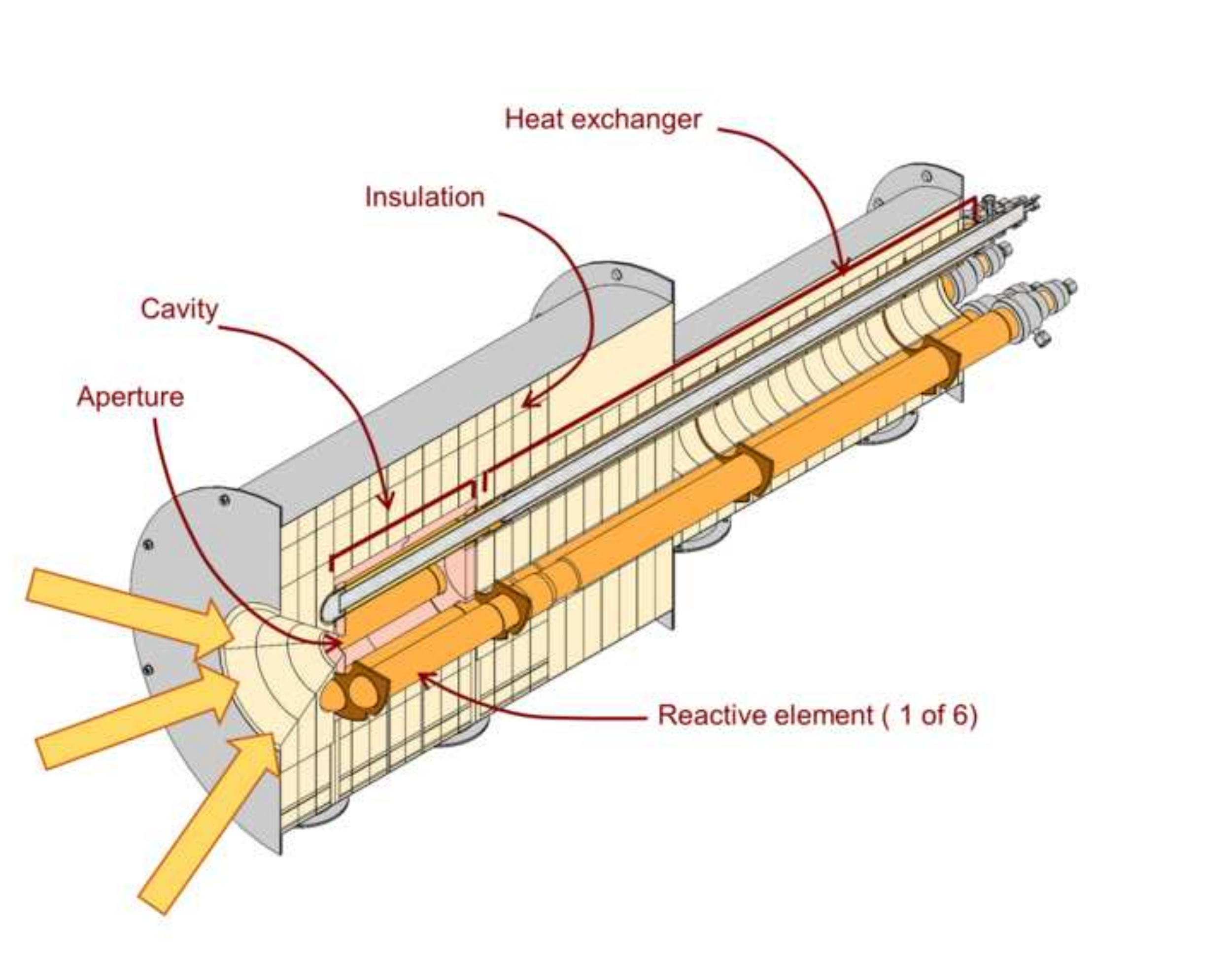

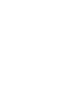

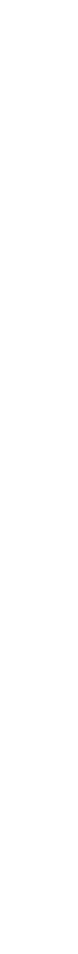

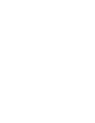




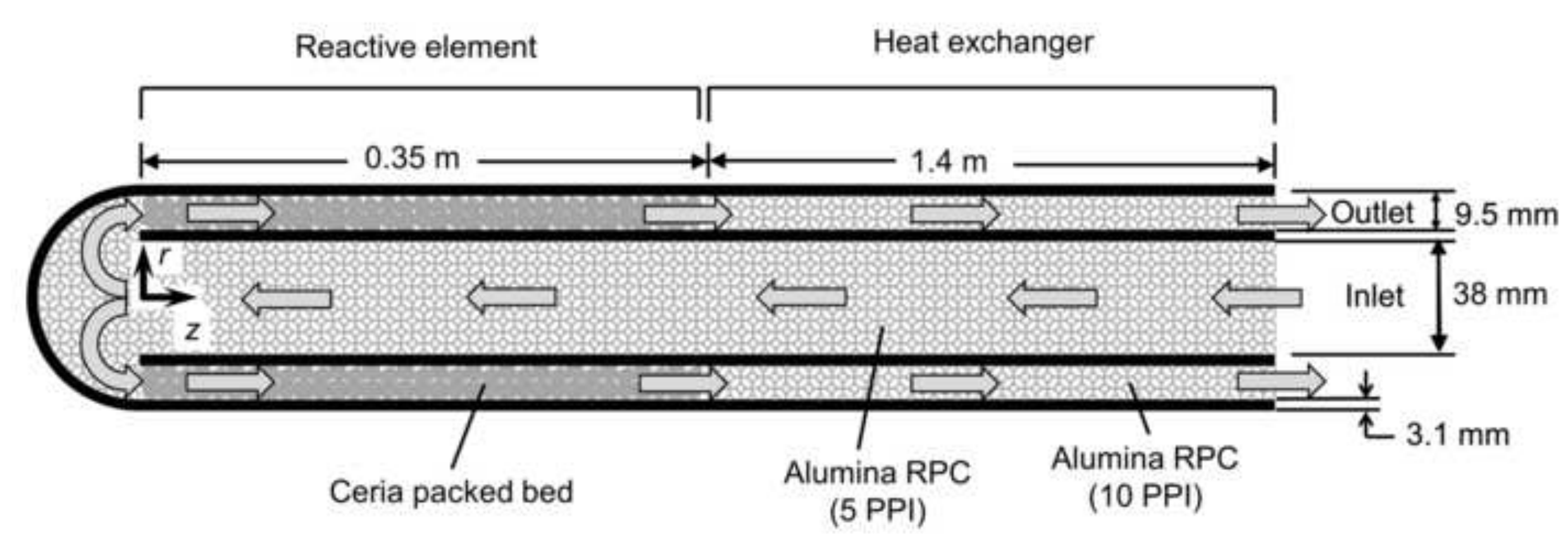




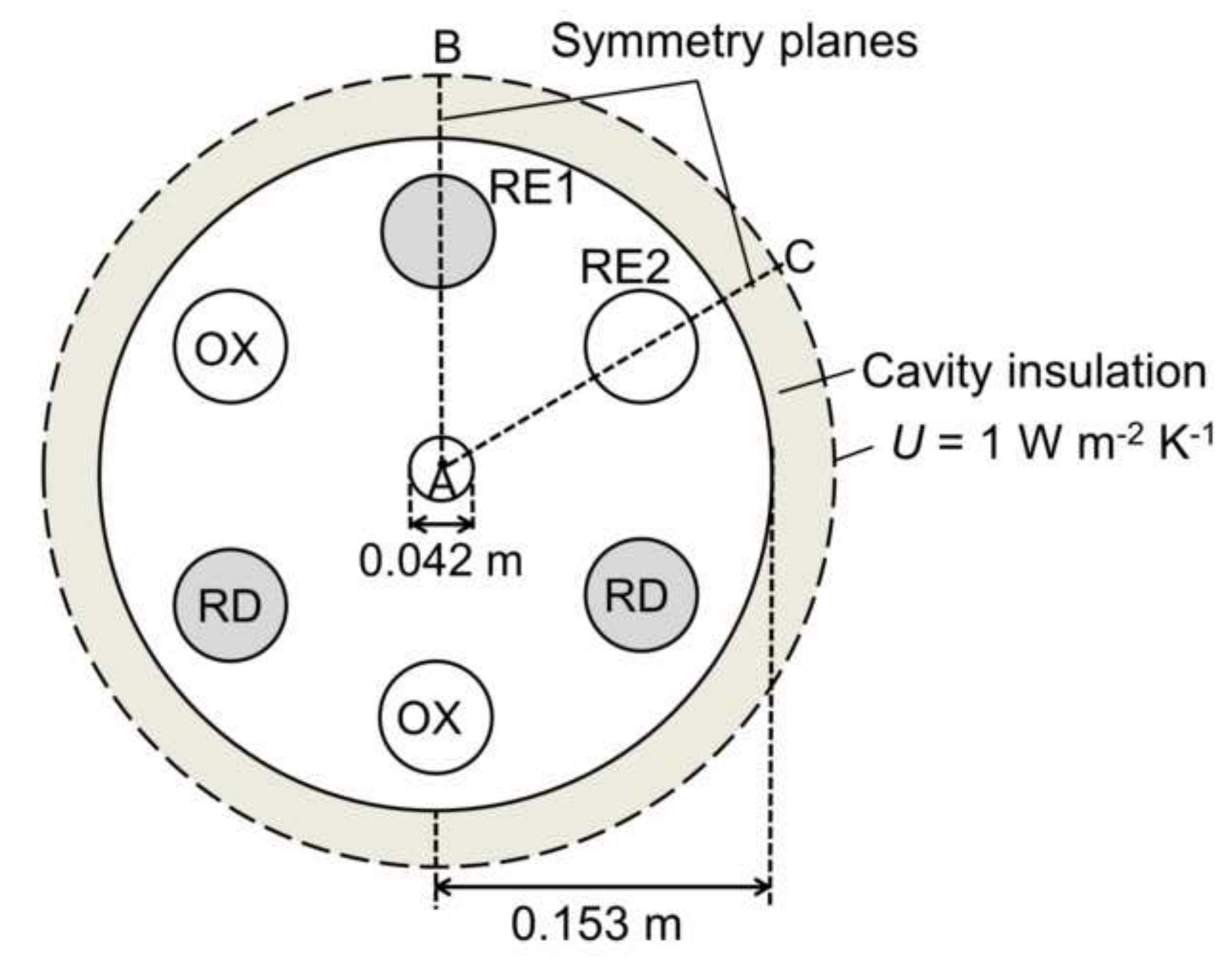




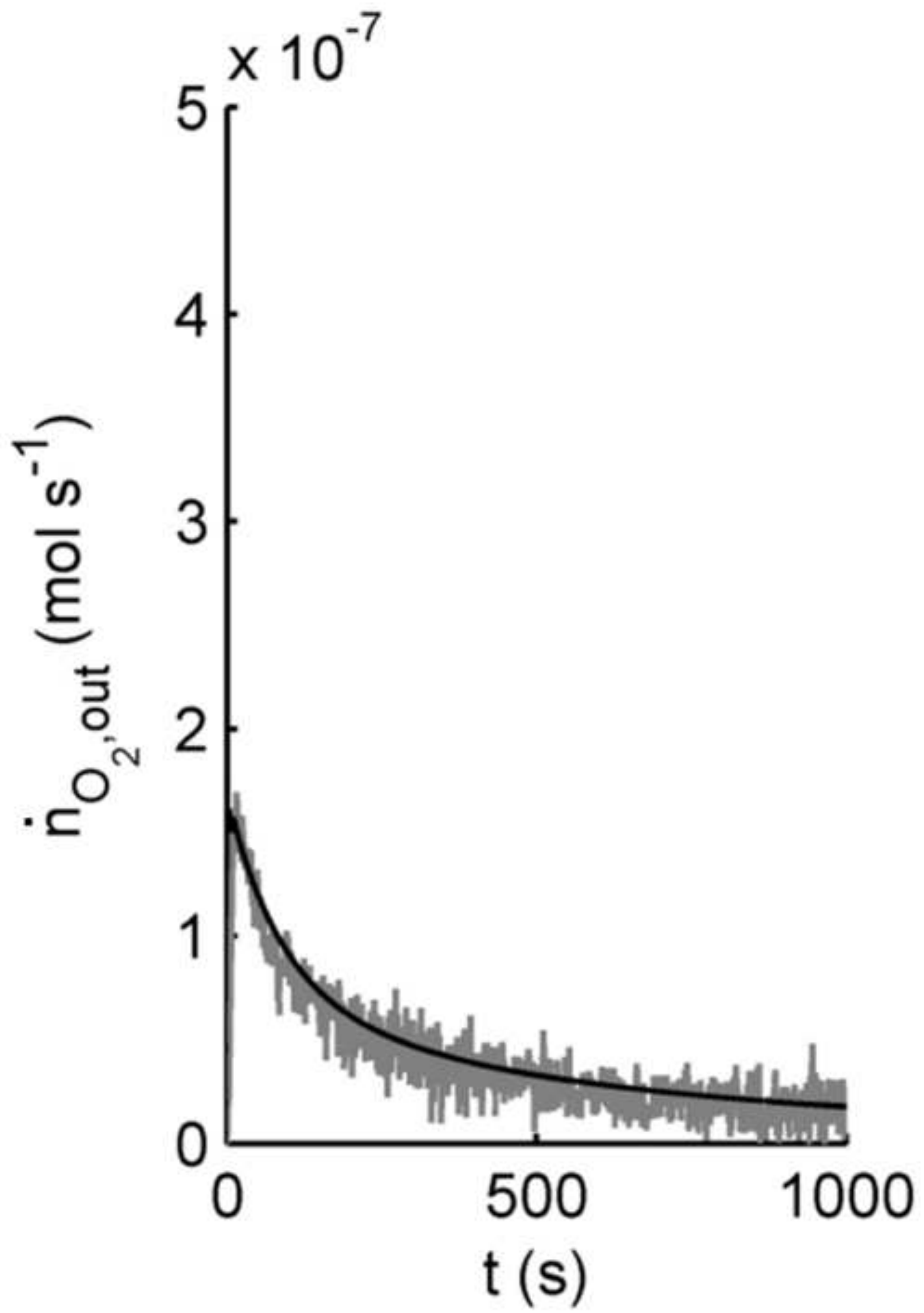




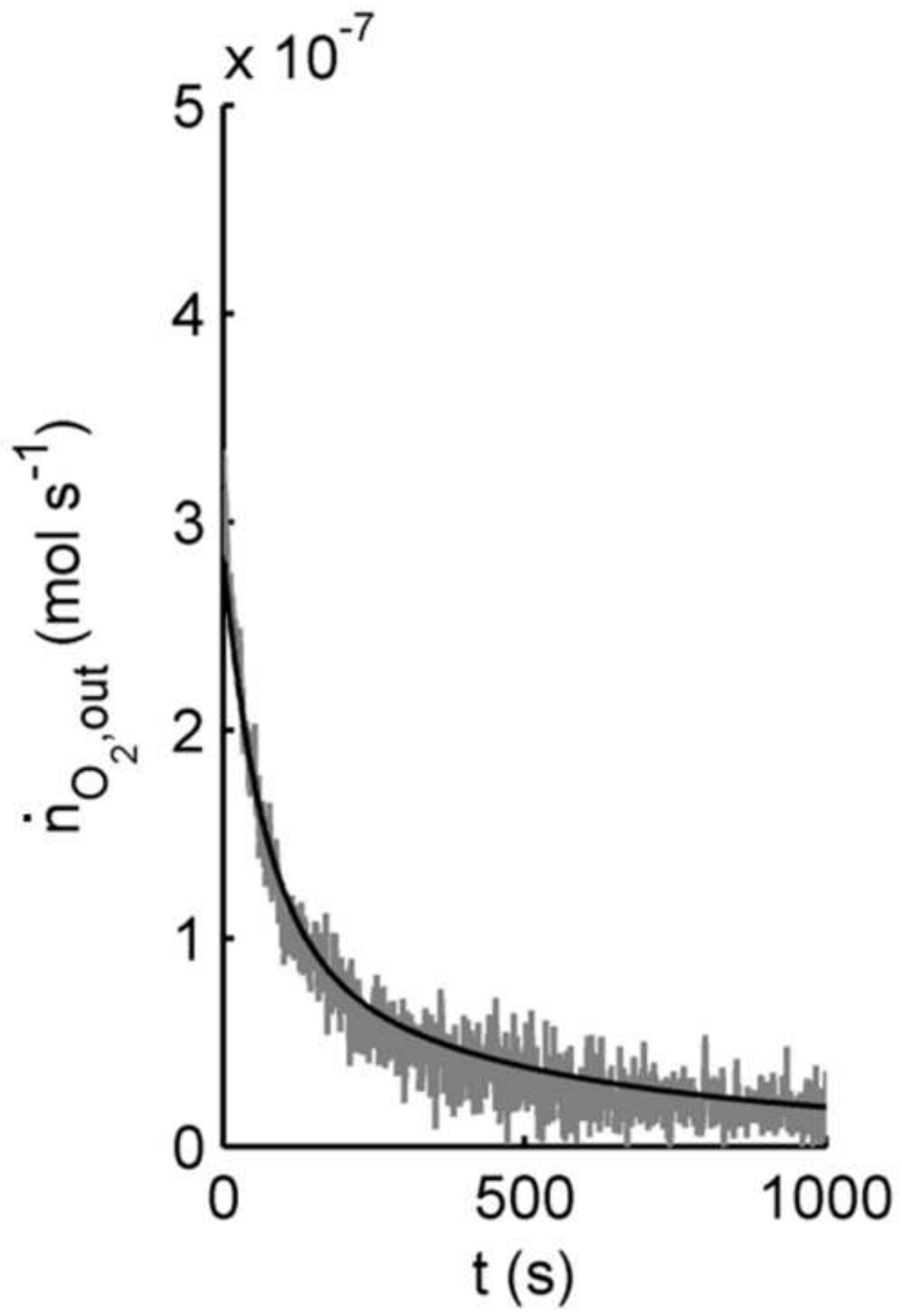




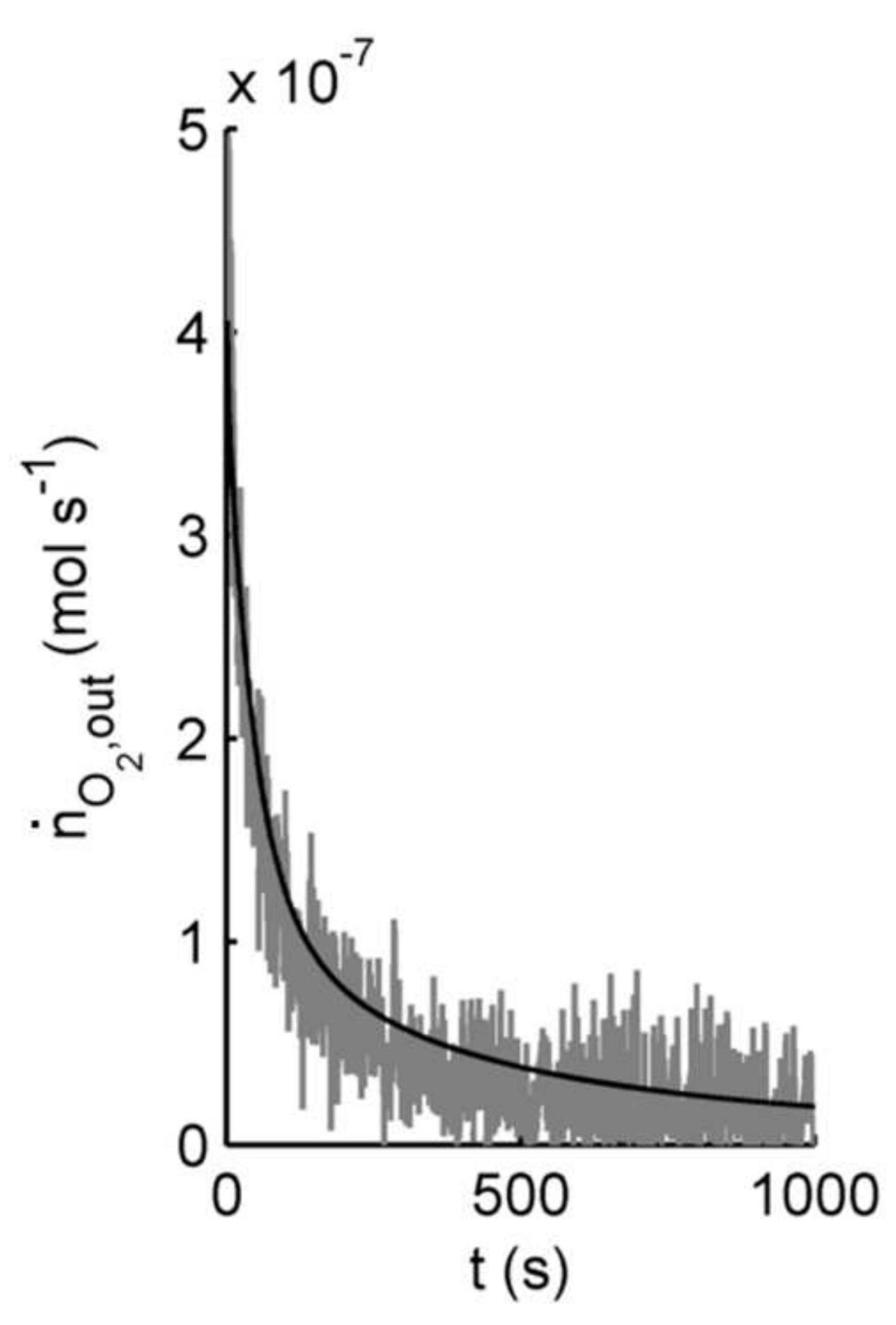

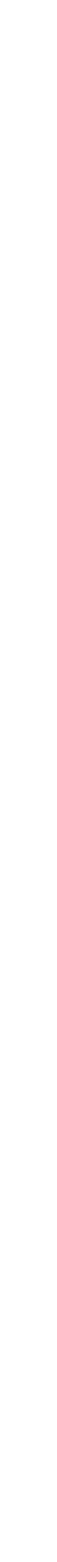

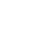




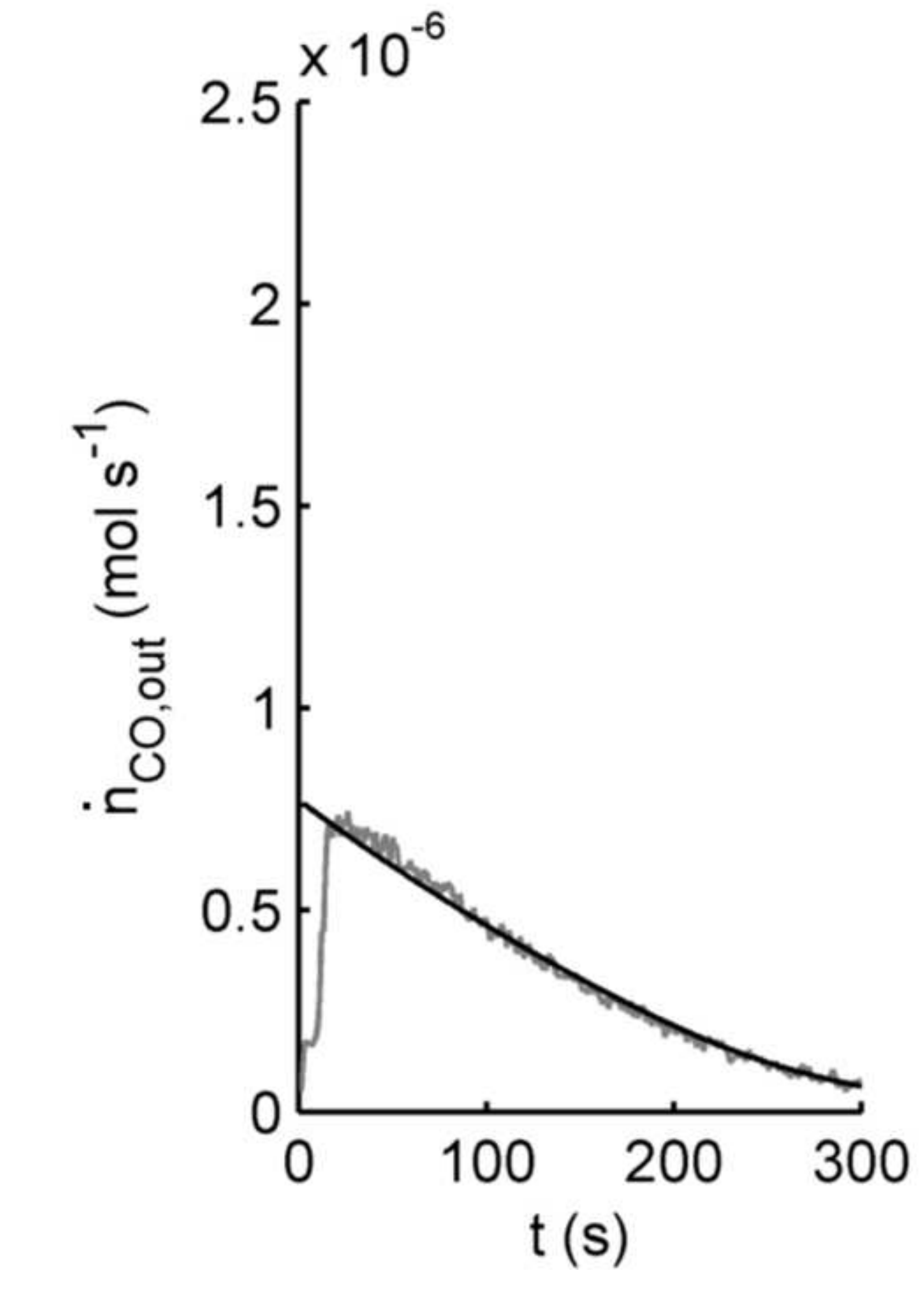

Figure 4a_single 


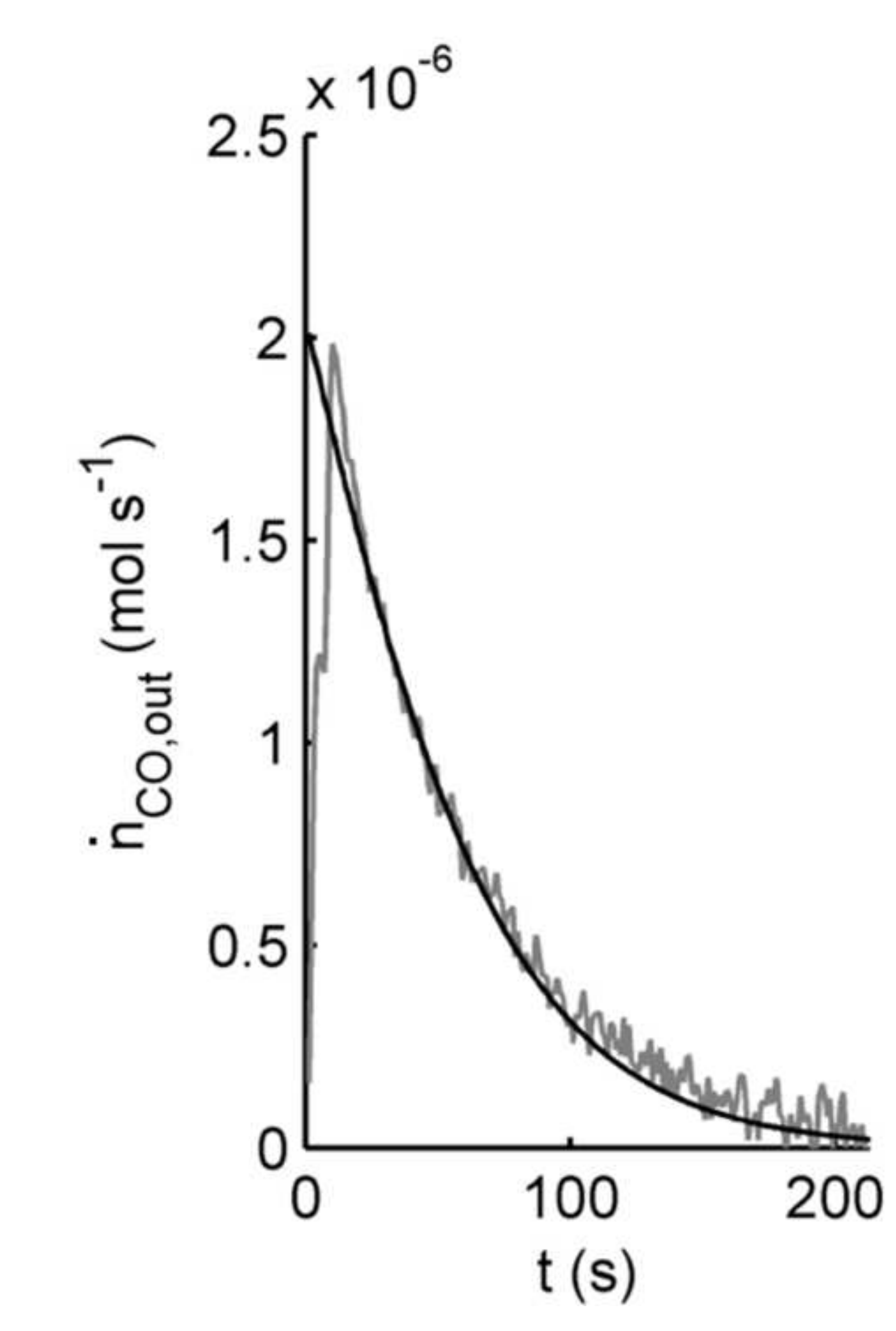

Figure 4b_single

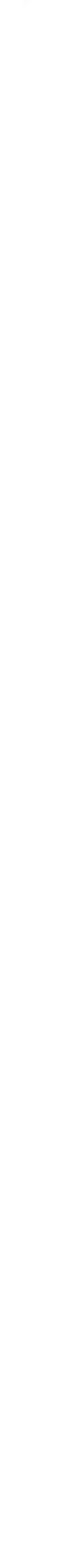

.

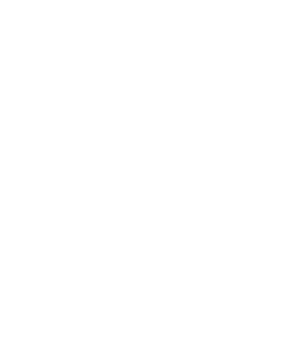

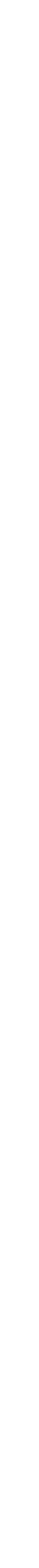




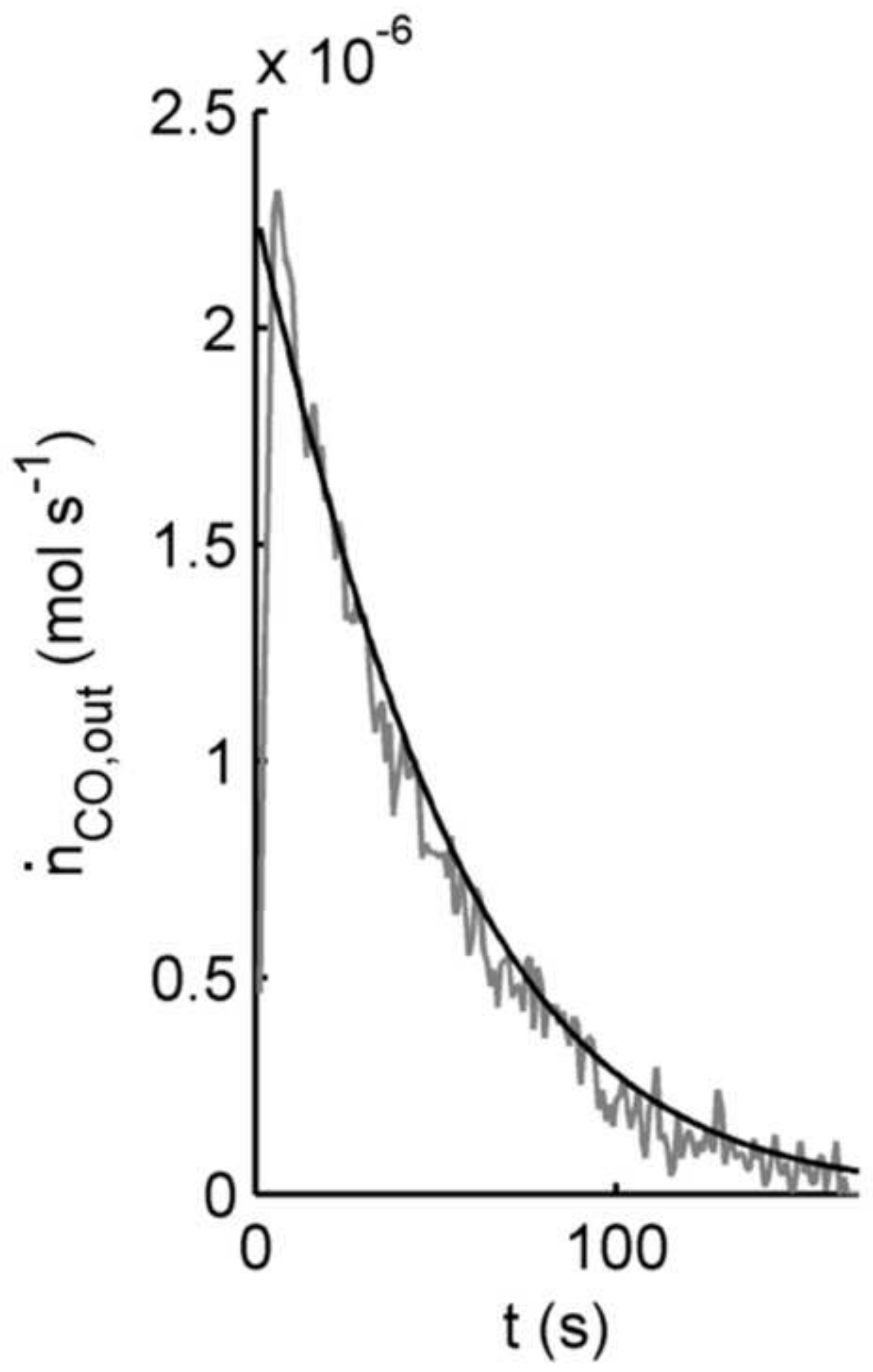

Figure 4c_single 


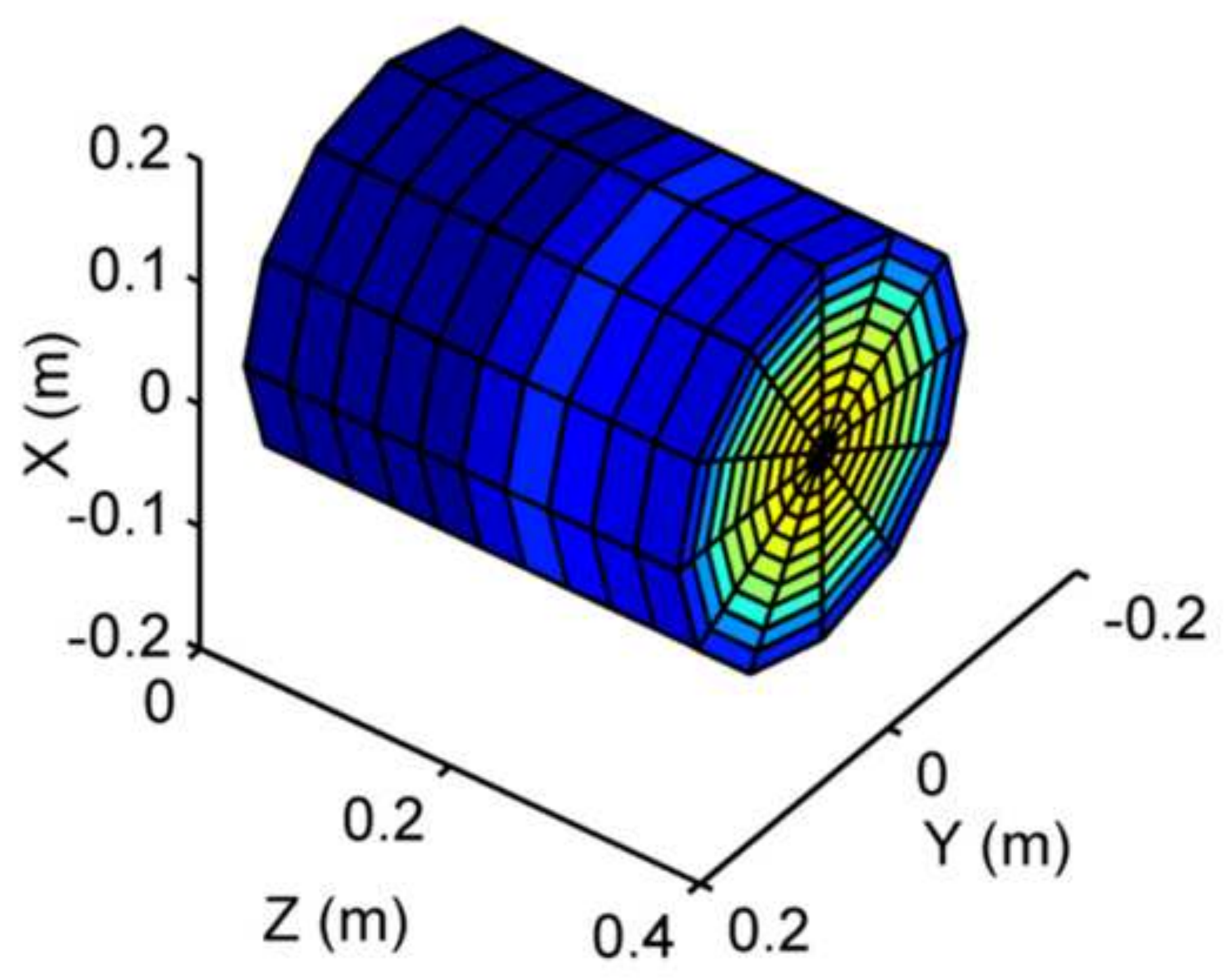

Figure 5a_single

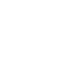

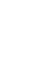

-

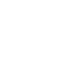

.

.

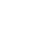

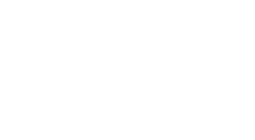

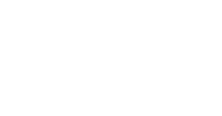

(⿸丆口

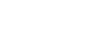

. 


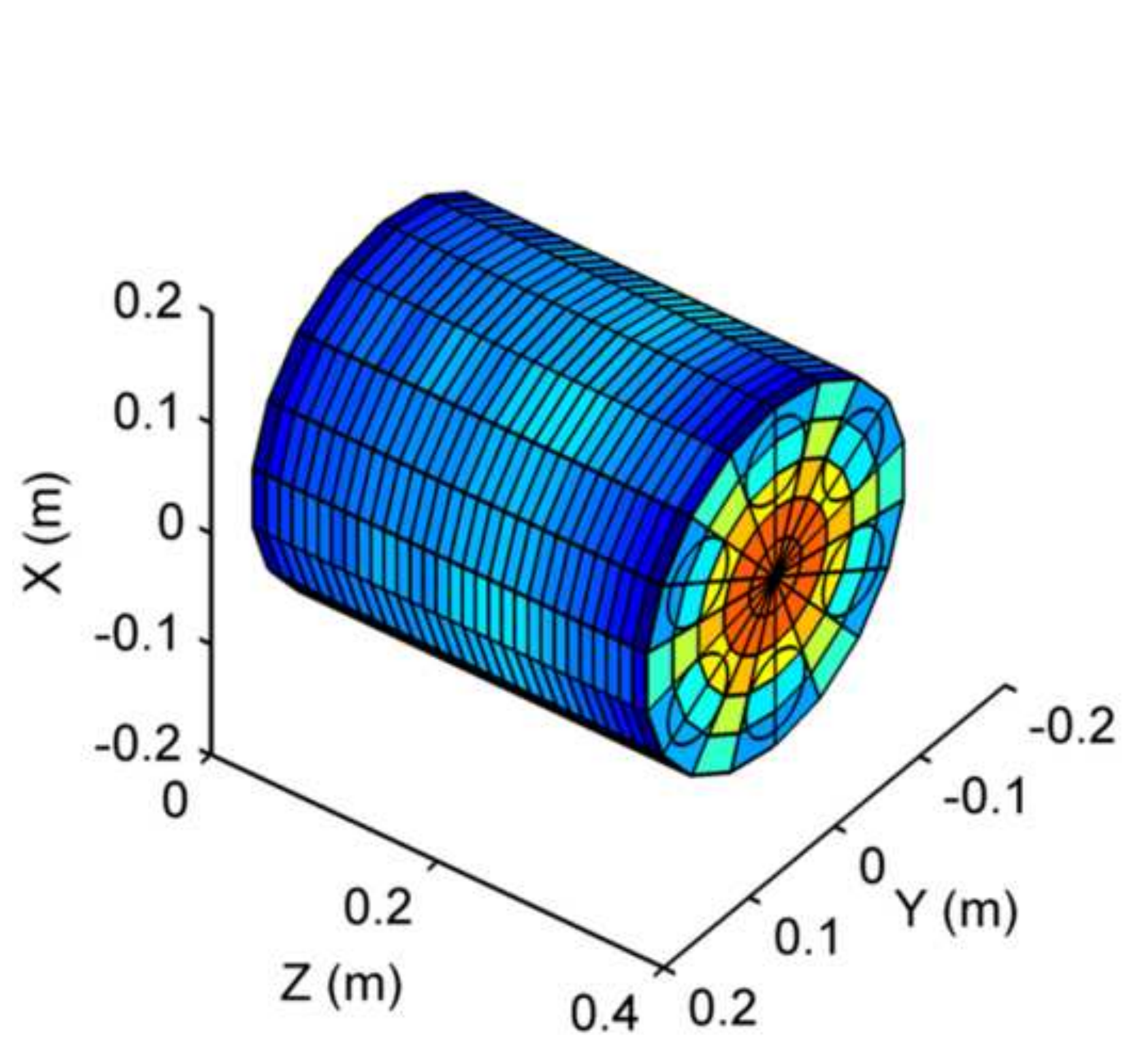

Figure 6a_single
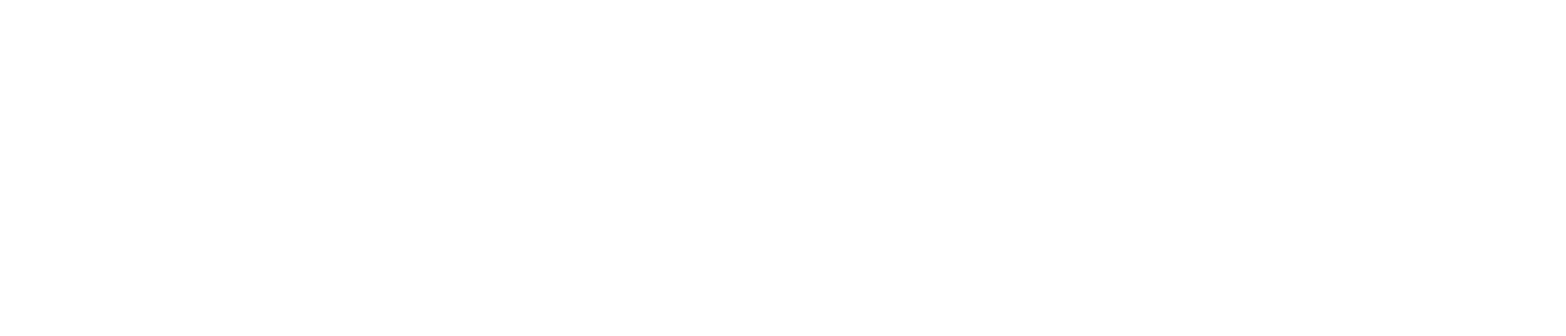


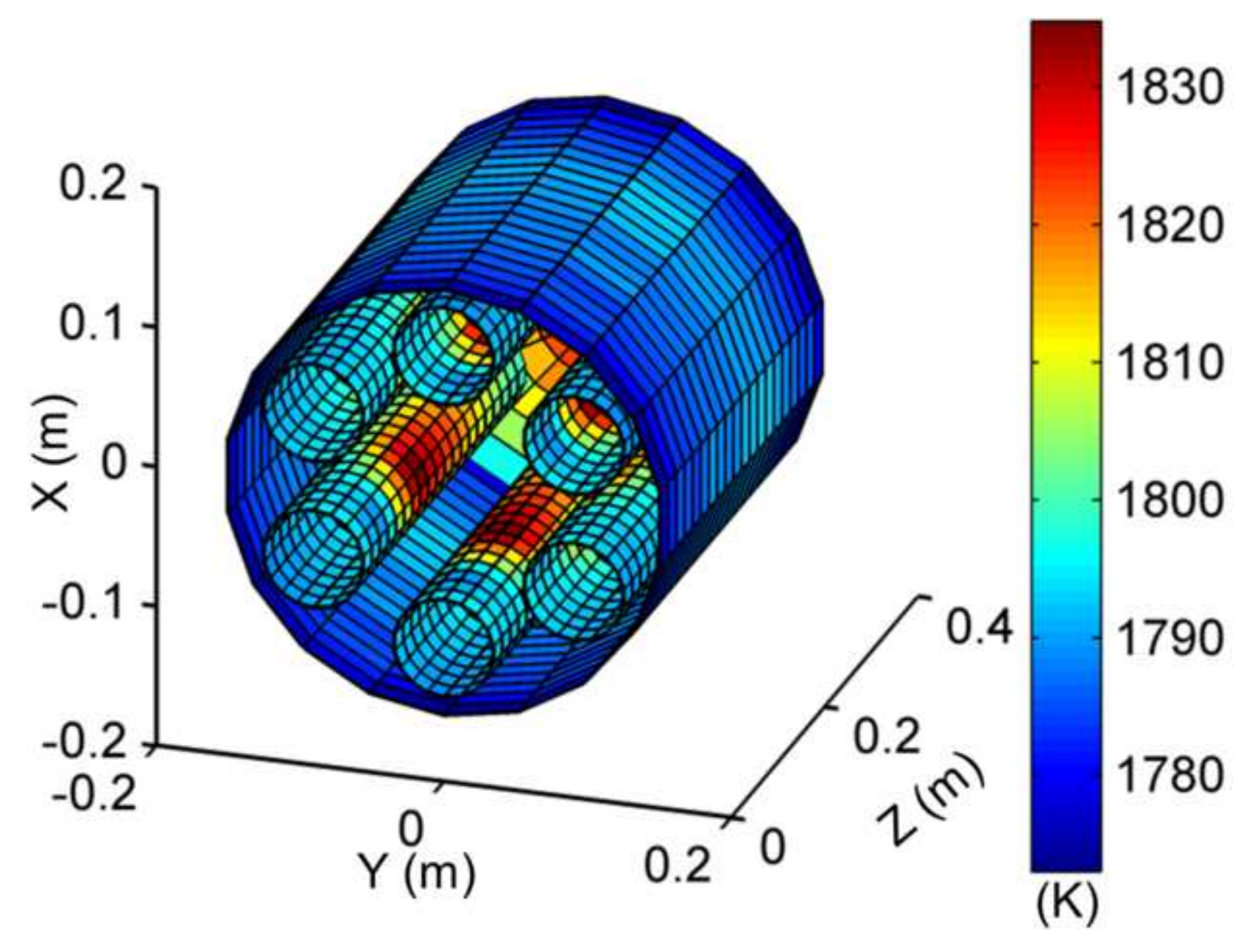

1830

1820

1810

1800

0.2

1 तो

1780

(K)

1790

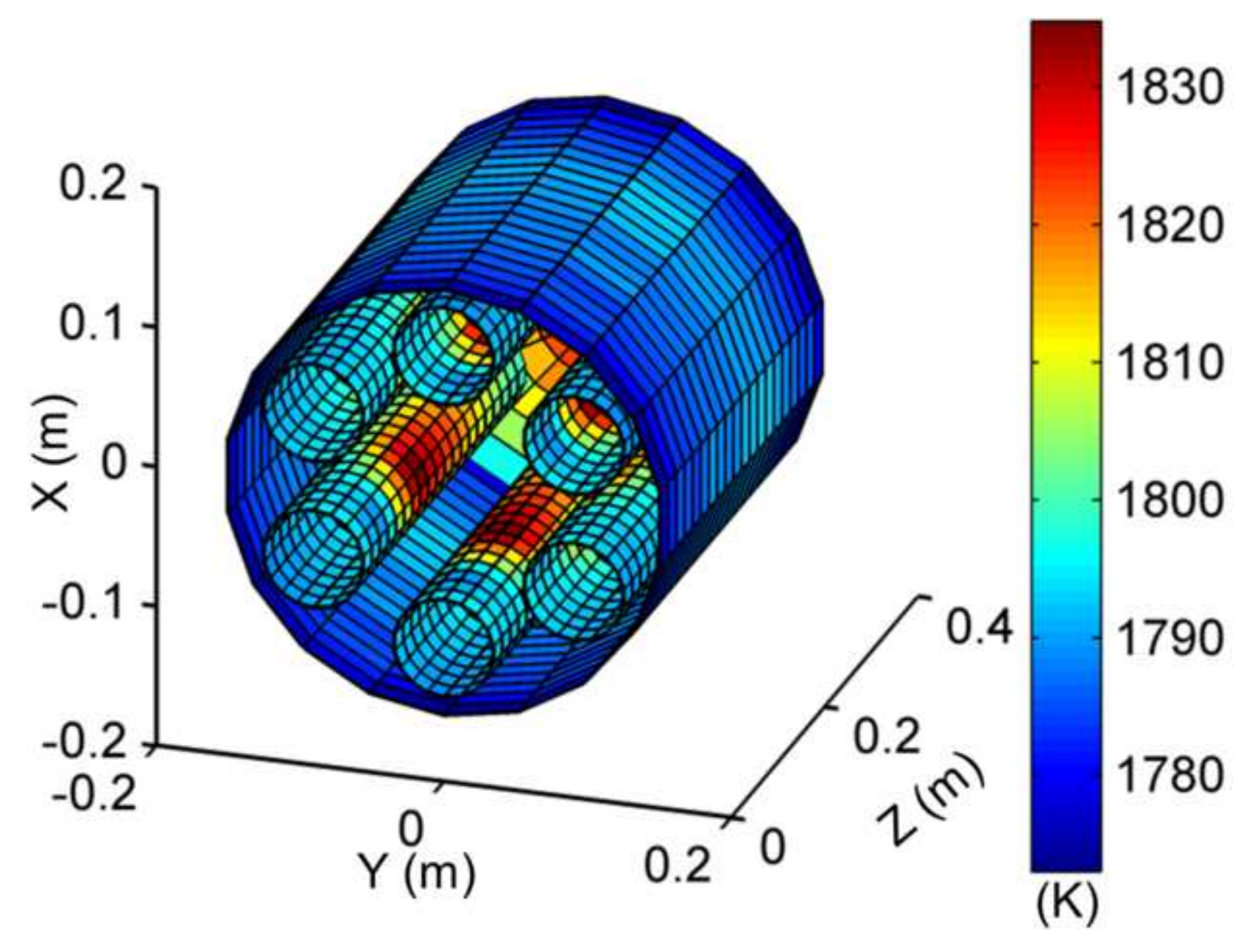




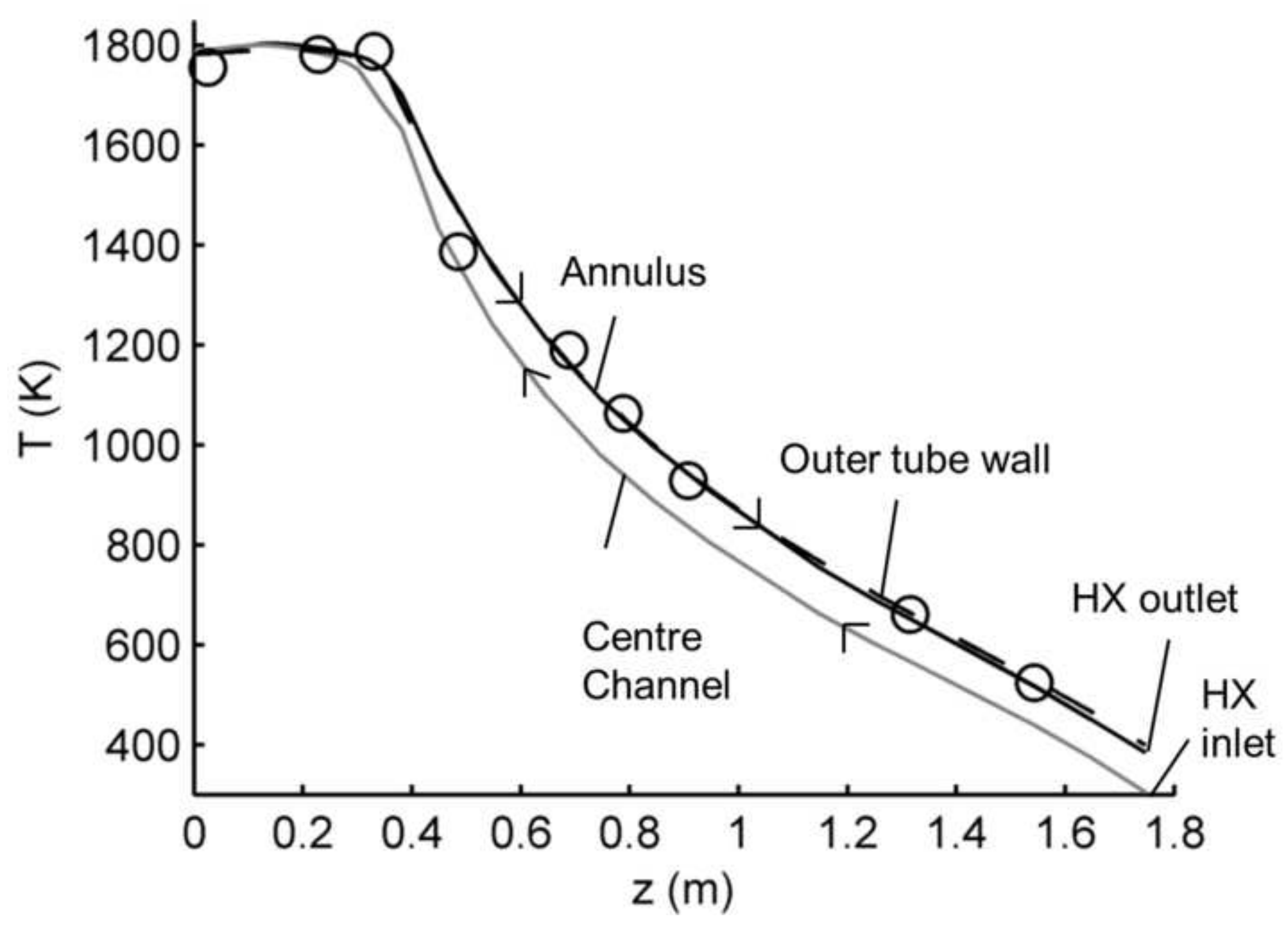


Figure 7b_single
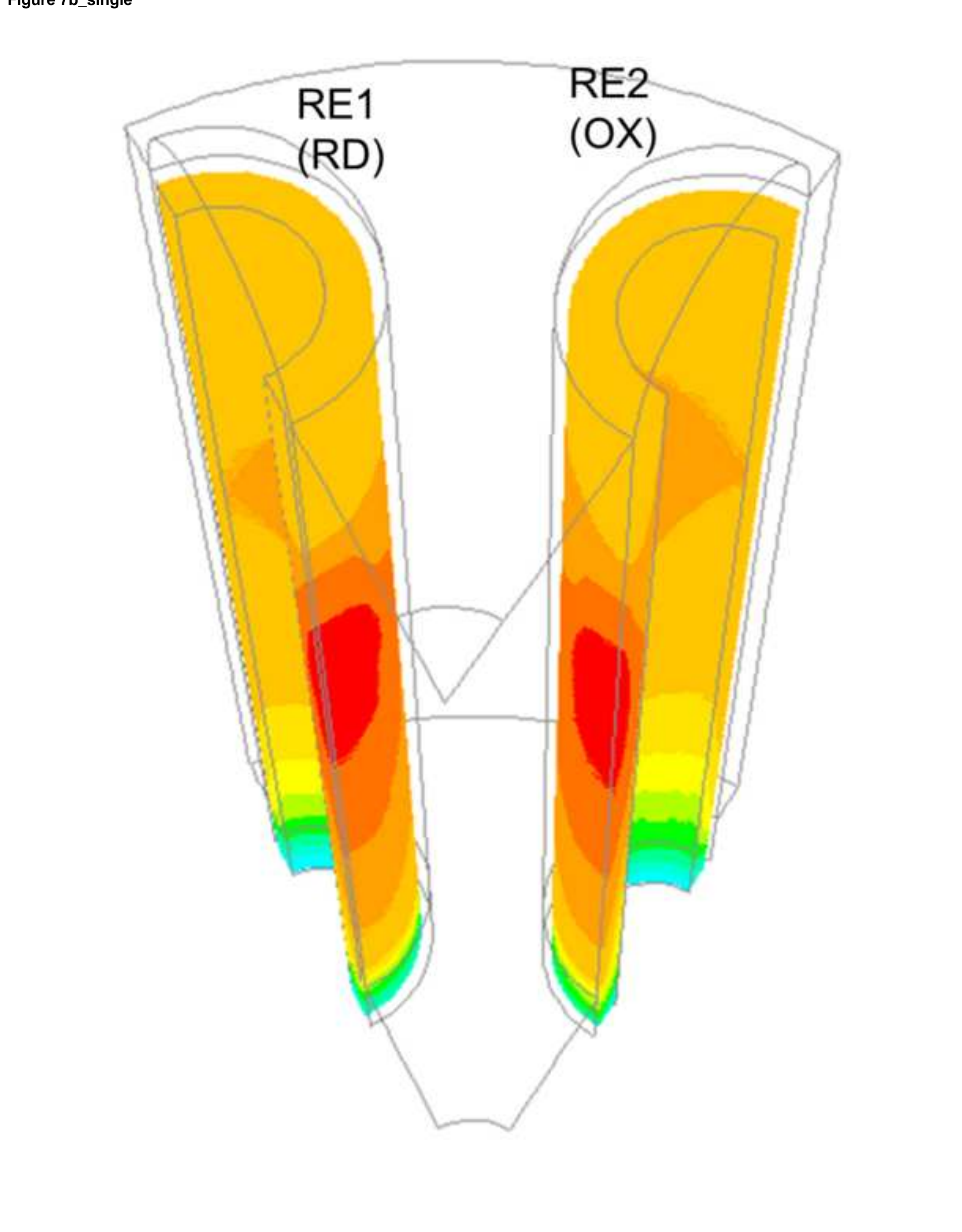

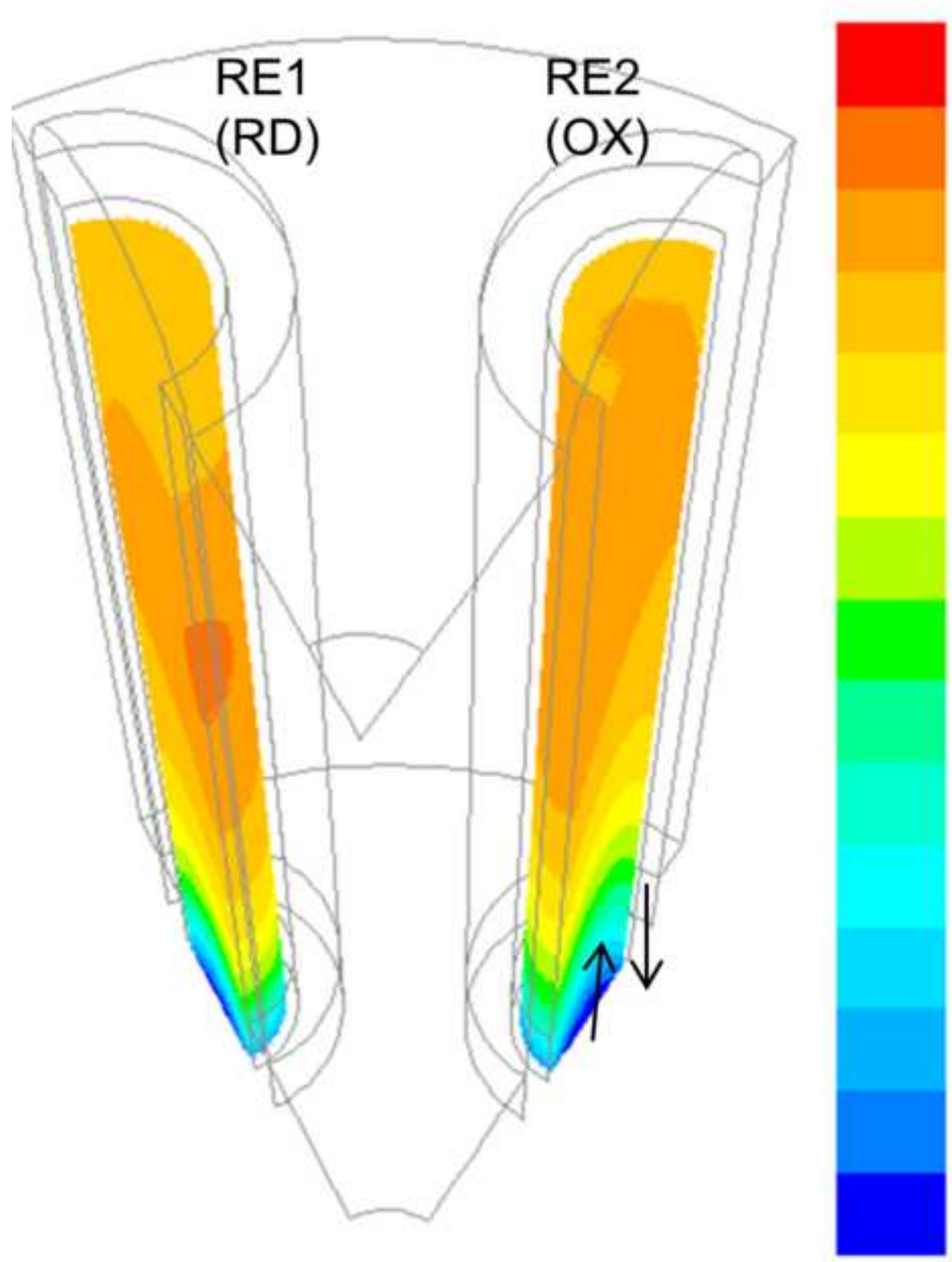

1835

1821

1808

1794

1780

1767

1753

1739

1726

1712

1698

1685

1671

1657

1644

1630 


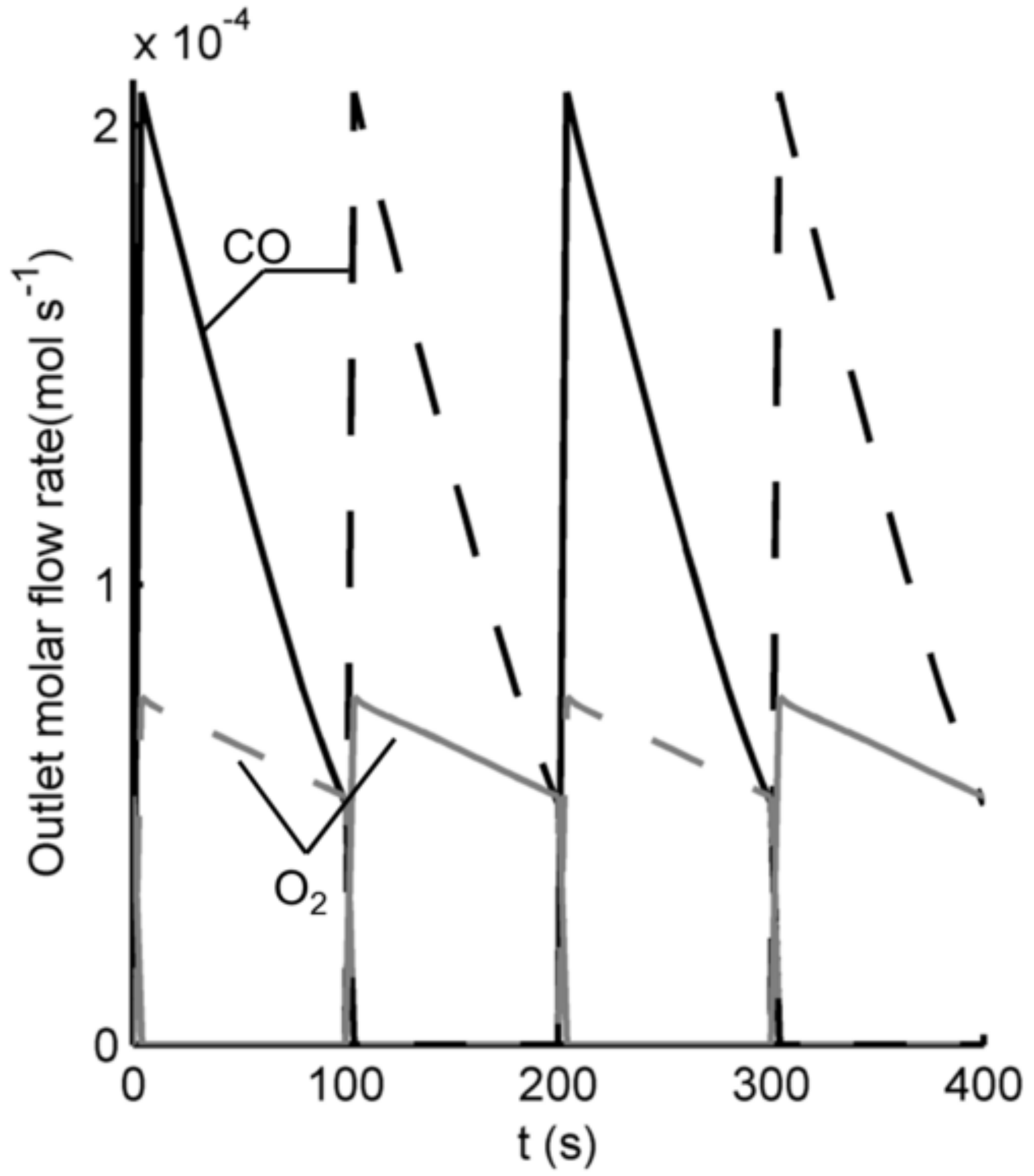




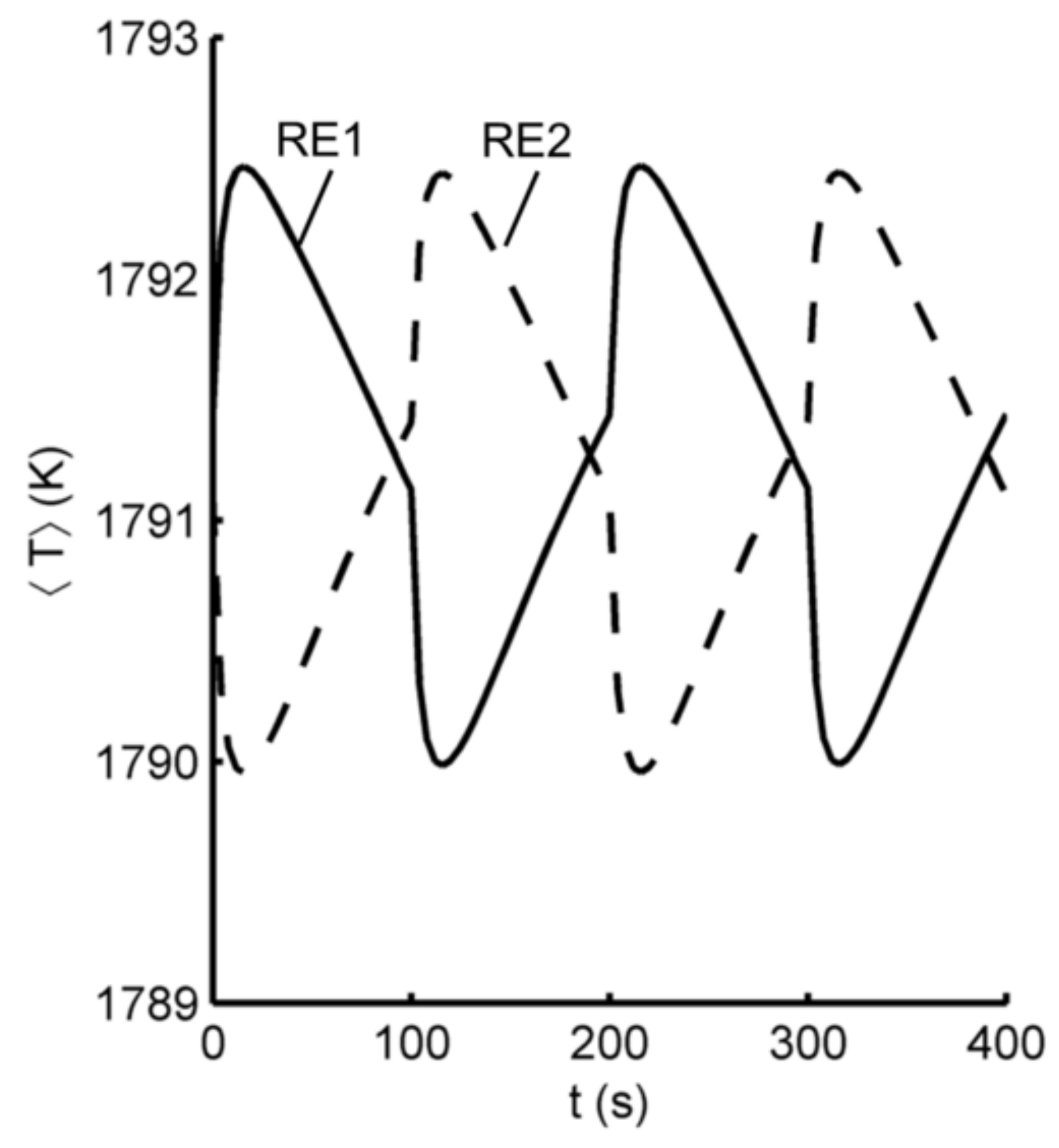

Figure 8b_single 

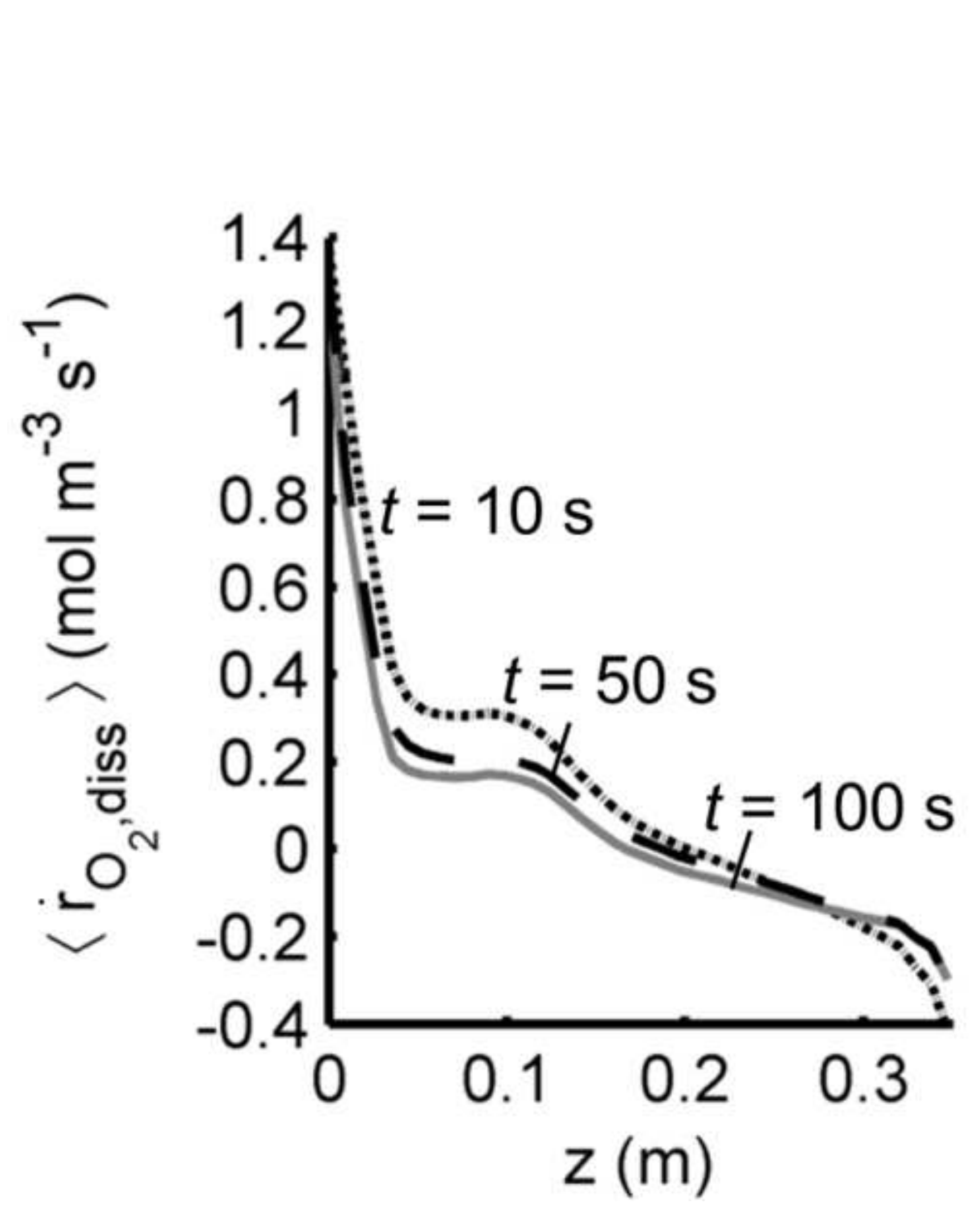

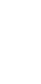
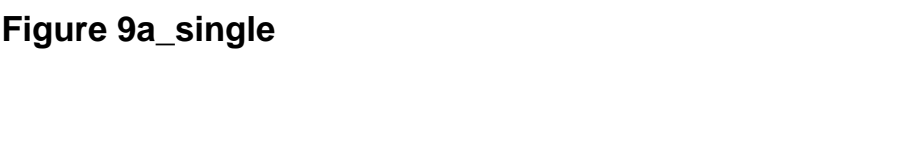

(




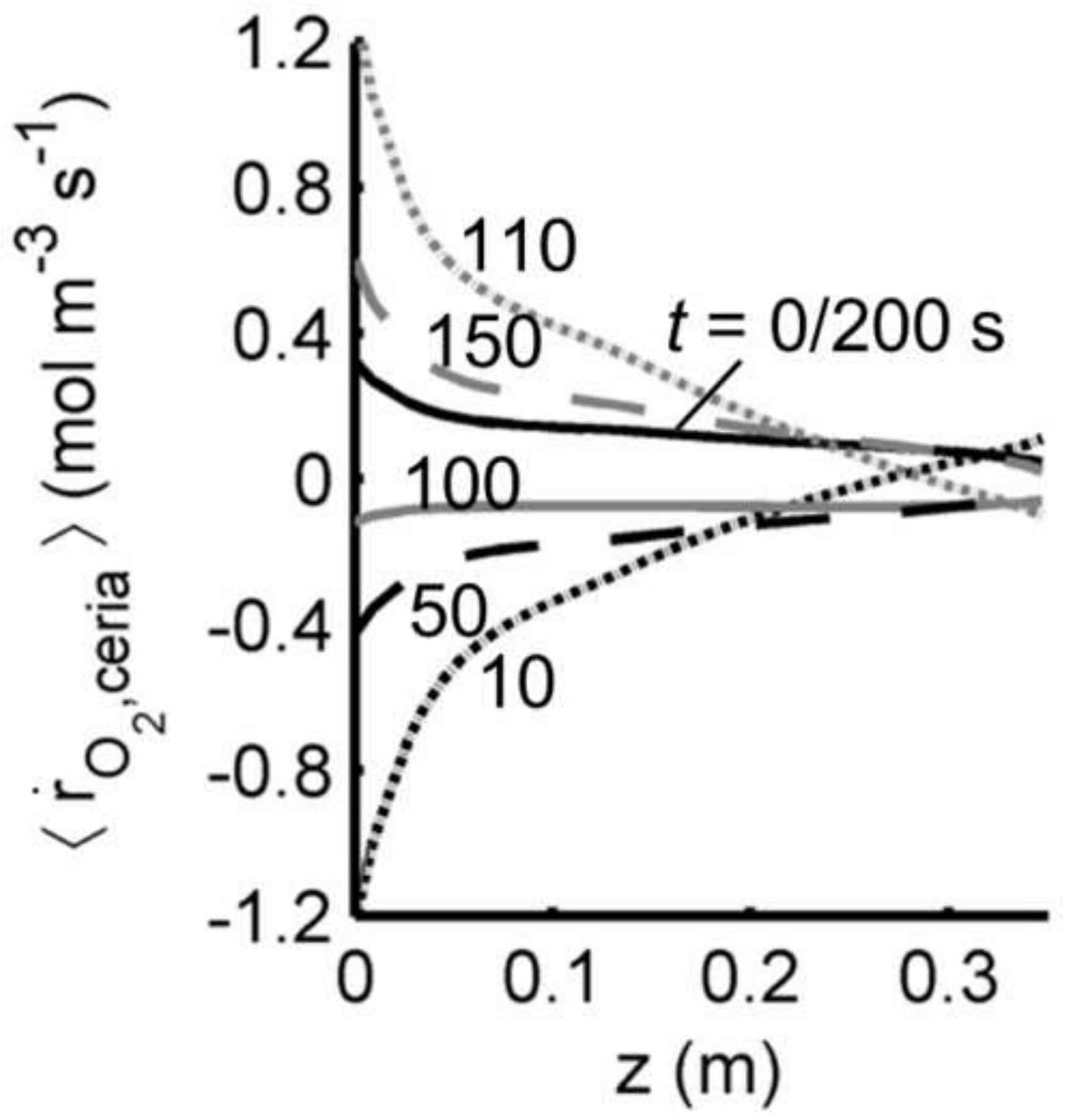

$$
\begin{array}{ccc}
0.1 \quad 0.2 & 0.3 \\
z(m) &
\end{array}
$$$$
150+110 t=0 / 200 \mathrm{~s}
$$

$$
\text { (n) }
$$

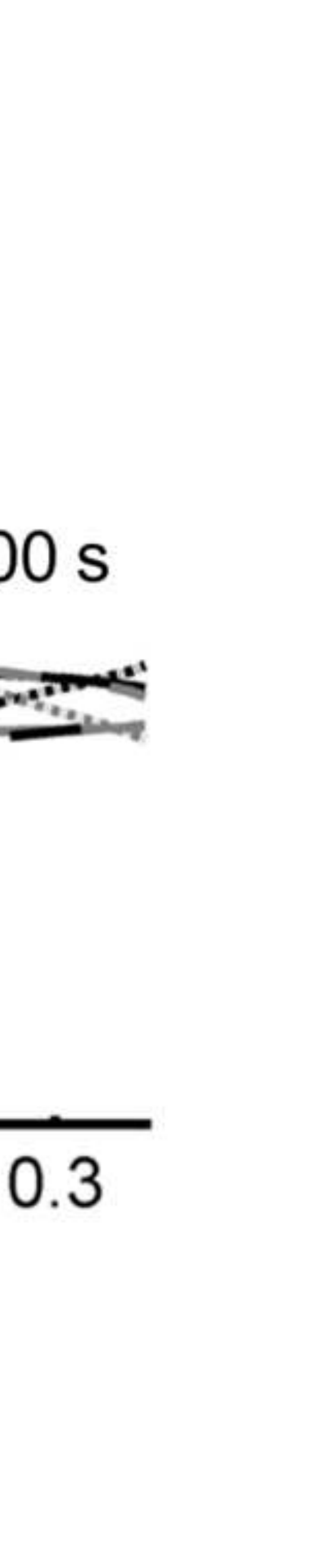




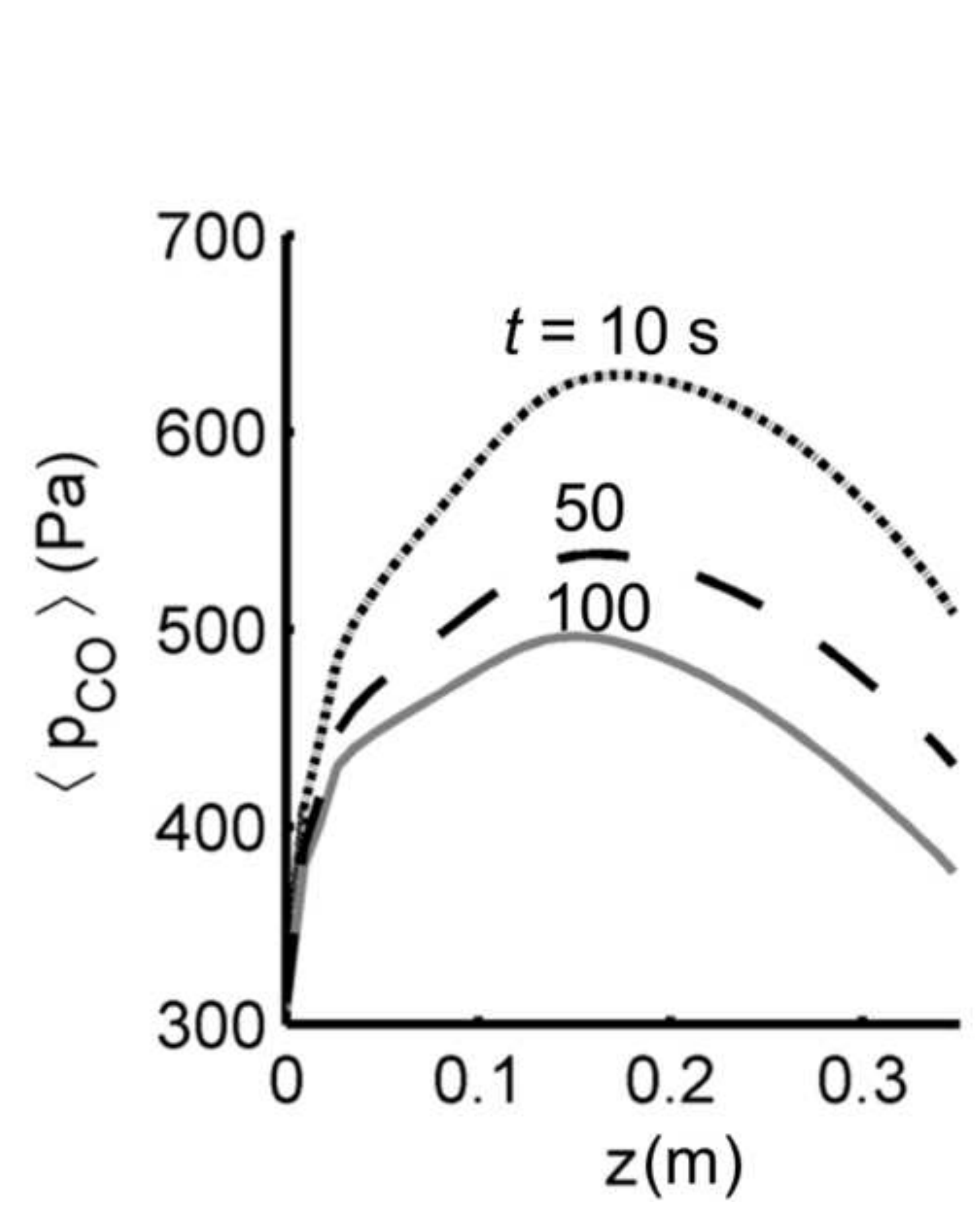

Figure 9c_single

\section{Figure 9csingle}

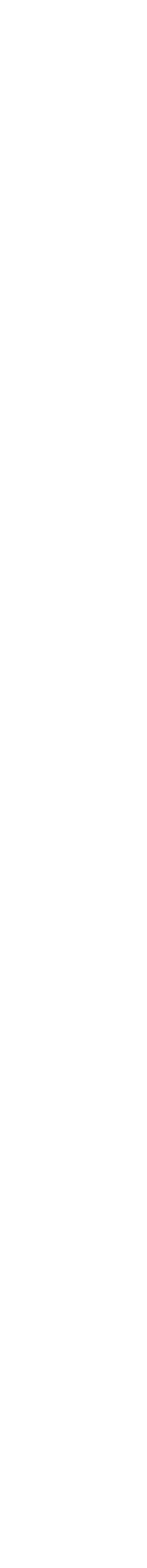




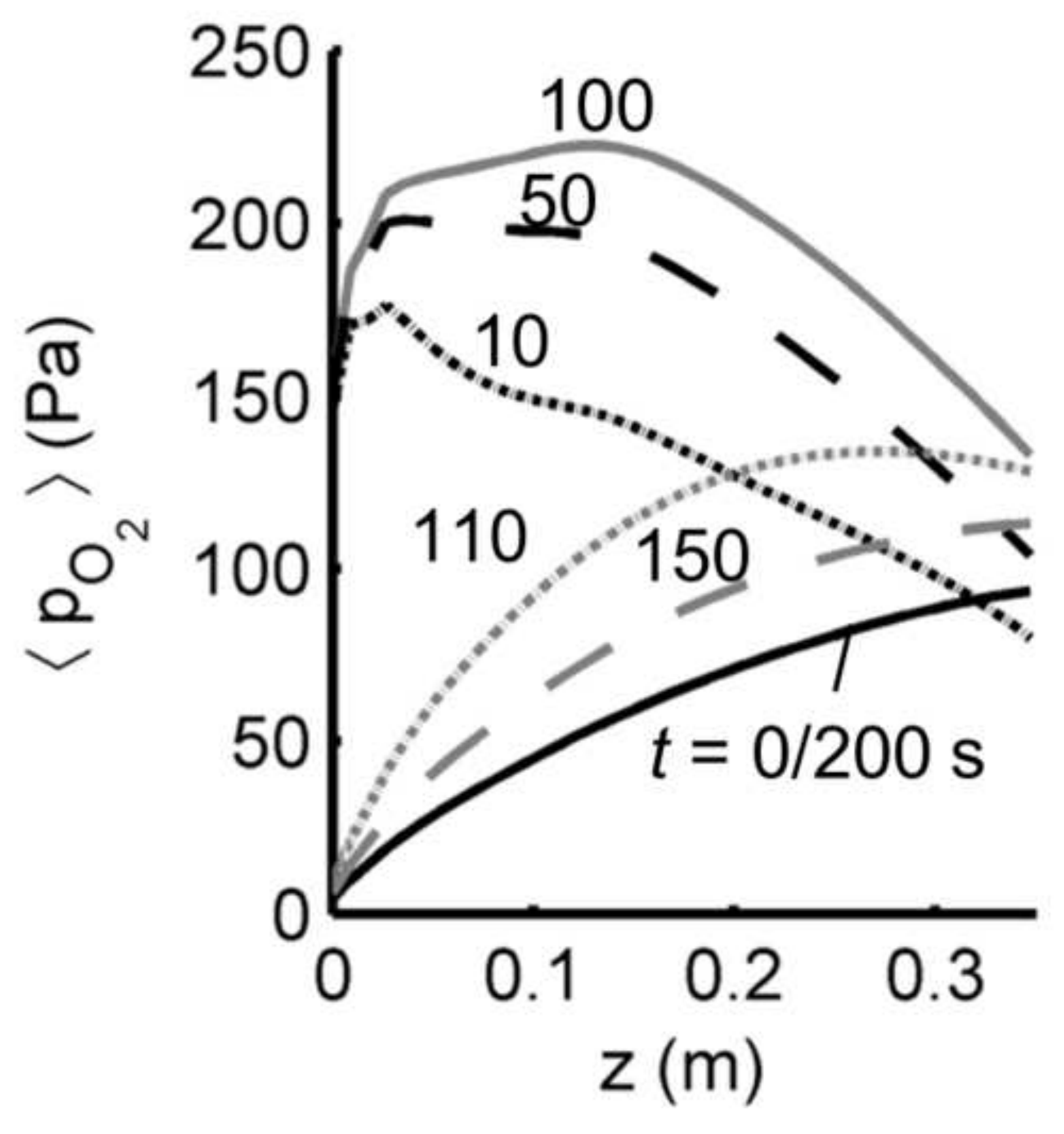

Figure 9d_single

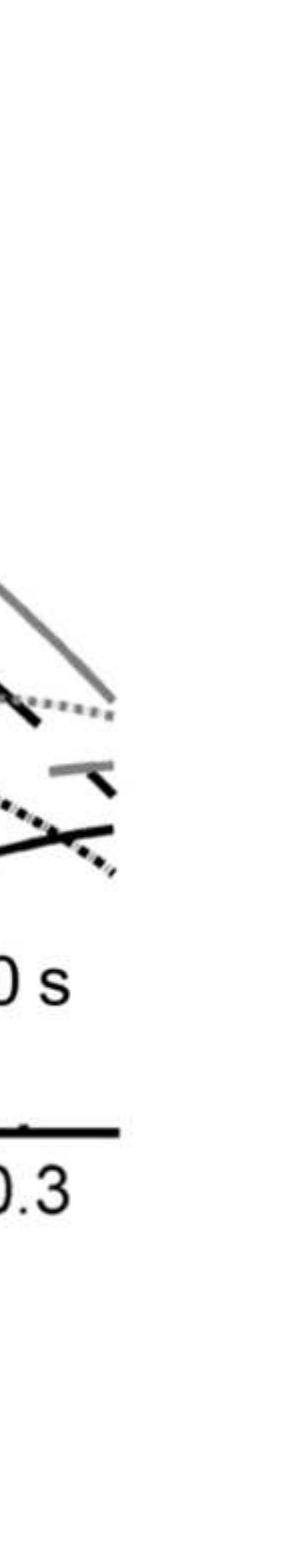




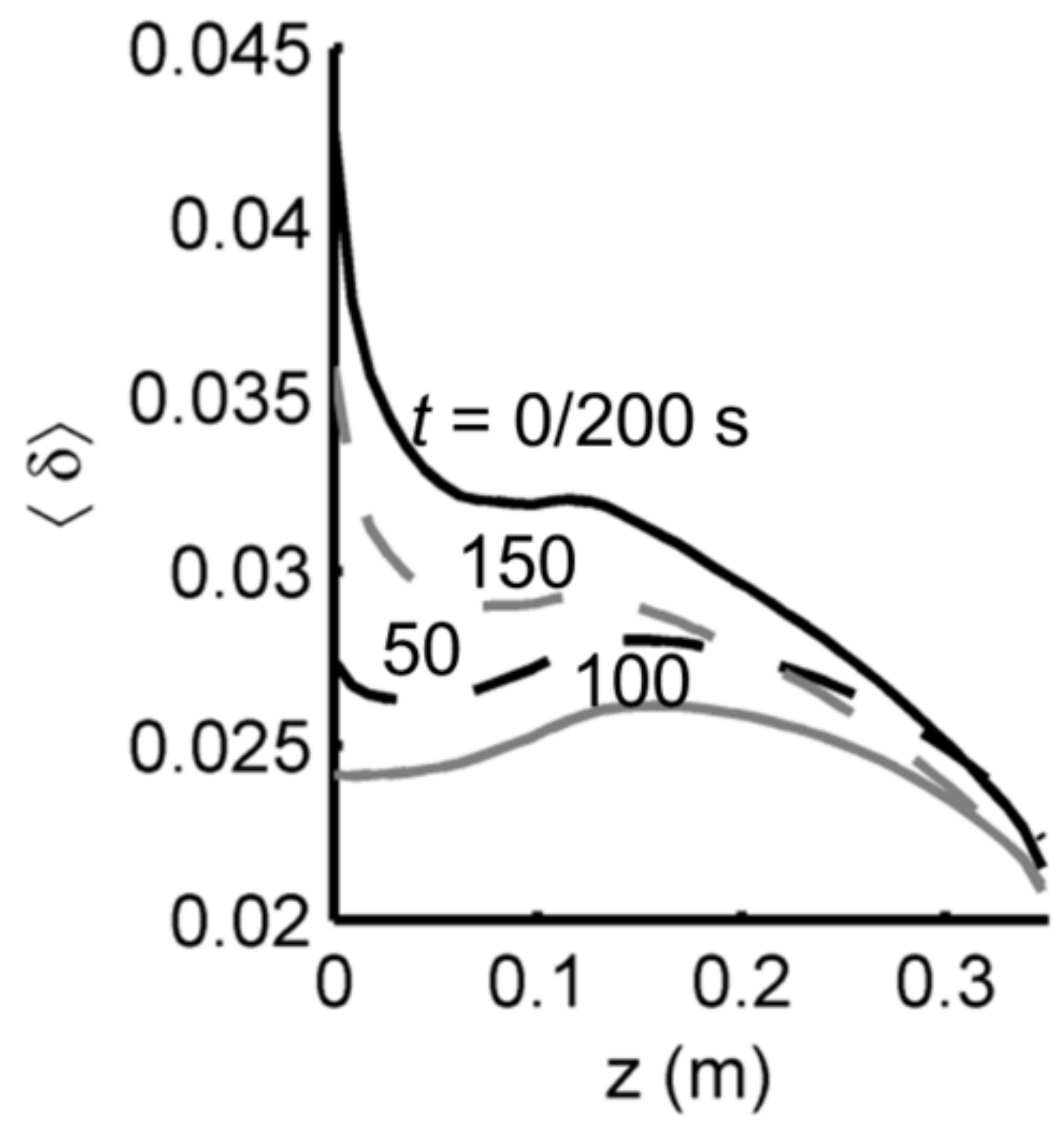

Figure 9e_single 


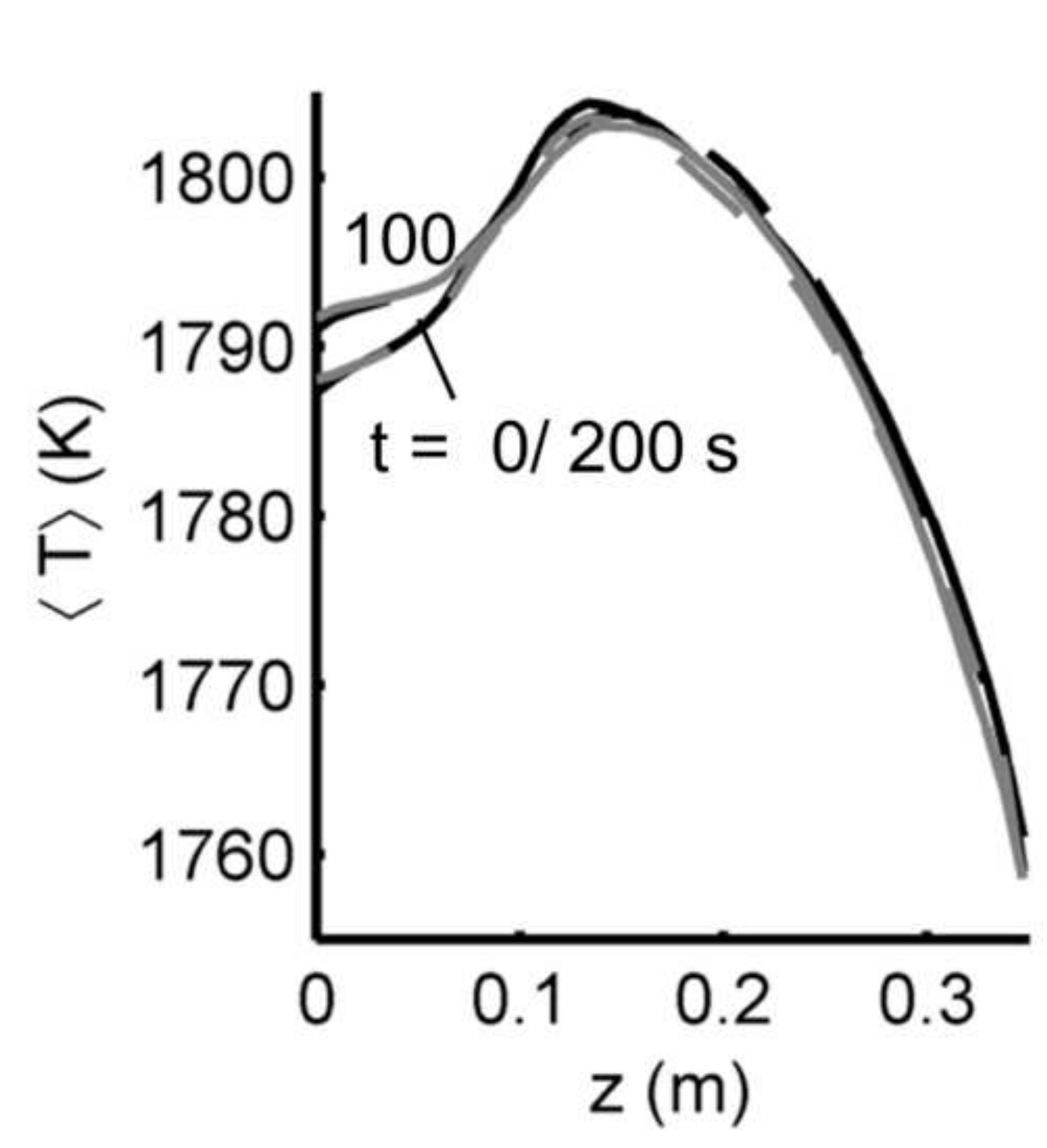

Figure 9f_single

.

(m)

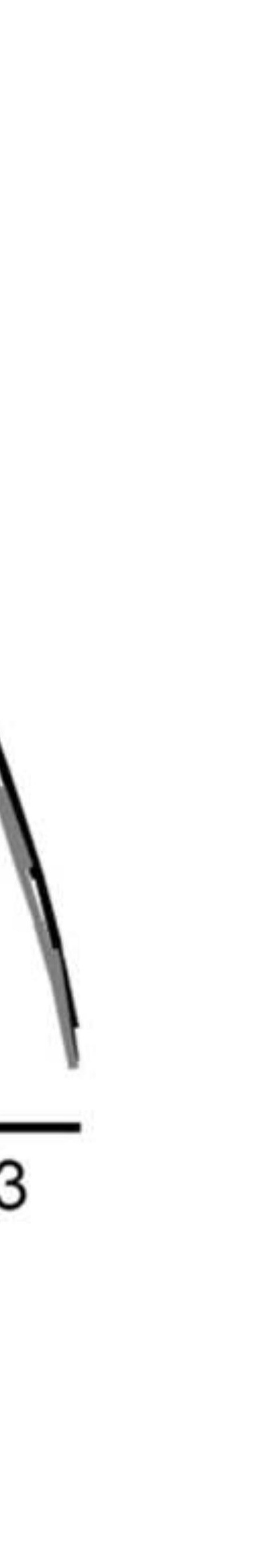




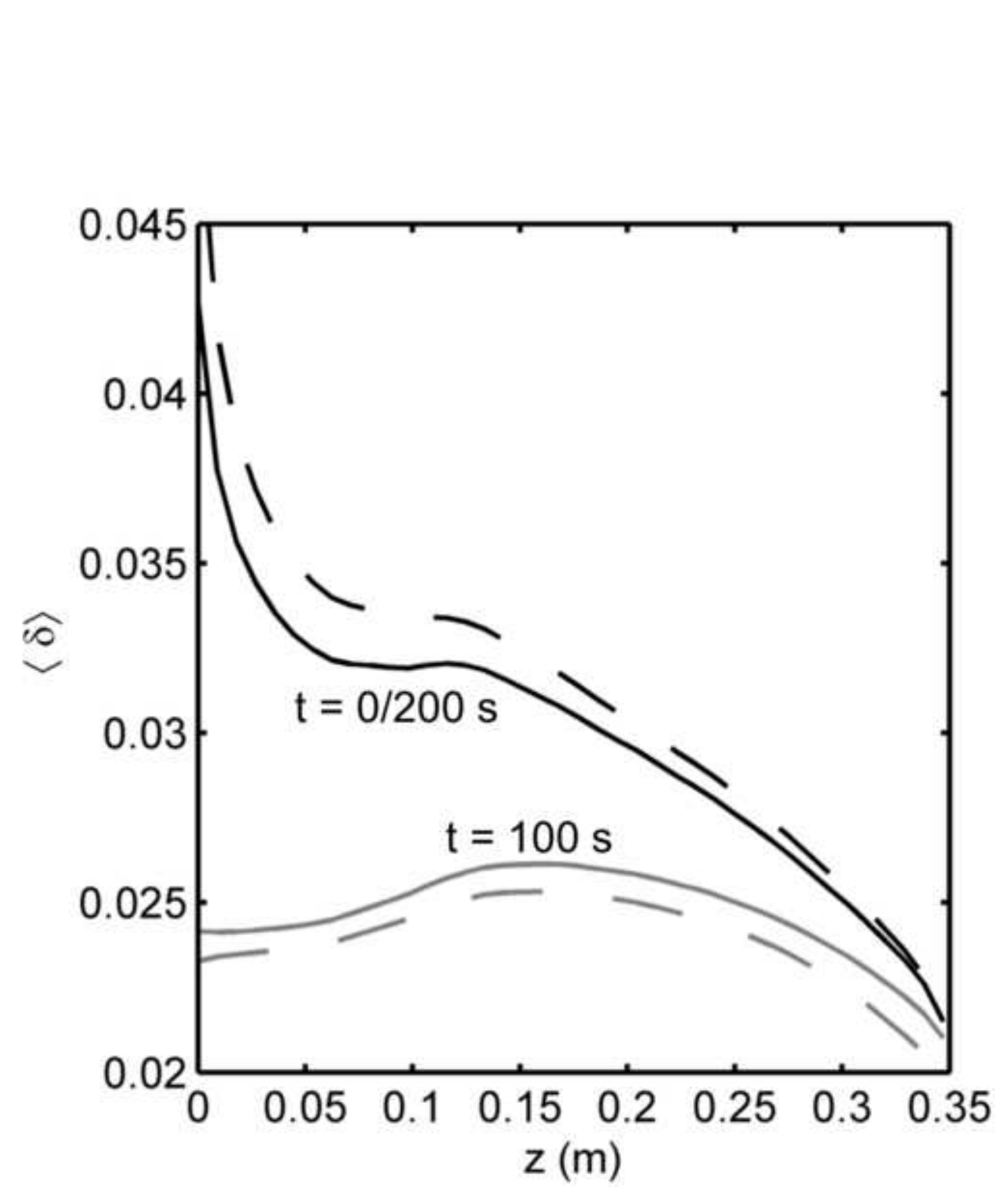

Figure 10_single

\footnotetext{
(
}
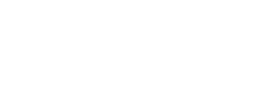

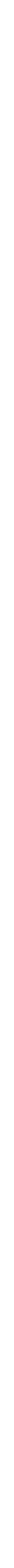

(n)

$$
\text { (1) }
$$

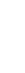

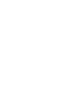$$
\text { (2) }
$$
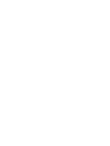
Table 1 List of operating conditions and boundary conditions at the specified surfaces of the model domain for the baseline case

\section{Operating Conditions}

\begin{tabular}{ll}
\hline Parameters & Value \\
\hline Input power $(\mathrm{kW})$ & 4.2 \\
Concentration ratio (suns/ $\left.\mathrm{kW} \mathrm{m}^{-2}\right)$ & 3000 \\
& \\
Sweep gas/oxidizer flow rate $\left(\mathrm{g} \mathrm{s}^{-1}\right)$ & $0.11 / 0.17$ \\
$\begin{array}{l}\text { Reduction/oxidation half-cycle time (s) } \\
\text { Sweep gas/oxidizer composition }\end{array}$ & $\mathrm{N}_{2}$ with $100 \mathrm{ppm} \mathrm{O}_{2} / 100 \% \mathrm{CO}_{2}$ \\
$\begin{array}{l}\text { Sweep gas and oxidizer inlet } \\
\text { temperature to the integrated reactive } \\
\text { element/heat exchanger }(\mathrm{K})\end{array}$ & 300
\end{tabular}

\section{Boundary Conditions ( $n$ is the unit normal area vector for the respective surface)}

\section{Surface}

Aperture

Cavity insulation

Symmetry planes

Gas inlet

Gas outlet

$\mathrm{RE} / \mathrm{HX}$ tube walls

\section{Conditions}

$$
\varepsilon_{\mathrm{ap}}=1 ; \frac{\partial T}{\partial n}=0
$$

$\varepsilon_{\mathrm{ins}}=1 ; k \frac{\partial T}{\partial n}=U\left(T-T_{\mathrm{amb}}\right)$

$\frac{\partial T}{\partial n}=0$

$\varepsilon_{\mathrm{RPC}}=1 ;$ Refer to equations (14) and (15); $T=$ $T_{c \text {,out }}$ (obtained by iterating with the heat exchanger model)

$$
\varepsilon_{\mathrm{RPC}}=1 ; p=p_{\mathrm{atm}}
$$

$\varepsilon_{\mathrm{RE} / \mathrm{HX}}=0.7 ; \boldsymbol{u}=0$ 
Table 2 Effective transport properties for the packed bed of ceria and RPC

\begin{tabular}{|c|c|c|}
\hline $\begin{array}{l}\text { Effective } \\
\text { Transport } \\
\text { Property } \\
\end{array}$ & Equation & Value \\
\hline \multicolumn{3}{|c|}{$\begin{array}{c}\text { Packed bed } \\
\phi_{\text {bed }}=0.45 ; \phi_{\text {particle }}=0.75 ; d_{\text {ceria }}=5 \times 10^{-3} \mathrm{~m}\end{array}$} \\
\hline$K\left(\mathrm{~m}^{2}\right)$ & $\frac{\phi_{\text {bed }}^{3} d_{\text {ceria }}^{2}}{180\left(1-\phi_{\text {bed }}\right)^{2}}($ M Kaviany, 1995) & $4.2 \times 10^{-8}$ \\
\hline$C_{E}\left(\mathrm{~m}^{-1}\right)$ & $\frac{1.8\left(1-\phi_{\text {bed }}\right)}{\phi_{\text {bed }}^{3} d_{\text {ceria }}}($ M Kaviany, 1995$)$ & 2112.5 \\
\hline 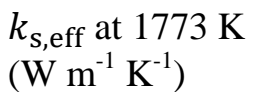 & $k_{s}\left(1-\phi_{\text {bed }}\right)\left(1-\phi_{\text {particle }}\right)($ M Kaviany, 1995$)$ & 0.12 \\
\hline$\beta\left(\mathrm{m}^{-1}\right)$ & $\begin{array}{c}\frac{3\left(1-\phi_{\text {bed }}\right)}{d_{\text {ceria }}}(\text { Hulst and Christoffel, 2012; Singh and } \\
\text { Kaviany, 1992) }\end{array}$ & 330 \\
\hline$\omega(-)$ & 1 & 1 \\
\hline \multicolumn{3}{|c|}{$\begin{array}{c}\text { Alumina RPC } \\
\phi_{\mathrm{RPC}}=0.85 ; 10 / 5 \text { PPI RPCs }\end{array}$} \\
\hline$K\left(\mathrm{~m}^{2}\right)$ & $\begin{array}{c}0.0073\left(1-\phi_{\mathrm{RPC}}\right)^{-0.224}\left(\frac{d_{f}}{d_{p}}\right)^{-1.11} d_{p}^{2} \\
d_{p}=\frac{0.0254}{\mathrm{PPI}} ; d_{f}=1.18 \sqrt{\frac{1-\phi_{\mathrm{RPC}}}{3 \pi}} \frac{d_{p}}{1-e^{-\frac{1-\phi_{\mathrm{RPC}}}{0.04}}} \\
\text { (Bhattacharya et al., 2002; Calmidi, 1998) }\end{array}$ & $5.8 \times 10^{-8} / 2.3 \times 10^{-7}$ \\
\hline$C_{E}\left(\mathrm{~m}^{-1}\right)$ & $\frac{0.3 a_{s f}}{\phi_{\mathrm{RPC}}^{2}} ; a_{s f}=\frac{3 \pi d_{f}\left(1-e^{-\frac{1-\phi_{\mathrm{RPC}}}{0.04}}\right)}{0.59 d_{p}^{2}}($ Bhattacharya et al., & $775 / 387$ \\
\hline $\begin{array}{l}k_{\mathrm{s}, \mathrm{eff}} \text { at } 1773 \mathrm{~K} \\
\left(\mathrm{~W} \mathrm{~m}^{-1} \mathrm{~K}^{-1}\right)\end{array}$ & $\frac{0.8 k_{s}}{3}\left(1-\phi_{\mathrm{RPC}}\right)($ Schuetz and Glicksman, 1984) & 0.25 \\
\hline$\beta\left(\mathrm{m}^{-1}\right)$ & $\frac{4.4\left(1-\phi_{\mathrm{RPC}}\right)}{d_{\mathrm{p}}}$ (Hendricks and Howell, 1996) & $260 / 520$ \\
\hline$\omega(-)$ & 0.81 (Hale and Bohn, 1992) & 0.81 \\
\hline
\end{tabular}

